University of South Florida

DIGITAL COMMONS

@ UNIVERSITY OF SOUTH FLORIDA
Digital Commons @ University of

South Florida

$12-1-2015$

\title{
Capturing the Benefits of Complete Streets
}

CUTR

Follow this and additional works at: https://digitalcommons.usf.edu/cutr_nctr

\section{Recommended Citation}

"Capturing the Benefits of Complete Streets," National Center for Transit Research (NCTR) Report No. CUTR-NCTR-RR-2013-07, Center for Urban Transportation Research, University of South Florida, 2015. DOI: https://doi.org/10.5038/CUTR-NCTR-RR-2013-07

Available at: https://scholarcommons.usf.edu/cutr_nctr/79

This Technical Report is brought to you for free and open access by the National Center for Transit Research (NCTR) Archive (2000-2020) at Digital Commons @ University of South Florida. It has been accepted for inclusion in Research Reports by an authorized administrator of Digital Commons @ University of South Florida. For more information, please contact digitalcommons@usf.edu. 


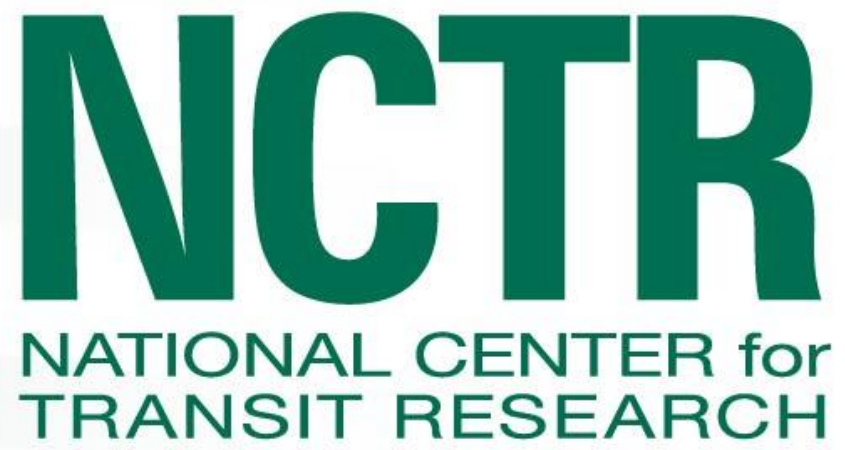

Final Report

\section{Capturing the Benefits of Complete Streets BDV26-977-04}

December 2015

PREPARED FOR

Florida Department of Transportation

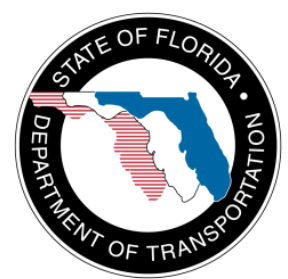




\section{CAPTURING THE BENEFITS OF COMPLETE STREETS \\ Final Report \\ BDV26-977-04}

Principal Investigator: Victoria Perk, Senior Research Associate

National Center for Transit Research (NCTR) at the

Center for Urban Transportation Research (CUTR)

University of South Florida

4202 E. Fowler Avenue, CUT 100

Tampa, Florida 33620-5375

perk@cutr.usf.edu

(813) 974-7327

Project Manager: Larry Hymowitz, Mobility Coordinator

FDOT Project Manager

Office of Modal Development

Florida Department of Transportation, District 4

3400 West Commercial Blvd.

Fort Lauderdale, Florida 33309

larry.hymowitz@dot.state.fl.us

(954) 777-4663

Project Staff:

Martin Catalá, Senior Research Associate

Maximilian Mantius, Research Assistant

Katrina Corcoran, Research Assistant 


\section{DISCLAIMER}

The opinions, findings, and conclusions expressed in this publication are those of the authors and not necessarily those of the State of Florida Department of Transportation. 


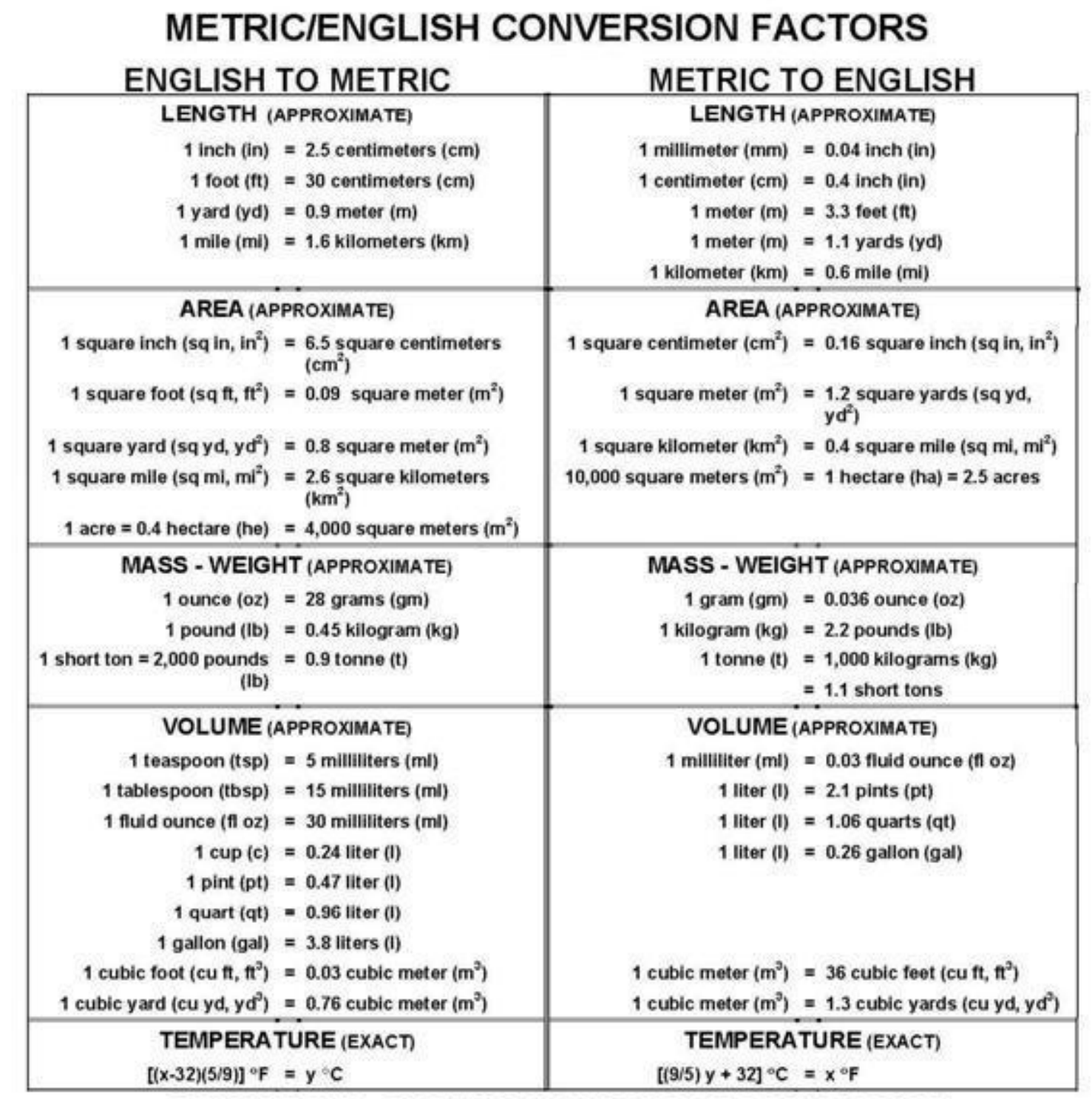

\section{QUICK INCH - CENTIMETER LENGTH CONVERSION}

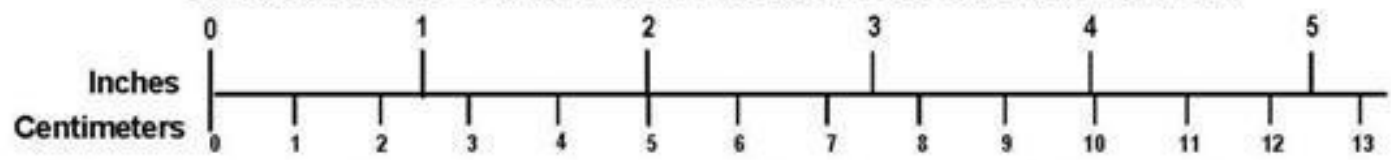

QUICK FAHRENHEIT - CELSIUS TEMPERATURE CONVERSION

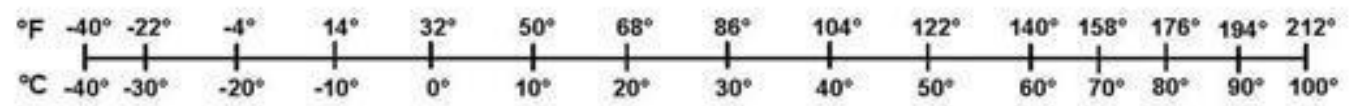

For more exact and or other conversion factors, see NIST Miscellaneous Publication 286. Units of Weights and Measures. Price \$250 SD Catalog No. C13 10286 
Technical Report Documentation Page

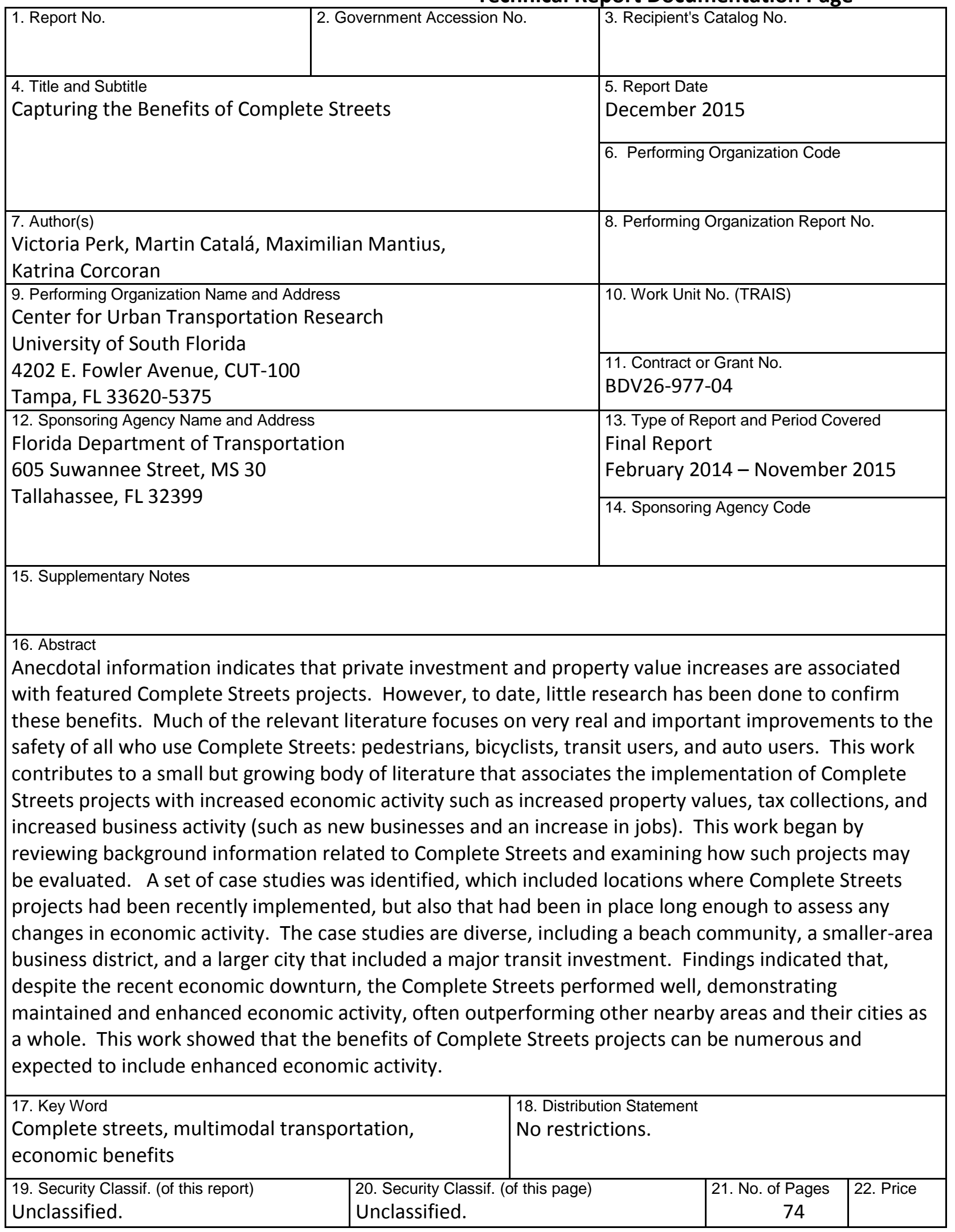

Form DOT F 1700.7 (8-72) Reproduction of completed page authorized 


\section{EXECUTIVE SUMMARY}

This executive summary describes the activities undertaken for this research on capturing the benefits of Complete Streets. Each chapter in the full report provides a summary of the work undertaken in each task of the effort.

\section{Purpose and Benefit of Research Study}

Anecdotal information indicates that private investment and property value increases are associated with featured Complete Streets projects; however, the studies do not compare them to the economic benefits or return on investment of non-Complete Streets projects or to the community or city as a whole. This research will lead to a better understanding of the differences among such projects in creating jobs, spurring private investment, increasing property values, and overall improved economic impacts. This will help transportation agencies to understand the marginal returns that can be expected from investments in non-traditional projects that improve accessibility of roadways for transit, bicyclists, and pedestrians and that reflect and promote community visions and plans.

\section{Research Objective}

This project begins to fill the gap in the literature regarding the economic impacts of Complete Streets projects and how those impacts may differ from more traditional roadways capacity investment projects that do not contain elements of Complete Streets. This research included a thorough look at the existing literature regarding Complete Streets and a summary of their impacts. Further, an appropriate methodology was identified for estimating the economic impacts of such projects. Finally, case studies were used to determine the relative impacts of such projects.

\section{Background}

Rather than designing roadways to primarily achieve greater vehicular travel speeds, Complete Streets initiatives promote safe access to all users: pedestrians, cyclists, and transit users, as well as motorists. According to the National Complete Streets Coalition, which is led by Smart Growth America, Complete Streets projects make it easier and safer for people to cross a street, walk, bike, and use public transportation. Such projects require an altered approach to planning, whereby communities direct their engineers and planners to "routinely design and operate the entire right-of-way to enable safe access for all users" [1].

There is not one singular definition of a Complete Streets project; each one is developed to fit within the unique context of a given community. Some elements of Complete Streets projects may include, but are not limited to, sidewalks, bike lanes, wide paved shoulders, bus lanes, accessible and comfortable transit stops or stations, frequent and safe opportunities to cross streets, median islands, accessible pedestrian signals, curb extensions, narrower travel lanes, 
and roundabouts. The approach to Complete Streets is applicable to rural as well as urban environments, although the elements of the projects will differ.

While it might be anticipated that Complete Streets projects would have a higher level of economic benefits (or return on investment) than projects that do not include Complete Streets elements, there has been no quantitative research in this regard. Further, many studies and reports that examine Complete Streets projects use qualitative analysis to reach their conclusions, which still leaves the true answer to the question of their impacts unanswered.

\section{What Are Complete Streets?}

Founded in 2005, the National Complete Streets Coalition, a product of Smart Growth America, encourages sustainable road design, efficient road networks and effective, pedestrian-friendly initiatives. Within the National Complete Streets Coalition lies the Complete Streets philosophy. Complete Streets is a movement with various interdisciplinary visions that encourage and promote multiple modes of transportation that are safe and accessible for all persons of a community, including the elderly and disabled. The movement revolves around redefining the uses of streets and how communities spend their finances for transportation purposes. By introducing various enhancements to roadways such as bike lanes, sidewalks and crosswalks, the Complete Streets movement is able to expand its philosophy of convenient road networks. With more people traveling by alternative methods, a natural shift towards a healthy and active lifestyle can likely follow. It is important to note that there is not a particular blueprint for Complete Streets; however, an ideal street contains sidewalks, bus bays, bike lanes and public transportation stops that are easily accessible; they contain roundabouts, secure crossing opportunities and medians [1]. Complete Streets policies help shift away from limited, incomplete streets towards a more comprehensive, self-serving network of streets.

\section{Who Has Adopted Complete Streets?}

Complete Streets have been adopted in numerous small towns, cities, and states although no federal mandate regarding the institution of strict policy has yet been issued. Most policies have been created at the local level, with cities and small towns initiating their own plans of action. As exhibited in Figure ES-1, approximately 34 percent of policies are adopted in small suburbs, while only nine percent of adopted policies happen in large cities [18]. As shown in Figure ES-1 below, a vast majority of Complete Streets policies have been adopted in locations of smaller size, most likely due to simpler implementation and lower costs associated with a smaller population. 


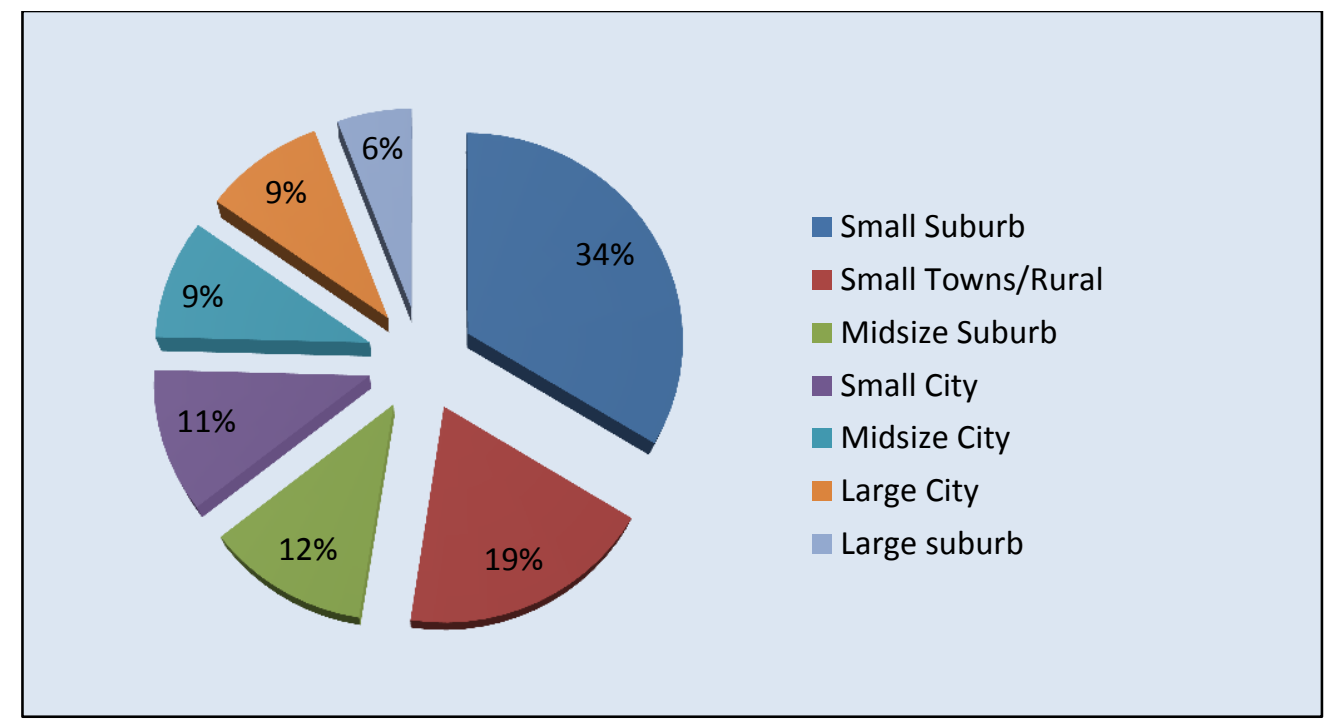

Figure ES-1 Complete Streets Policy Geography [18] [6]

The number of Complete Streets policies adopted has increased each year over the past decade. For example, in 2008 alone, 25 policies were adopted; the following year (2009), the number of policies adopted increased to 42 [6]. Skipping ahead to 2014, 70 Complete Streets policies were adopted across the country in that one year alone [19]. It is evident that the popularity and the progression of these policies has increased over the years-communities across the country are starting to desire the safe, efficient, and livable streets that are encouraged by the National Complete Streets Coalition. The National Complete Streets Coalition maintains a Policy Atlas which is updated bimonthly. Currently, more than 700 regional and local jurisdictions in 48 states, Puerto Rico, and the District of Columbia have adopted a Complete Streets policy or have committed in writing to do so [20].

\section{Evaluating Complete Streets Projects}

As mentioned previously, a body of research on the impacts of Complete Streets is continuing to grow. Initially, much of the research focused primarily on safety concerns for pedestrians and bicyclists. Researchers began documenting how the addition of particular components or amenities such as crosswalks, pedestrian signals, and better sidewalks and bicycle lanes improved safety for pedestrians and bicyclists, and made them more likely to use the facilities. In addition to safety, research was conducted to estimate impacts of Complete Streets elements on the level of physical activity, public health, and air quality [31] [33] [34] [37] [38] [39]. However, others began to envision the possibility of additional benefits, economic in nature. If pedestrians, bicyclists, and transit users felt an increased sense of safety along a corridor, more of them might use the corridor more often and also provide a boost to the surrounding businesses. Perhaps a walkable environment could be an amenity that increases surrounding property values, both commercial and residential. Research emerged 
showing that Complete Streets projects could positively affect retail sales and that a walkable environment can have many benefits, including increased property values [14] [32] [35] [41].

In 2014, the Center for Inclusive Design and Environmental Access and GOBike Buffalo developed a document to assist in the evaluation of Complete Streets initiatives and to assist communities in creating an evaluation plan for their individual Complete Streets policies or programs. The work focuses on the following outcomes [45]:

- Bicycle/pedestrian impacts

- Citizen feedback

- Economic impact

- Environmental impact

- Health impact

- Multimodal level of service

- Safety

For the outcome of economic impact listed above, several measures are suggested, including commercial and residential property values, foreclosure data, and retail sales (sales volume or tax receipts).

A year later, Smart Growth America and AARP published a practitioner's guide to evaluating Complete Streets projects. Similar to the work by the Center for Inclusive Design and Environmental Access and GOBike Buffalo, and following on the idea of providing a comprehensive set of outcomes and measures to evaluate Complete Streets projects, this work provided seven performance goals, each with a set of measures that can be used to evaluate how well a project meets a particular goal. The seven goals are listed as [46]:

1. Access

2. Economy

3. Environment

4. Place

5. Safety

6. Equity

7. Public health

\section{Methodology}

At the beginning of this project, a specific methodology had not been identified. Instead, the development of a methodology was embedded within the research as a separate task. The idea of using case studies and control areas, along with a particular set of measures to evaluate the projects was initially proposed, with the understanding that the methodology would be 
developed and refined based on research into potential case study sites and information gathered from the literature review. Since the start of this project, additional research reports

have been published which have provided new and valuable information for the conduct of this research. Specifically, reports by the New York City Department of Transportation and AARP/Smart Growth America have added additional understanding and lessons learned about the evaluation of Complete Streets projects [44] [46]. The former provided insight into the selection of case study sites, while the latter provided a framework for additional measures to consider for the analysis.

For this research, the methodology included the selection of up to five Complete Streets case study sites, both within and outside of Florida. Appropriate control areas (i.e., non-Complete Street sites) were to be selected, as appropriate, using input from local planning staff associated with the Complete Streets sites or others with local knowledge. Based on a recent similar study in New York, it is possible that suitable control areas may not be available; in those cases, the results from the Complete Streets projects were compared (proportionately) with similar results from the city and/or county in which the project was located [44].

\section{Quantitative Measures}

Based on the information compiled for this research, a set of measures to estimate economic benefits has been identified. Each type of measurement is described below:

\section{Employment}

For the businesses adjacent to the Complete Streets corridor, employment information can be used to assess economic vitality. The number of jobs can be available directly from the businesses as well as using available Longitudinal Employer-Household Dynamics (LEHD) data, which provides information on the location on jobs as well as wage ranges.

\section{Land Values}

County property appraiser databases are easy to access and provide data on market values, sale prices, and property taxes paid for the current year and also going back several years. For the case study sites selected for this research, the relevant property information was available back to at least 2005. These data could be used on their own and also in addition to other constructed measures.

\section{Qualitative Measures}

While the focus of this research was on the quantitative measures, the analysis benefits from additional qualitative analysis. This information came from any local reports or articles about the projects, and discussions with individuals representing the local government, local chambers of commerce, and adjacent businesses. Detailed information on sales tax collections 
or sales volumes was not available for this research; however, some of this information was captured in the qualitative analysis.

\section{Case Study Projects and Results}

The case studies selected for this research include:

- Gainesville, Florida - Main Street Corridor

- Fort Myers Beach, Florida - Estero Boulevard, North End

- Cleveland, Ohio - Euclid Avenue Corridor

Additional suggested case study sites that did not have data available for this project, but could be used in further research are:

- Cape Canaveral, Florida - Ridgewood Avenue

- West Jefferson, North Carolina - West Jefferson Streetscape Project

The case studies utilized in this project performed well when compared to other areas in their cities or their cities as a whole, using the data available for this work. Increased property values and property tax collections were found for the Gainesville and Cleveland case studies, when comparing years before and after the implementation of the respective Complete Streets projects. For the Fort Myers Beach case study, property values and tax collections were lower after the Estero Boulevard North End project was implemented; however, the changes were no worse that the Town of Fort Myers Beach as a whole. Most of the time periods covered by this research include those years during the 2007-2009 recession and the subsequent housing market collapse. For the case study sites, overall property values did not begin to recover until 2012 or 2013. Lee County (and its cities, including Fort Myers and the Town of Fort Myers Beach) was one of the most significantly impacted areas in the country during the housing crisis [54] [55].

Despite the lower property values in the Fort Myers Beach case study, job growth along the corridor far outpaced growth in the city after the implementation of the Estero Boulevard North End project. The same was true in the Cleveland case study (where the total number of jobs in the city actually fell during the time period studied), while the job growth along Gainesville's Main Street Corridor was moderately higher than the growth in the city during the same time period.

Overall, the results of the case study analyses show that the Complete Streets projects are associated with increased property values and job growth along the respective corridors. While a direct causal link cannot be established, these results are consistent with other recent research showing that Complete Streets projects are associated with increased economic activity. 


\section{Conclusion}

This project has attempted to go beyond the clear safety benefits of Complete Streets projects to show that such projects also make economic sense. Research was outlined in this report that demonstrated that Complete Streets projects, in many cases, are showing economic benefits. In most cases, a direct causal link cannot be established; however, there is a strong association between such projects and increased economic activity that often outpaces other areas in the city and the city itself. The benefits are further enhanced because the cost of many of the Complete Streets elements themselves tends to represent relatively small portions of overall project costs.

The case studies presented in this research represent a wide variety of Complete Streets applications: from a business district in Gainesville, Florida, to a beach community in Fort Myers Beach, to a larger urban city up north (Cleveland, Ohio) with a major transit investment. Additional case studies suggested but not completed include a residential area in Florida (Cape Canaveral) and smaller town in North Carolina. There is a plethora of new Complete Streets projects in the planning and construction phases in Florida and around the country. Clearly, communities across the nation have realized that Complete Streets projects represent improved transportation planning.

It is recommended that this research be continued to advance the knowledge and understanding of the economic impacts of these projects. Further research can strengthen the anecdotal and causal linkages between such projects and increased economic activity through the acquisition and use of more comprehensive data. To ensure that comparable data are available for any new potential case study sites in various time periods, it may be necessary to purchase large data sets that contain detailed data on business activity. The use of such data sets allows for a larger number of uniform measures on individual business activity that can be applied to any number of case study sites or projects selected for future research.

Beyond the three case study sites that were fully analyzed in this report, there are several other sites and projects that were described in this report that could be considered as case studies in a future research project. The residential Complete Streets project in Cape Canaveral, Florida and the small-town project in West Jefferson, North Carolina, are two such examples. The Buffalo-Niagara project (New York) is another potential case study. Other sites for future study in Florida might include additional segments of the project on Estero Boulevard in Fort Myers Beach (as they are completed), projects in Tampa, and projects in southeast Florida including Fort Lauderdale. Another potential case study in Florida for future research that was not mentioned earlier in this report is the City of Delray Beach. After a period of decline, the city worked to transform a stretch of Atlantic Avenue into a pedestrian-friendly corridor with revitalized businesses by calming traffic and also restoring old and abandoned buildings [61].

Currently, there are 50 Complete Streets policies in place in Florida cities and counties, including the Florida Department of Transportation [20]. In the near future, it is clear that there will be many additional projects, particularly in Florida, that can be studied for their 
effects. As such, there will be additional research opportunities to showcase the wide-ranging benefits, including economic benefits, of Complete Streets. 


\section{TABLE OF CONTENTS}

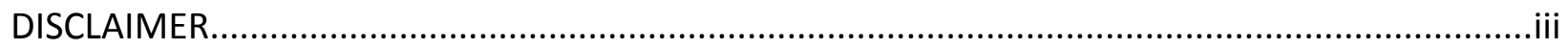

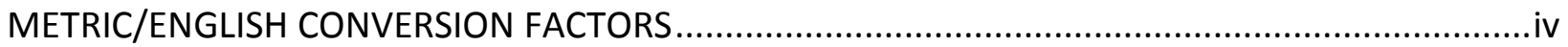

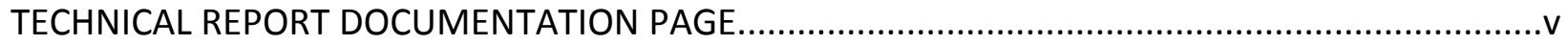

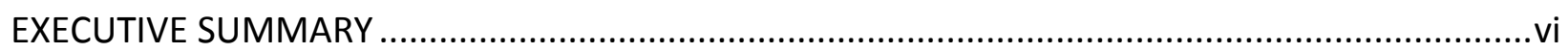

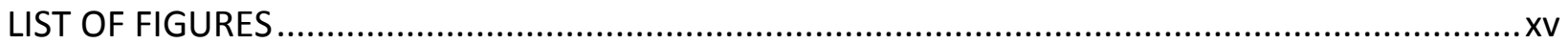

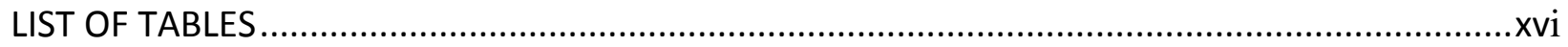

CHAPTER 1: Literature and Background Information ...................................................... 1

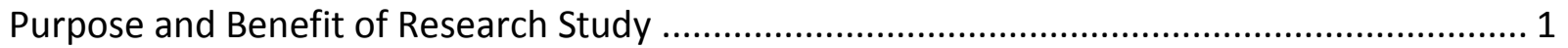

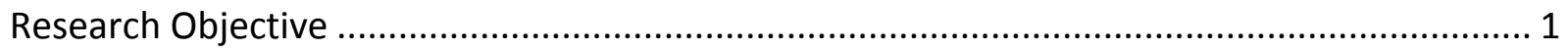

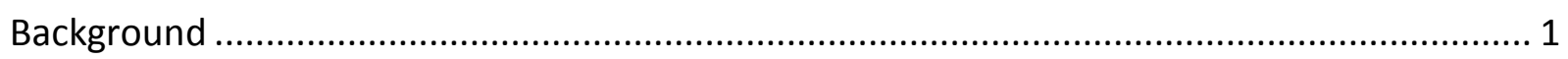

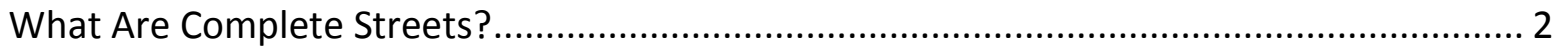

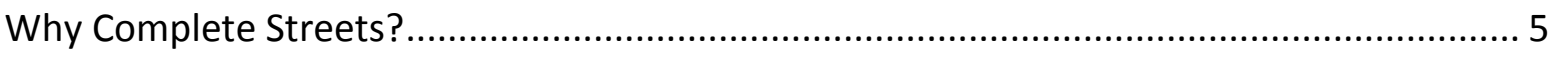

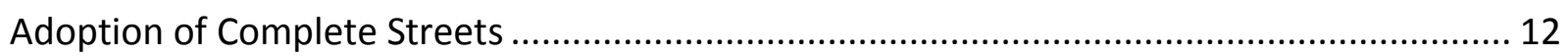

Who Has Adopted Complete Streets? ......................................................................... 12

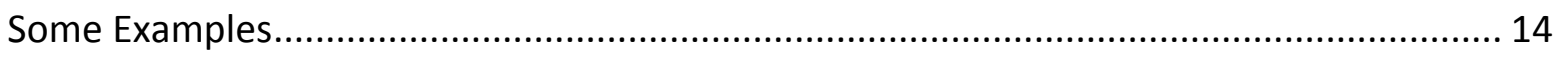

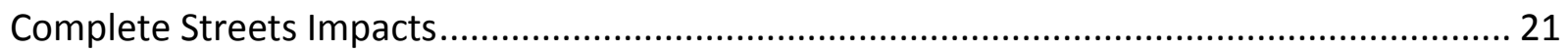

Measuring the Performance of Complete Streets ............................................................... 23

CHAPTER 2: Methodology and Identification of Case Study Sites ......................................... 26

Evaluating Complete Streets Projects.............................................................................. 26

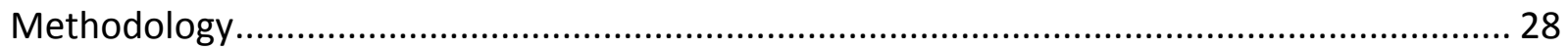

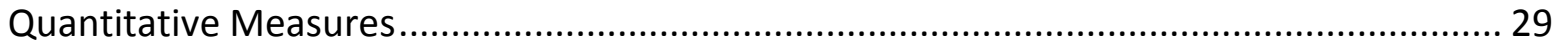

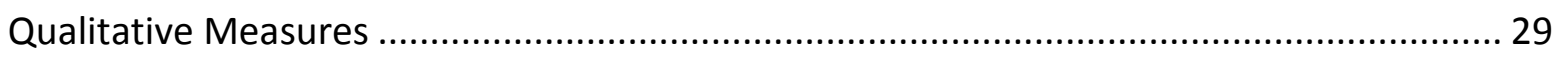

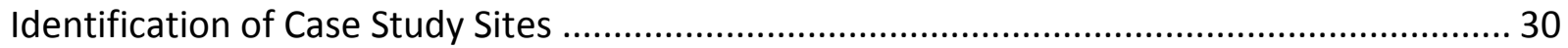

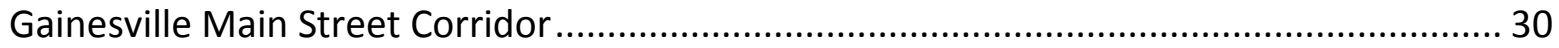

Fort Myers Beach - Estero Boulevard ................................................................... 31

Cleveland, Ohio - Euclid Avenue Corridor ................................................................. 32

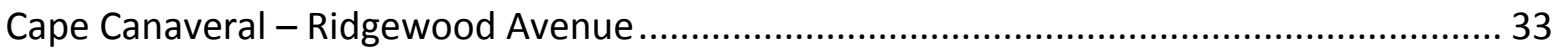

North Carolina - West Jefferson Streetscape Project ................................................... 33

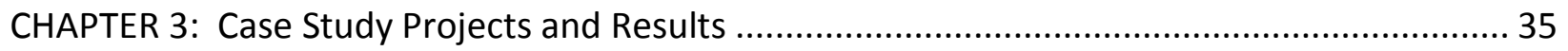

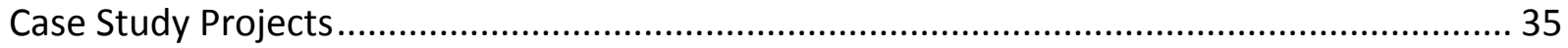

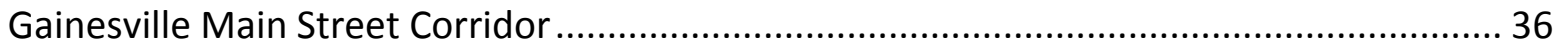

Fort Myers Beach - Estero Boulevard ........................................................................ 41

Cleveland, Ohio - Euclid Avenue Corridor .................................................................. 47

Cape Canaveral - Ridgewood Avenue..................................................................... 51

North Carolina - West Jefferson Streetscape Project...................................................... 51

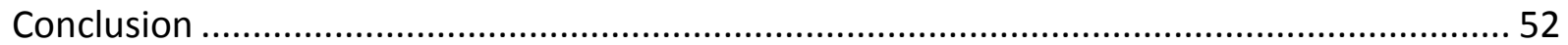

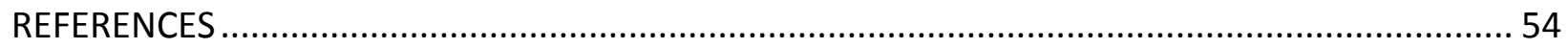




\section{LIST OF FIGURES}

Figure ES-1: Complete Streets Policy Geography ................................................................iii

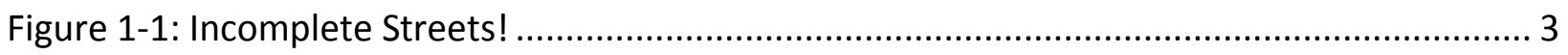

Figure 1-2: Examples of Complete Streets................................................................................ 4

Figure 1-3: Examples of Barrier-Separated Bike Lanes......................................................... 7

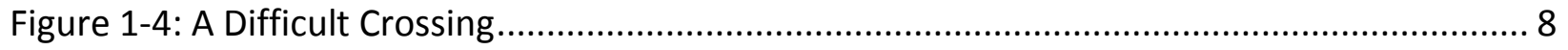

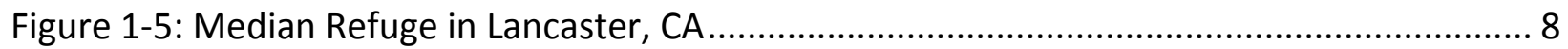

Figure 1-6: Poor Sidewalk Conditions Impede Pedestrian Mobility ....................................... 10

Figure 1-7: Pedestrian Amenities that Enhance Pedestrian Mobility......................................... 10

Figure 1-8: Pedestrian Amenities that Enhance Pedestrian Mobility....................................... 11

Figure 1-9: Complete Streets Policy Geography ..................................................................... 13

Figure 1-10: Number of Complete Streets Policies Nationwide ............................................. 14

Figure 1-11: Tampa, Florida, Mayor Bob Buckhorn at the Newly Constructed Roundabout at the Intersection of $22^{\text {nd }}$ Street and $22^{\text {nd }}$ Avenue ......................................... 15

Figure 1-12: A Typical Roundabout Structure .................................................................. 15

Figure 1-13: Painted Intersection Project and Parklet in Fort Lauderdale ................................. 16

Figure 1-14: Complete Streets Elements in West Palm Beach, FL......................................... 17

Figure 1-15: Before and After Complete Streets, West Palm Beach, FL................................. 18

Figure 1-16: Complete Streets in Charlotte, NC ................................................................ 19

Figure 1-17: Renderings of the Niagara Street Gateway Project in Buffalo, NY....................... 21

Figure 2-1: Gainesville's Main Street Corridor before (2008) and after (2012) ........................ 30

Figure 2-2: Fort Myers Beach Estero Boulevard Project .................................................... 31

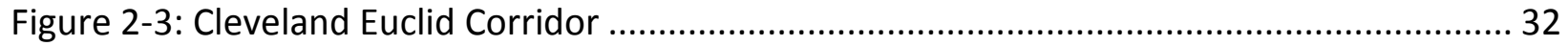

Figure 2-4: West Jefferson, North Carolina - Streetscape Project ......................................... 33

Figure 3-1: Gainesville's Main Street Corridor - North $8^{\text {th }}$ Avenue to Depot Avenue ............... 36

Figure 3-2: Gainesville's Main Street Corridor before (2008) and after (2012) ...................... 37

Figure 3-3: Gainesville's Main Street Corridor - 2015 ........................................................ 38

Figure 3-4: Fort Myers Beach - Estero Boulevard Project, North End .................................... 41

Figure 3-5: Fort Myers Beach - Estero Boulevard Project, North End before (2007)

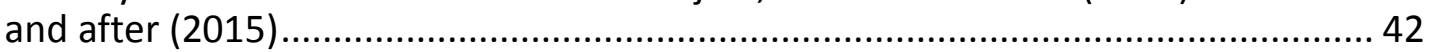

Figure 3-6: Fort Myers Beach Estero Boulevard Project, Completed North End ...................... 43

Figure 3-7: Fort Myers Beach Estero Boulevard Project, Completed North End ...................... 44

Figure 3-8: Cleveland, Ohio - Euclid Avenue Corridor..................................................... 47

Figure 3-9: Cleveland, Ohio - Euclid Avenue Corridor Completed Project ............................... 49

Figure 3-10: West Jefferson, North Carolina - Streetscape Project ....................................... 52 


\section{LIST OF TABLES}

Table 1-1: Potential Benefits and Costs of Complete Streets............................................... 25

Table 3-1: Changes in Market Values of Parcels and Property Taxes Paid

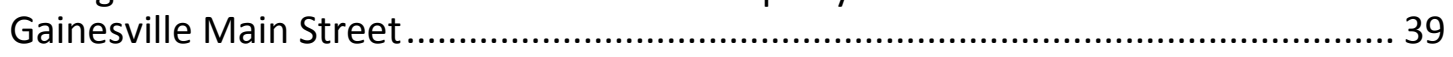

Table 3-2: Changes in Number of Jobs - Gainesville Main Street and City of Gainesville ........... 40

Table 3-3: Changes in Market Values of Parcels and Property Taxes Paid Fort Myers Beach, Estero Boulevard, North End .................................................... 45

Table 3-4: Changes in Number of Jobs - Fort Myers Beach, Estero Boulevard, North End

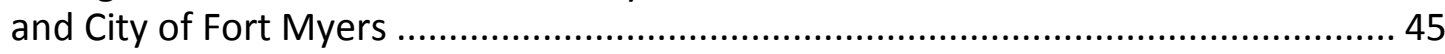

Table 3-5: Changes in Number of Jobs - Cleveland Euclid Corridor and City of Cleveland......... 51 


\section{CHAPTER 1: LITERATURE AND BACKGROUND INFORMATION}

This report provides a summary of the activities undertaken for this research on economic benefits of Complete Streets. Each chapter provides a summary of the work undertaken in each task of the work. This first chapter contains a summary of relevant literature and background information and begins with some information about the project.

\section{Purpose and Benefit of Research Study}

Anecdotal information indicates that private investment and property value increases are associated with featured Complete Streets projects; however, the studies do not compare them to the economic benefits or return on investment of non-Complete Streets projects or to the community or city as a whole. This research will lead to a better understanding of the differences among such projects in creating jobs, spurring private investment, increasing property values, and overall improved economic impacts. This will help transportation agencies to understand the marginal returns that can be expected from investments in non-traditional projects that improve accessibility of roadways for transit, bicyclists, and pedestrians and that reflect and promote community visions and plans.

\section{Research Objective}

This project begins to fill the gap in the literature regarding the economic impacts of Complete Streets projects and how those impacts may differ from more traditional roadways capacity investment projects that do not contain elements of Complete Streets. This research included a thorough look at the existing literature regarding Complete Streets and a summary of their impacts. Further, an appropriate methodology was identified for estimating the economic impacts of such projects. Finally, case studies were used to determine the relative impacts of such projects.

\section{Background}

Rather than designing roadways to primarily achieve greater vehicular travel speeds, Complete Streets initiatives promote safe access to all users: pedestrians, cyclists, and transit users, as well as motorists. According to the National Complete Streets Coalition, which is led by Smart Growth America, Complete Streets projects make it easier and safer for people to cross a street, walk, bike, and use public transportation. Such projects require an altered approach to planning, whereby communities direct their engineers and planners to "routinely design and operate the entire right-of-way to enable safe access for all users" [1].

There is not one singular definition of a Complete Streets project; each one is developed to fit within the unique context of a given community. Some elements of Complete Streets projects may include, but are not limited to: sidewalks, bike lanes, wide paved shoulders, bus lanes, accessible and comfortable transit stops or stations, frequent and safe opportunities to cross 
streets, median islands, accessible pedestrian signals, curb extensions, narrower travel lanes, and roundabouts. The approach to Complete Streets is applicable to rural as well as urban environments, although the elements of the projects will differ.

While it might be anticipated that Complete Streets projects would have a higher level of economic benefits (or return on investment) than projects that do not include Complete Streets elements, there has been no quantitative research in this regard. Further, many studies and reports that examine Complete Streets projects use qualitative analysis to reach their conclusions, which still leaves the true answer to the question of their impacts unanswered.

\section{What Are Complete Streets?}

Founded in 2005, the National Complete Streets Coalition, a product of Smart Growth America, encourages sustainable road design, efficient road networks and effective, pedestrian-friendly initiatives. Within the National Complete Streets Coalition lies the Complete Streets philosophy. Complete Streets is a movement with various interdisciplinary visions that encourage and promote multiple modes of transportation that are safe and accessible for all persons of a community, including the elderly and disabled. The movement revolves around redefining the uses of streets and how communities spend their finances for transportation purposes. By introducing various enhancements to roadways such as bike lanes, sidewalks and crosswalks, the Complete Streets movement is able to expand its philosophy of convenient road networks. With more people traveling by alternative methods, a natural shift towards a healthy and active lifestyle can likely follow. It is important to note that there is not a particular blueprint for Complete Streets; however, an ideal street contains sidewalks, bus bays, bike lanes and public transportation stops that are easily accessible; they contain roundabouts, secure crossing opportunities and medians [1]. Complete Streets policies help shift away from limited, incomplete streets towards a more comprehensive, self-serving network of streets. The evolution of Complete Streets is based upon the idea of Context-Sensitive Solutions (CSS), which can also be described as a different approach to transportation planning and design. CSS emphasizes a balancing of competing stakeholder needs, including safety, mobility, community, and environmental [2]. The concept behind CSS is to design projects that fit the needs of users of all modes.

Before providing pictorial examples of what Complete Streets look like, it may be instructive to be reminded of what they are not. Figure 1-1 obviously illustrates very unsafe and unfriendly conditions for pedestrians, cyclists, and transit users. 


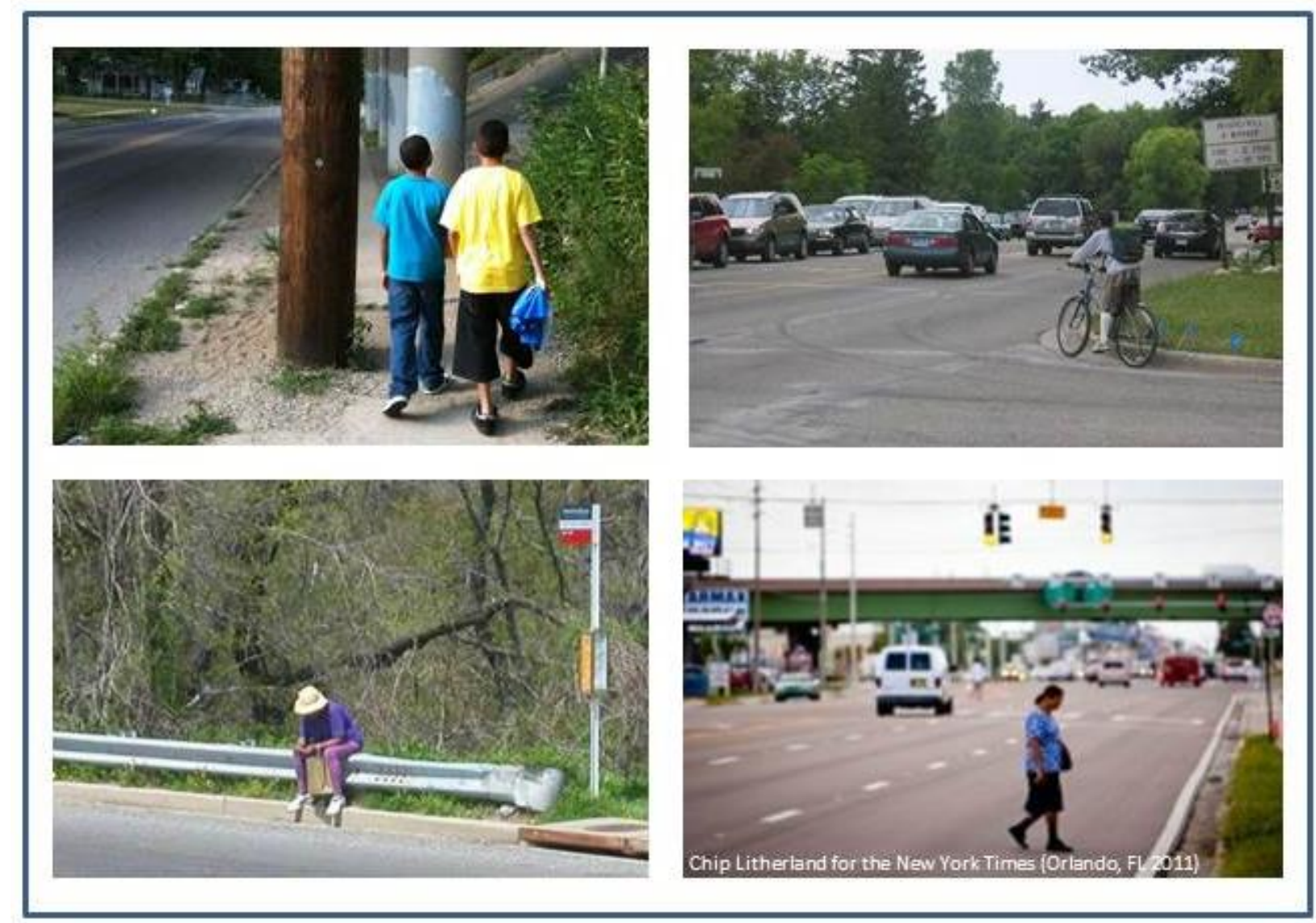

Source: Bent, Zabe. The State of Complete Streets: Lessons on Implementing State Complete Street Policies. May 2014. Presentation at the 2014 APTA Bus and Paratransit Conference (except where noted in the Figure).

Figure 1-1: Incomplete Streets!

In Figure 1-2, however, examples of Complete Streets are shown. Several elements of Complete Streets can be seen in these photographs, including landscaping, street trees, wide sidewalks, clear crosswalks and pavement markings, accessible transit, and separated bike lanes.

Various cities, towns and states have their own vision and implementation process for Complete Streets; however, they all revolve around the same principles that are uniquely embedded within Complete Streets policy. Current, conventional street design enables traffic congestion, pollution and discourages physical activity in transporting oneself, while Complete Streets design ensures that pedestrians of all ages and abilities have the potential to travel freely and safely. Instituting thoughtful design enables an active, healthier citizenry and community, and has the potential to prevent the climb of obesity rates. As progress continues to be made at the local level, a lifestyle with more transportation options presents itself. Additional discussion of Complete Streets policies can be found in a later section of this chapter (titled Adoption of Complete Streets). 


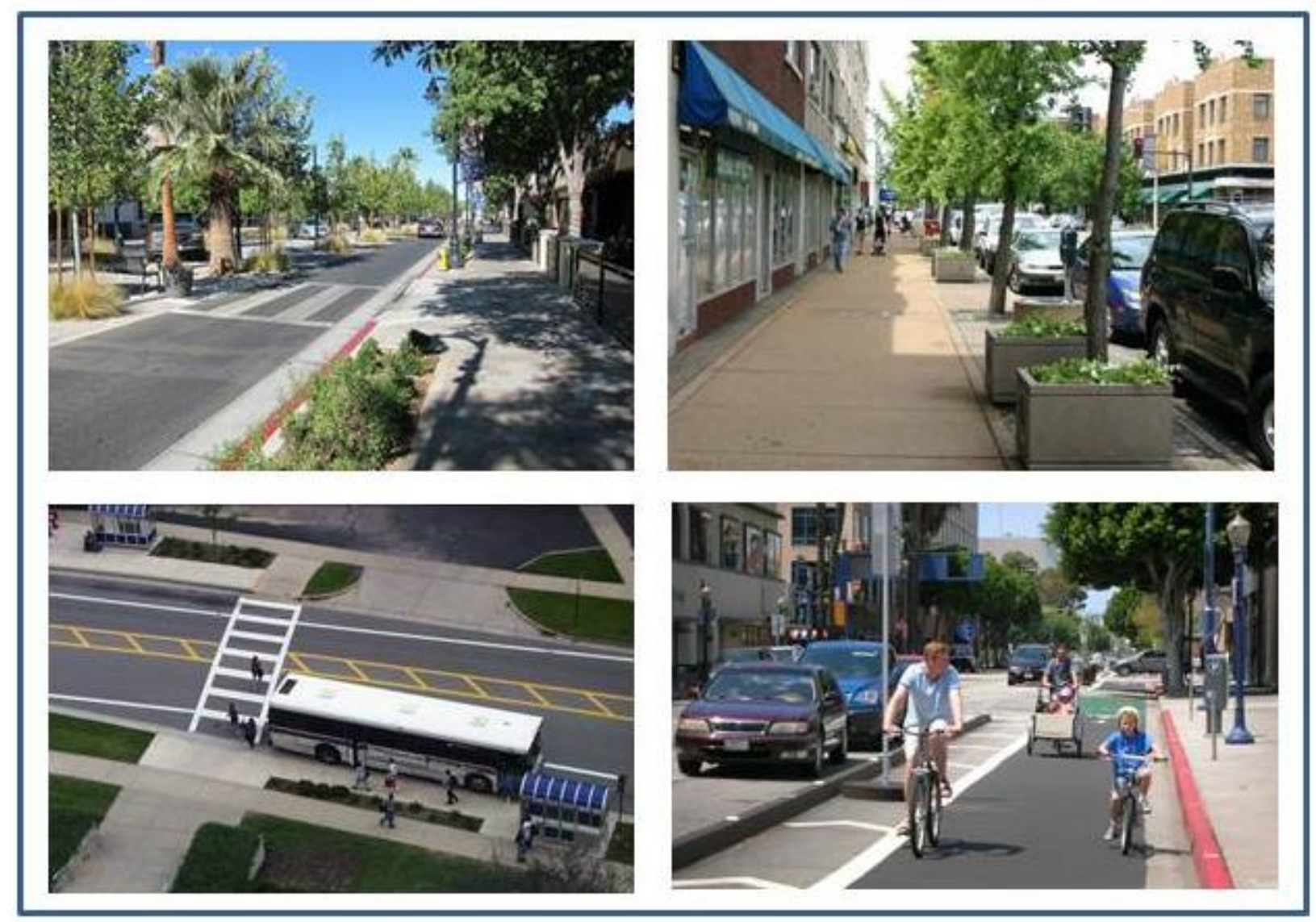

Source: Clockwise from top left, http://saferoutescalifornia.org/2012/08/30/lancaster/;

http://www.heartlandsconservancy.org/wp-content/uploads/2012/11/Economic-Advantages-of-Complete-

Streets.pdf ; http://www.studio-111blog.com/incremental-urbanism/;

http://www.smartgrowthamerica.org/documents/cs/cs-brochure-policy.pdf

Figure 1-2: Examples of Complete Streets

A Safe Streets Act of 2013 (HR 2468) was introduced in the U.S. House of Representatives in 2013 by Congresswoman Doris O. Matsui. Sponsored with bipartisan support, it "requires each state to have in effect within two years a law, or each state department of transportation and metropolitan planning organization (MPO) an explicit policy statement, that requires all federally-funded transportation projects, with certain exceptions, to accommodate the safety and convenience of all users in accordance with certain complete streets principles" [3]. Complete Street principles can be defined as policies at various levels of government that pledge well-being and timeliness for an array of transportation modes and its peoples and take into consideration individuals with a variety of backgrounds during preparation and development [1]. HR 2468 also "requires the Secretary of Transportation (DOT) to establish a method for evaluating compliance by state departments of transportation and MPOs with complete streets principles" [3]. As of this writing, there are 33 cosponsors of the bill with the majority coming from the state of California. After being introduced in the House, HR 2468 has since been referred to the Subcommittee on Highways and Transit. 
It is noteworthy to include that there exists a bill related to HR 2468-Safe Streets Act of 2014 (S. 2004). Introduced in the Senate in February 2014 by Senator Mark Begich, S. 2004 is essentially an identical bill (word-for-word) to HR 2468 [4]. The variance exists in the fact that HR 2468 was created in the House of Representatives while S. 2004 was created in the Senate. Since its creation, S.2004 has been referred to the Senate Committee on Environment and Public Works.

\section{Why Complete Streets?}

Complete Streets are gaining favor due to the many benefits they provide, including safety improvements, environmental improvements, use of alternative modes, increased capacity, improving quality of life for vulnerable populations such as the elderly, disabled, and youth, and economic benefits [5]. Complete Streets initiatives have even been encouraged by parties outside the transportation realm. It is important to note that the Center for Disease Control and other health organizations have encouraged the implementation of Complete Streets initiatives as they are seen as a simple, yet strategic, fight against the obesity epidemic [6]. Various groups also advocate for such policies. These groups include, but are not limited to, America Association of Retired Persons (AARP); Institute of Transportation Engineers (ITE); and groups representative of elected officials - the U.S. Conference of Mayors and the National League of Cities [6]. With expression for modification in roadway systems by the National Complete Streets Coalition, it is evident that other groups are just as eager to advocate for enhancements in the current transportation design process.

\section{Safe Choices}

Many streets across the country are in need of refurbishing and enhancements yet lack the communal sponsorship and organization to push for such improvements. Living with inadequate streets that provide little use outside of transporting vehicles can be inconvenient for public transportation, appear unattractive and can hinder safety. Providing methods of alternative transportation and improving roadways and networks for pedestrians through Complete Streets permits people to lead a safer, convenient lifestyle with more transportation options. Complete Streets allow for individuals to have an array of choices in transporting themselves. Instead of feeling the need to drive in a car for a quick errand, bike lanes, paved sidewalks and effective pedestrian crossings allow for people to walk, bike or take transit to their destination, creating convenience, a healthier environment, and an active lifestyle. Having options in the community also creates a sense of freedom - one is not inclined to the obligation of a single method of transportation when multiple options are available and can be accessed easily and safely. Figure 1-3, on the following page, provides additional examples of barrier-separated bike lanes on Kinzie Street in Chicago and Laurier Avenue in Ottawa. 
Further, there is evidence that shifting consumer preferences are increasing the demand for the alternate modes of transit, bicycling, and walking [7]. These shifting preferences can be due to several factors, including changing demographics, economic issues, health concerns, and environmental concerns. In San Francisco and Los Angeles, recent roadway design preference surveys were conducted among pedestrians, drivers, cyclists, and transit users. The surveys found that all four groups wanted to see better crossings, more and better bike lanes, and other characteristics associated with Complete Streets [8]. Many groups are also driving less and walking, biking, and using transit more, particularly younger people, and a body of research has grown to study the transportation preferences of young people and how they may influence transportation policy and project design [9]. As such, it seems that the components of Complete Streets are increasingly what people want in their communities.

\section{An Aging Population}

Complete Streets initiatives and their pedestrian-friendly policies are an important step in assisting the elderly. It is estimated that roughly 25 percent of U.S. drivers will be 65 years or older by 2025-an indication that road design will inevitably increase in importance in regards to the aging population [10]. Endorsed by AARP, Inc., Complete Streets contain the potential to transform traditional street design to better accommodate elderly road users. Currently, many roads lack adequate characteristics of safe streets. In a poll conducted by AARP, it was found that 50 percent of adults aged 50 years or older reported that main roads closest to their homes were not safe to cross. Furthermore, roughly 40 percent of those surveyed reported deficient sidewalks in their neighborhoods [10]. It is important to understand that much of the current road system fails to consider not only the average pedestrian, but also fails to take into account the elderly and the more fragile populace. Figure 1-4 shows a daunting situation for an elderly woman as she prepares to cross a very wide road with few pedestrian amenities. 


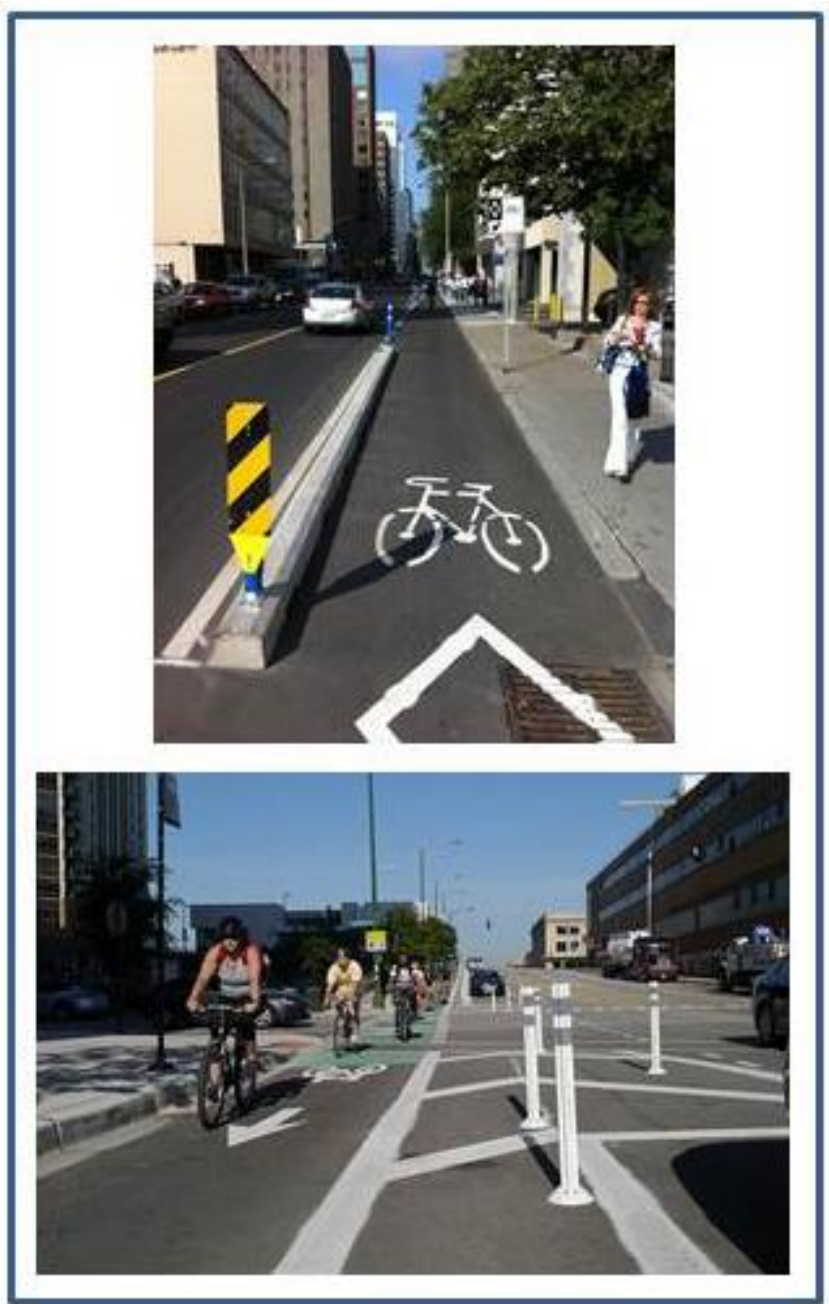

Source: Top, http://completestreetsforcanada.ca/examples/laurier-avenue-west-ottawa Bottom, http://chicagocompletestreets.org/your-streets/bikeways/barrier-protected-bike-lanes/

Figure 1-3: Examples of Barrier-Separated Bike Lanes

A better scenario would involve elements of Complete Streets such as pedestrian signals and median refuge islands, as shown in Figure 1-5 to make the crossing safer. Data from the 2009 National Household Travel Study show that older Americans have increased their use of transit in recent years. Between 2001 and 2009, transit usage by those age 65 and older increased by 40 percent (as a share of all trips they take), which reverses the trend of the past few decades [11]. Whether dependent or choice riders, it is clearly important to design and maintain safe access to public transit for these older users (as well as all users). 


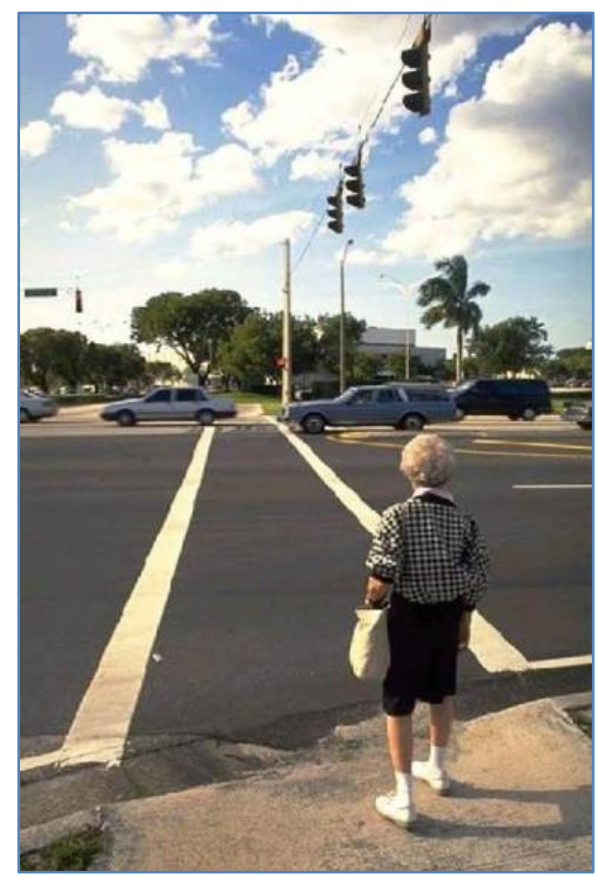

Photo by Dan Burden, Walkable \& Livable Communities Institute

Figure 1-4: A Difficult Crossing

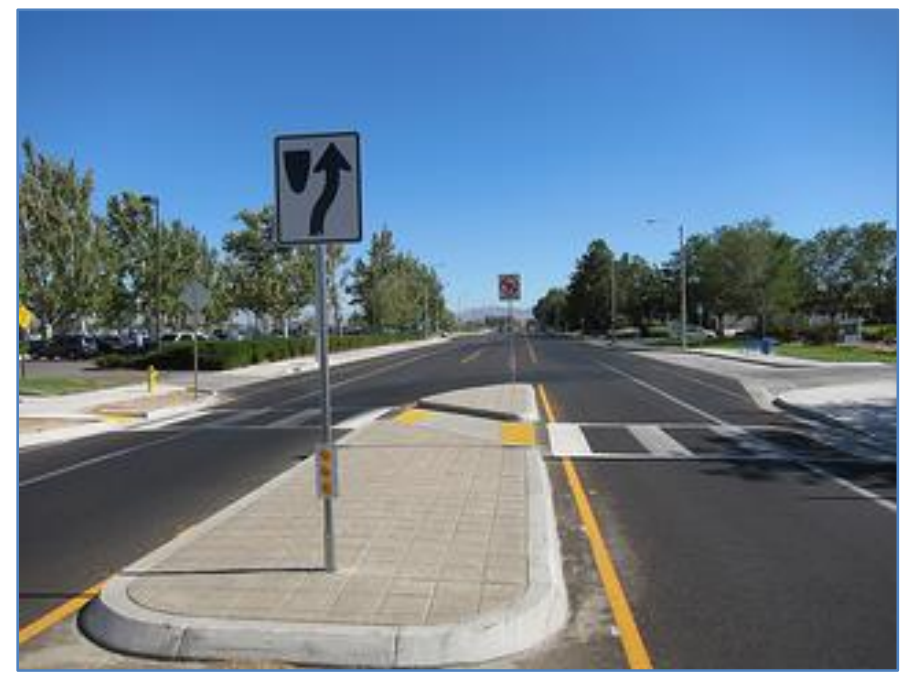

Source: http://saferoutescalifornia.org/2012/08/30/lancaster/

Figure 1-5: Median Refuge in Lancaster, CA 
By encouraging initiatives at the local, regional and state level, Complete Streets emphasizes three main principals to enhance the road environment for older drivers [10]. The first principle revolves around simply slowing down. Reducing the speeds at which vehicles are permitted to travel gives more time for older drivers to react to traffic and pedestrians, resulting in a lower pedestrian fatality rate. It is found that a change in speed from $40 \mathrm{MPH}$ to $30 \mathrm{MPH}$ has a significant effect on pedestrian safety. There is a 70 percent chance of survival for pedestrians hit at $30 \mathrm{MPH}$; conversely, there is an 80 percent chance of death for pedestrians hit at $40 \mathrm{MPH}$ [10]. The second principle revolves around making transportation networks easy to navigate for older pedestrians and drivers who have lost some of their finesse. Constructing turn lanes with wider bounds enable safer turns for both drivers and pedestrians. The third and final principle revolves around enjoying the view-making it easier for the elderly to read and understand signs, cues and basic transit information. Simple improvements to road design include larger signs; the reduction of sign clutter, reflective and bright pavement markings; median implants and sufficient landscape and lighting. By instituting Complete Streets ideals, older persons can experience the benefits of a safer transportation environment.

\section{Disabled Persons and the Transportation Disadvantaged}

Much of the issues that relate to the average pedestrian intensify in seriousness when dealing with persons with disabilities. Many disabled pedestrians are in wheelchairs, have poor vision, cannot hear well or are simply physically slower moving. Roughly one in five Americans suffers at least one of these hindrances [10]. Incomplete streets-streets without pedestrian-friendly tools - cause a hazard for disabled persons. It is quite difficult for disabled persons to safely cross a street without the proper crosswalk or proper sidewalk. Bus stops placed inconveniently in a patch of grass without a cutout curb or sidewalk cause difficulty for users relying on wheelchairs. Through Complete Streets - thoughtfully designed transportation road networks - pedestrians of all backgrounds can safely and efficiently transport themselves with the enhanced road design.

By some estimates, nearly a third of the American population is transportation disadvantaged [7]. According to research conducted by Clifton, Bronstein, and Morrissey, Complete Streets are certainly beneficial for the transportation disadvantaged, although the benefit to them may not be directly acknowledged as a leading factor in the implementation of such projects. Nonetheless, these authors emphasize that the most vulnerable populations should be served first, with transportation equity as one of the most essential public health objectives [12]. In addition to the role of communities in advocating for Complete Streets, there is also a role for transit providers to play in ensuring successful implementation of such projects. Transit agencies should know the characteristics of their ridership, the safety and walkability of their routes, and the safety and walkability of the access to the routes. They should be partners with other entities in the community in designing, implementing, and operating Complete Streets projects [13]. 
Figure 1-6 illustrates sidewalk conditions that would be difficult for any pedestrian, let alone someone who has a disability. Complete Streets elements provide better sidewalks, crossings, and appropriate barriers, as shown in Figure 1-7, to ensure easy and safe access for all, including those with disabilities.

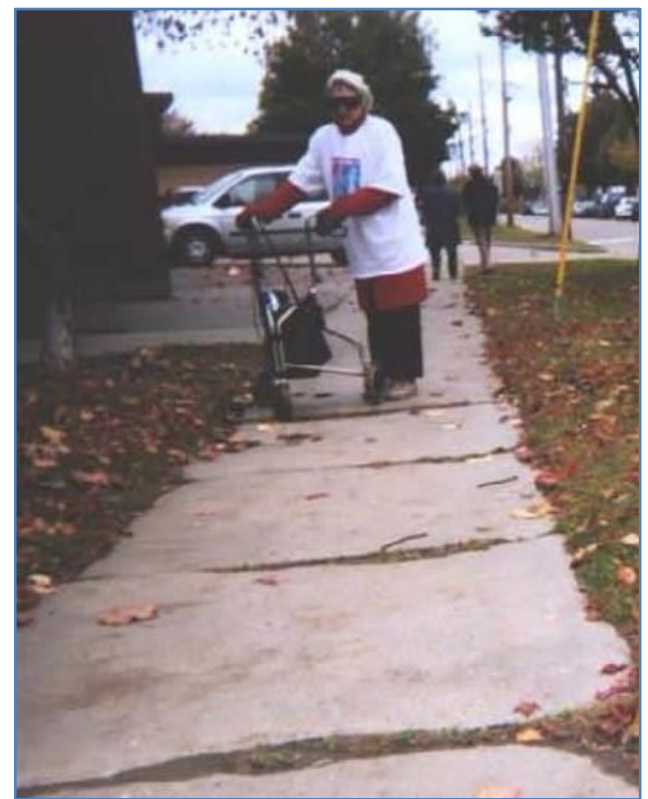

Source: Planning Complete Streets for an Aging America. Guzman, Shannon. May 2014.

Presentation at the 2014 APTA Bus and Paratransit Conference [14]

Figure 1-6: Poor Sidewalk Conditions Impede Pedestrian Mobility

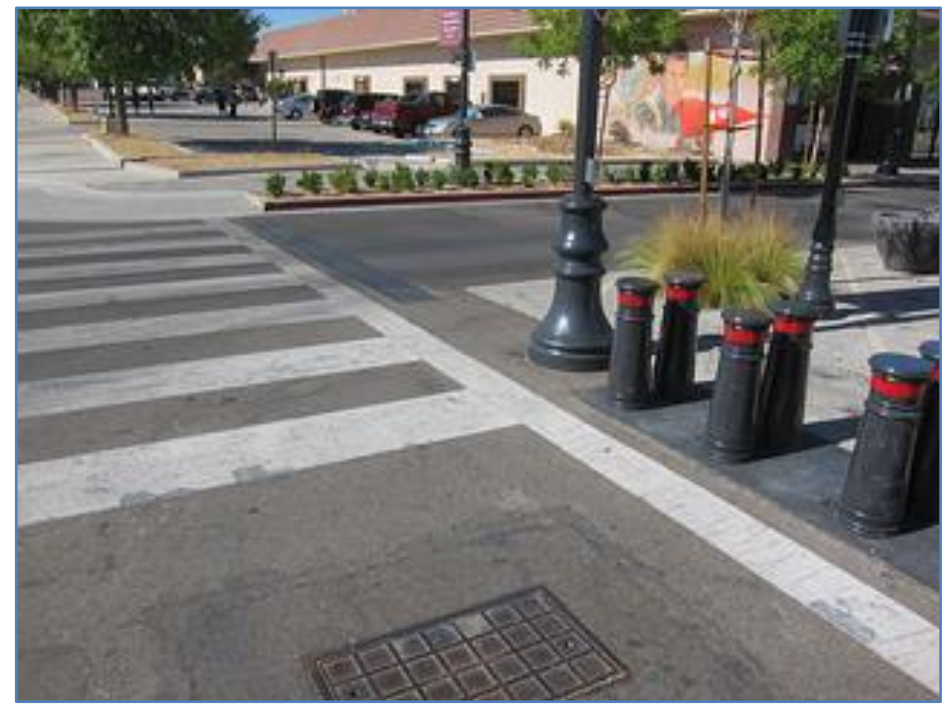

Source: http://saferoutescalifornia.org/2012/08/30/lancaster/

Figure 1-7: Pedestrian Amenities that Enhance Pedestrian Mobility 


\section{Economic Growth}

In addition to the safety benefits to all users of a roadway, Complete Streets projects are believed to support the economic vitality of the corridor(s) and surrounding areas. Dan Burden, of Walkable Communities, Inc., stated, "First fix the streets, then the people and business will follow" [15]. Walkability is touted as a good investment that has the potential to increase property values, attract tourists, attract business, and increase retail sales. A Realtors survey in 2011 found that three out of four homebuyers considered places to take walks and sidewalks to be important factors in their decisions [16]. As stated earlier in this chapter in the section titled Complete Streets Are What People Want, there is evidence that homebuyers as well as businesses want the improvements in quality of life that safer, walkable/bikeable, and transitfriendly streets can offer. It is an objective of this research to show that this is true for Complete Streets projects and that the magnitudes are different than non-Complete Streets projects. Figure 1-8 provides additional examples of Complete Streets elements.

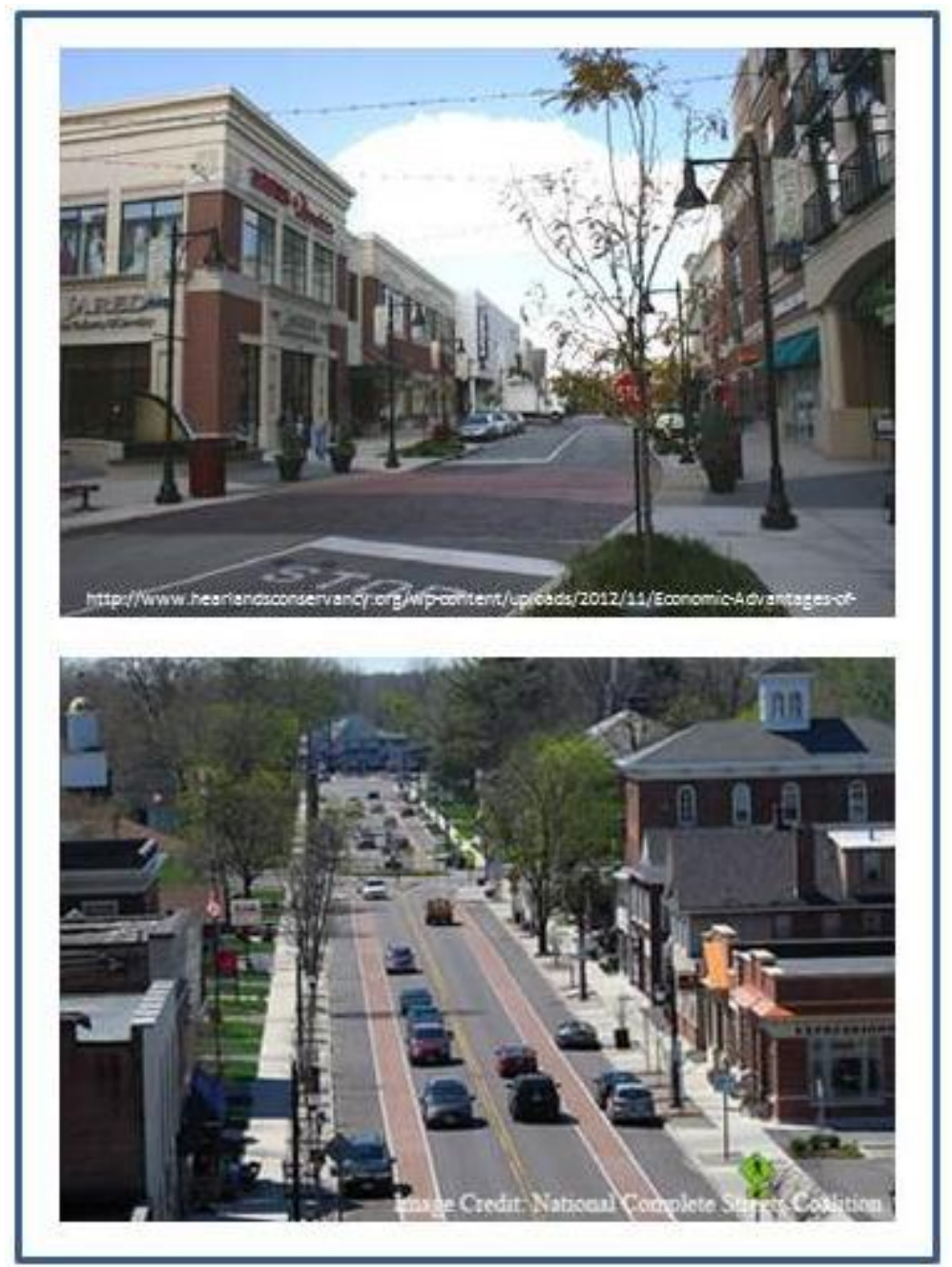

Figure 1-8: Pedestrian Amenities that Enhance Pedestrian Mobility 


\section{Adoption of Complete Streets}

Complete Streets initiatives are increasingly encouraged at all levels of government-local, state and federal-and are enacted by elected officials and other community leaders through city councils and state legislatures. There exists a responsibility of these persons and agencies to affirm the pledges of communities to form multimodal transportation webs. The intention of such Complete Streets policies is to modify the processes that transportation agencies take in designing roadways so that every mode of transportation is considered in every step of the design process. Whether the modification is a simple crosswalk or a more complex roadwidening design, the ultimate goal is to create a system of road networks that are complete, safe and accessible for multimodal transportation [6]. This commitment affirms the idea that a design strategy for multimodal users takes priority over the traditional, single automobile design strategy and is an essential integration for engineers and other alike professional planners. The National Complete Streets Coalition outlines several elements that would ensure a comprehensive policy. Such a policy should: include a vision, specify "all users," apply to both new and retrofit projects, make exemptions specific, encourage street connectivity, cover all roads, use the latest and best design guidelines, be context-sensitive, set measurable performance standards, and include specific next steps for policy implementation [17].

There can exist various challenges, however, in implementing Complete Streets policy. In order for policy implementation to be successful, LaPlante and McCann specify four conditions that must be accomplished:

- Rewrite and/or refocus agency policies and procedures to serve all modes of transportation

- Rewrite and/or adapt design guidelines

- Train and develop staff in policy implementation and serving all modes

- Collect data on all users and modes of transportation for before-and-after performance measurements [6].

Through these procedures, a restructuring in the design of road networks will inevitably take place, usually beginning with the initial phases of scoping the new design. Many communities that have enacted Complete Street policies have found that there is substantial financial savings by assessing transportation developments earlier rather than later with the help of check-lists, cross-departmental meetings, and strategic model design [6].

\section{Who Has Adopted Complete Streets?}

Complete Streets have been adopted in numerous small towns, cities, and states although no federal mandate regarding the institution of strict policy has yet been issued. Most policies have been created at the local level, with cities and small towns initiating their own plans of action. As exhibited in Figure 1-9, approximately 34 percent of policies are adopted in small suburbs, while only 9 percent of adopted policies happen in large cities [18]. As shown in Figure 
1-9, below, the vast majority of Complete Streets policies have been adopted in locations of smaller size, most likely due to most likely due to simpler implementation and lower costs associated with a smaller population.

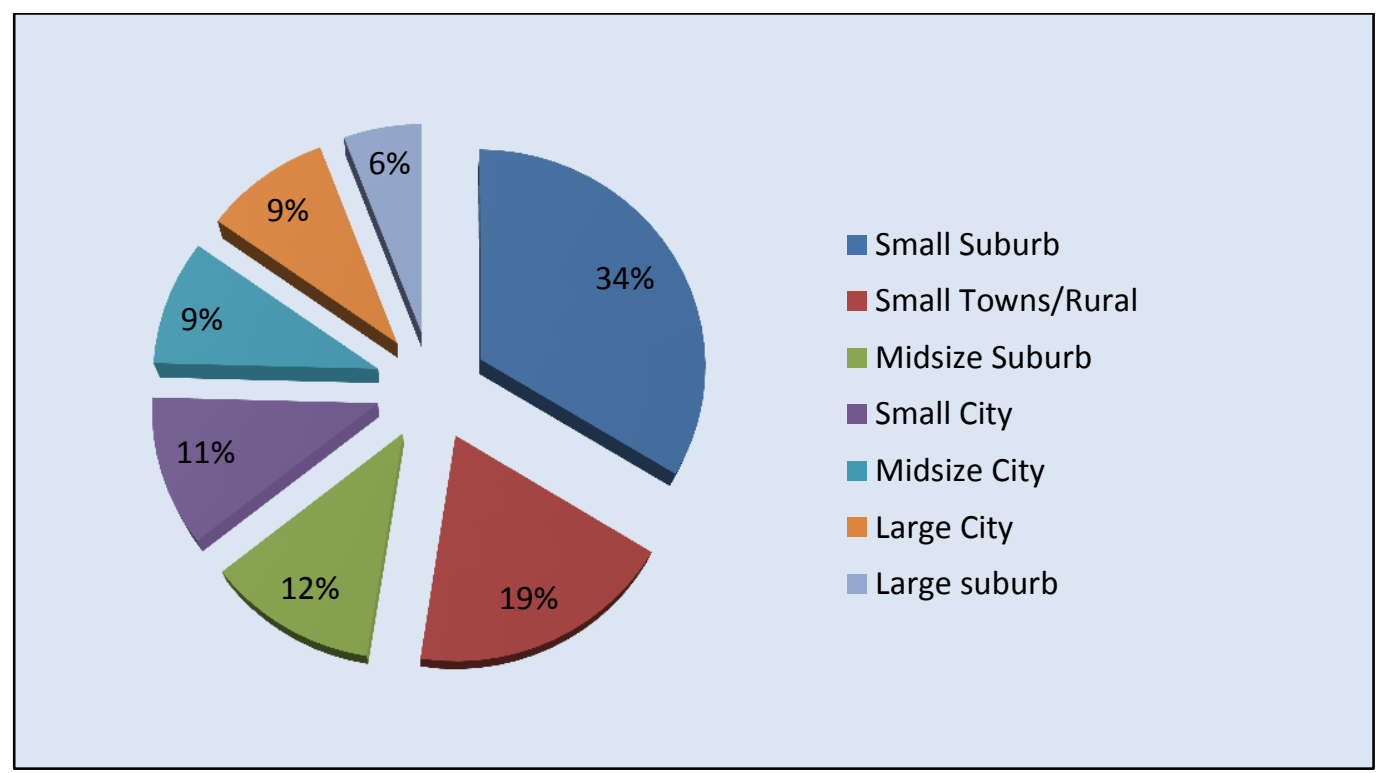

Figure 1-9: Complete Streets Policy Geography [18] [6]

The number of Complete Streets policies adopted has increased each year over the past decade. For example, in 2008 alone, 25 policies were adopted; the following year (2009), the number of policies adopted increased to 42 [6]. Skipping ahead to 2014, 70 Complete Streets policies were adopted across the country in that year alone [19]. As seen in Figure 1-10, below, it is evident that the popularity and the progression of these policies has increased over the years-communities across the country are starting to desire the safe, efficient, and livable streets that are encouraged by the National Complete Streets Coalition.

The National Complete Streets Coalition maintains a Policy Atlas which is updated bimonthly. Currently, more than 700 regional and local jurisdictions in 48 states, Puerto Rico, and the District of Columbia have adopted a Complete Streets policy or have committed in writing to do so [20]. 


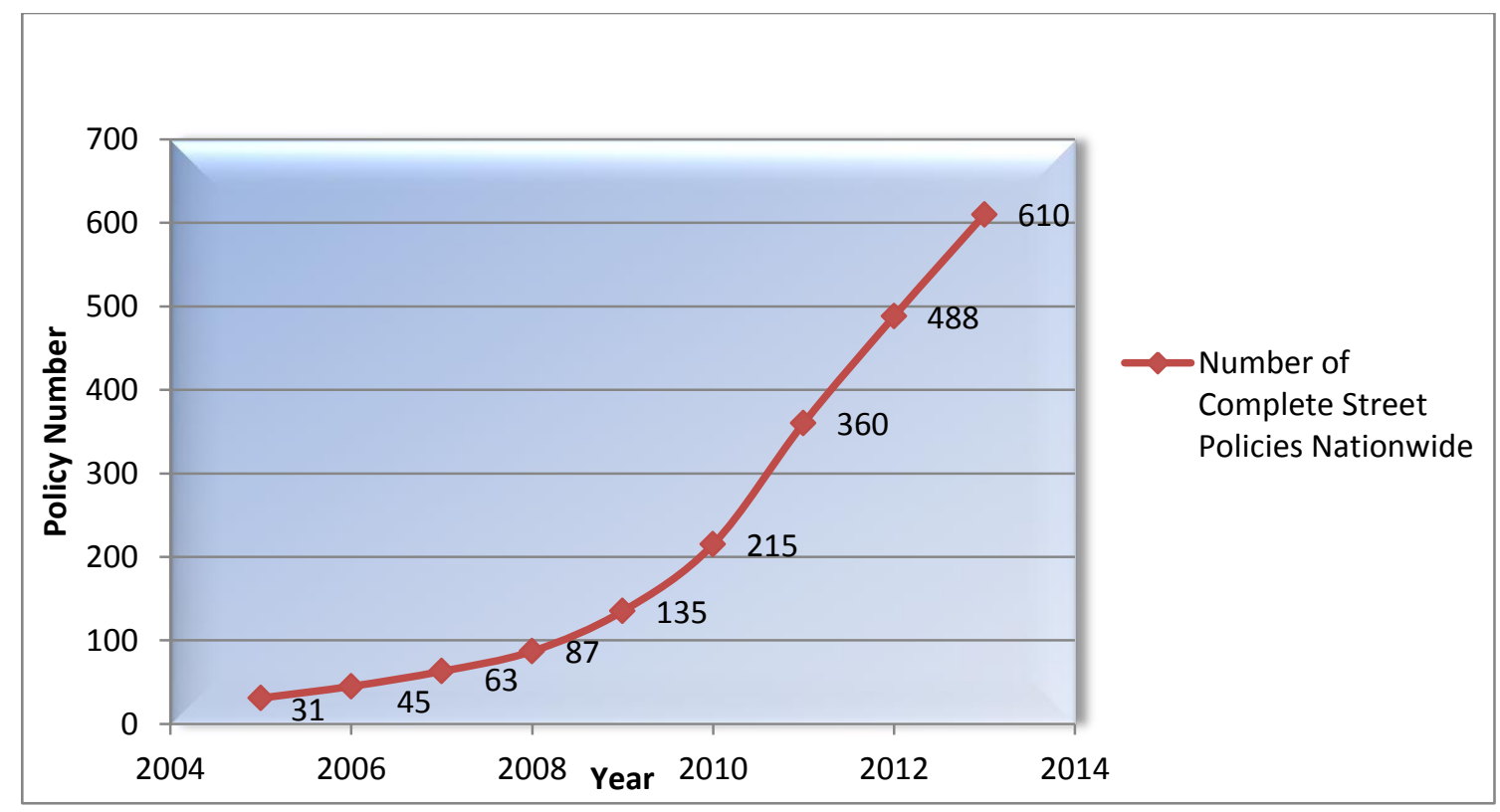

[18]

Figure 1-10: Number of Complete Streets Policies Nationwide

\section{Some Examples}

As more communities desire safer and more convenient roadways, these types of transportation-related policies arise. This section highlights just a few examples of Complete Streets policy and projects, including some in Florida. The jurisdictions discussed in this section, along with others not included herein, will be further considered as potential case study sites for the next tasks of this research project.

\section{Tampa, Florida}

Just recently, in 2013, the City of Tampa, Florida, enhanced a local roadway based on Complete Street principals by constructing a roundabout near the intersection of 22nd Street and 22nd Avenue, just north of the Ybor City area. This design allows traffic to move more smoothly and safely and also enhances the aesthetics of the area-a tall pillar is centered within the roundabout, neatly surrounded by an array of flora and brick-patterned crosswalks, as shown in Figure 1-11. A typical roundabout is illustrated in Figure 1-12. Current Tampa Mayor Bob Buckhorn expresses, "Improvements like this are more than infrastructure and landscaping; they're about creating complete streets that work for everyone, generating new economic opportunities and transforming a community" [21]. 


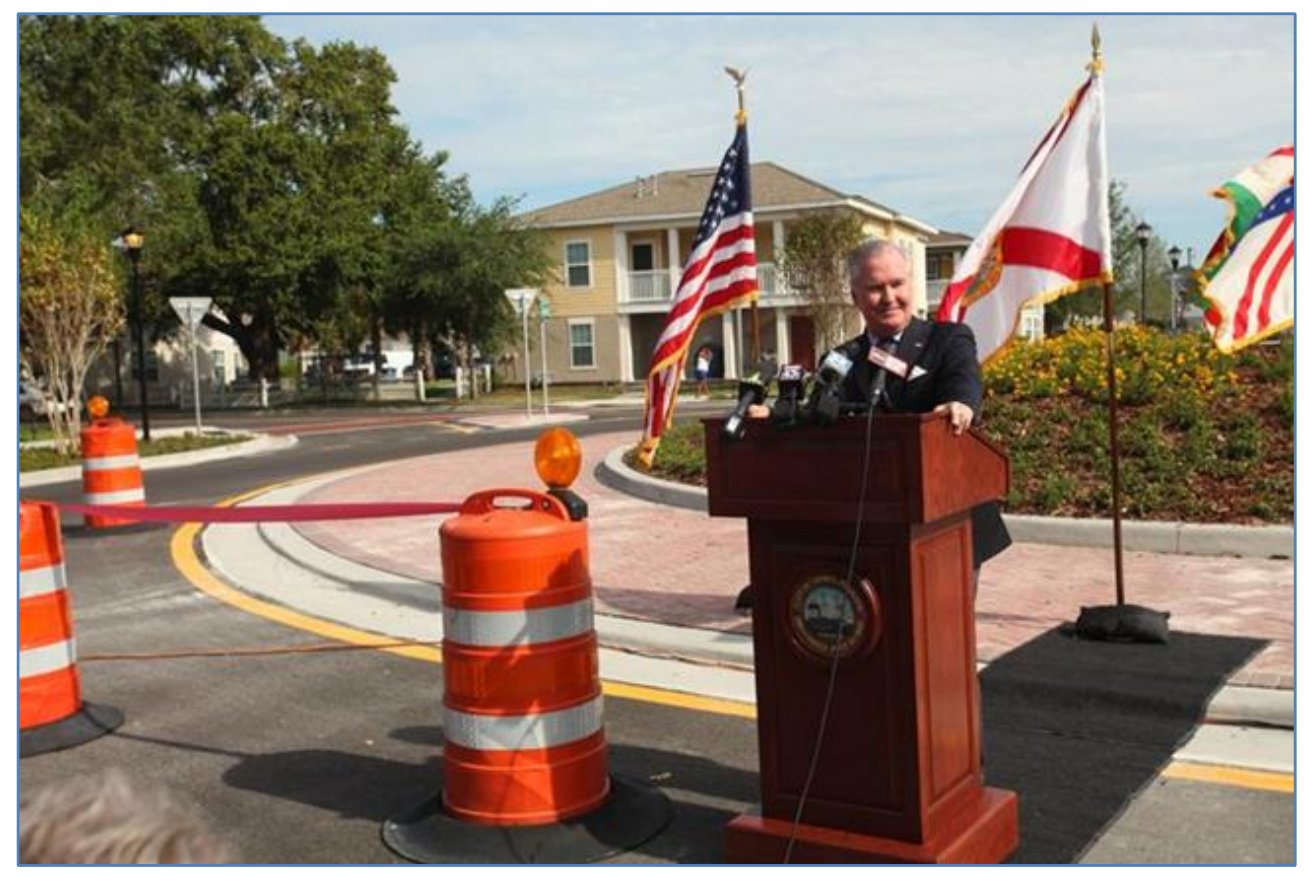

Figure 1-11: Tampa, Florida, Mayor Bob Buckhorn at the Newly Constructed Roundabout at the Intersection of $22^{\text {nd }}$ Street and $22^{\text {nd }}$ Avenue [22]

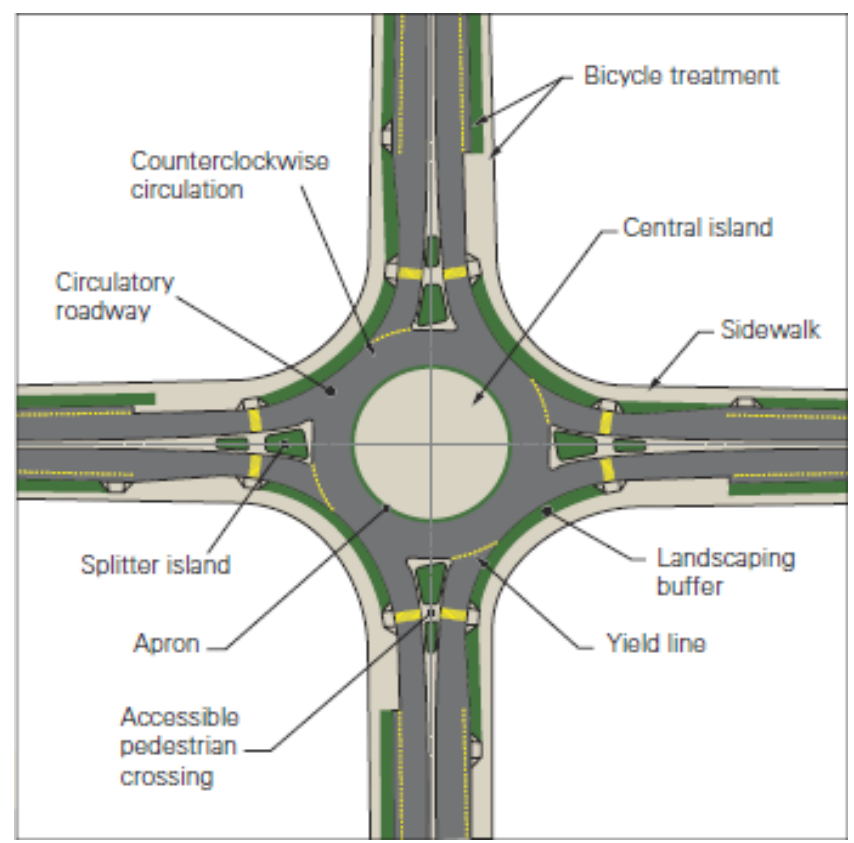

Figure 1-12: A Typical Roundabout Structure [23] 


\section{Fort Lauderdale, Florida}

Fort Lauderdale, Florida, has also adopted Complete Streets methods (as has Broward County, which contains Fort Lauderdale and other cities in the county). In early 2014, it was ranked third in the United States by the National Complete Streets Coalition for its creation of pedestrian-friendly initiatives enacted in 2013. Specifically, the City was one of the first on the eastern coast of the U.S. to allow for "parklets" to be created outside of small businesses, as shown in the photo on the right in Figure 1-13. In addition, Fort Lauderdale is also one of the first east-coast cities to provide specific guidance for parklets. These structures are essentially parking spaces in front of business establishments, such as shops, cafes or restaurants, which can be reconstructed into a patio-like sanctuary for local pedestrians [24]. Reconstructed parking spaces would contain, but not be limited to, benches, tables, chairs and plantsanything that might provide a sense of community and ease traffic for the multiple modes of transportation. Business owners can apply for parking spaces through the city in hopes of providing passersby a place to rest and increasing sales with the new, pedestrian-friendly Complete Streets elements.

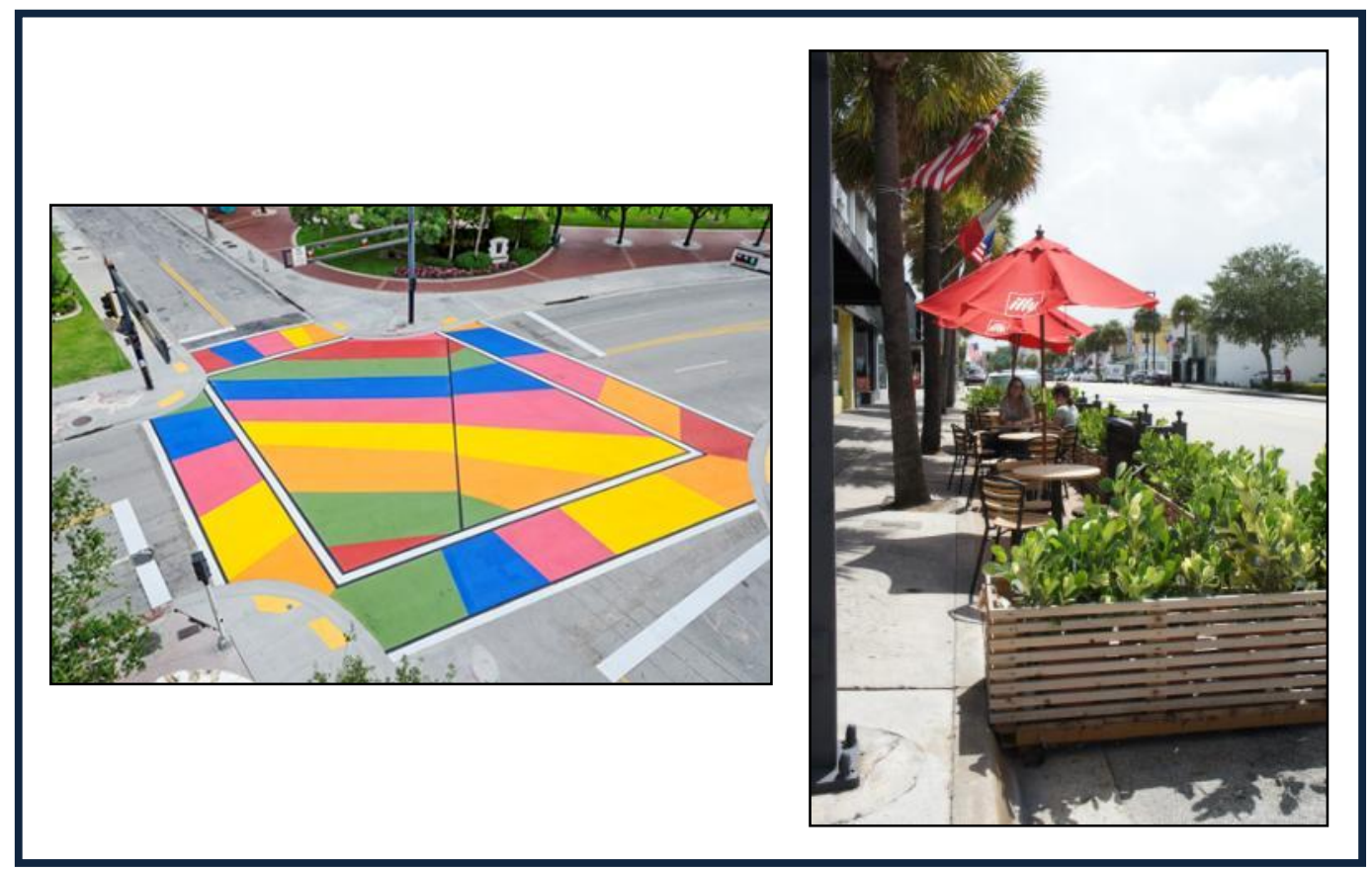

Photos: City of Fort Lauderdale

Figure 1-13: Painted Intersection Project and Parklet in Fort Lauderdale

Fort Lauderdale is involved in numerous Complete Streets efforts and other activities to increase mobility and provide alternatives to driving a car. In addition to parklets, some notable highlights of these initiatives include the implementation of sharrows (shared-use 
arrows for bicyclists and motorists), a bike valet program for major events so users can have a secure location to park their bikes during these events, Open Streets events to provide the public with access to public streets for recreational access without vehicle traffic, and the notable Connecting the Blocks Painted Intersection Project. As shown in the photo on the left in Figure 1-13, the painted intersection projects are works of public art meant to transform the space into a vibrant, pedestrian-friendly community place [25] [26].

\section{West Palm Beach, Florida}

While the term "Complete Streets" was not coined until 2003, West Palm Beach, Florida was already serving as a model for other communities with its CityPlace "lifestyle center" that showed that such a development could support economic revitalization while also focusing on pedestrian safety [27]. CityPlace opened in 2000.

The City has also undertaken several traffic calming projects that have included elements such as narrowed streets, mini traffic circles, speed humps, bulbed curbs, an interactive fountain, restoration of buildings, and the provision of space for events. The projects have been deemed very successful, with measurable increases in economic activity and increases in property values [15]. Figure 1-14 illustrates examples of Complete Streets elements in West Palm Beach, while Figure 1-15 shows a before and after look at a street in the city.

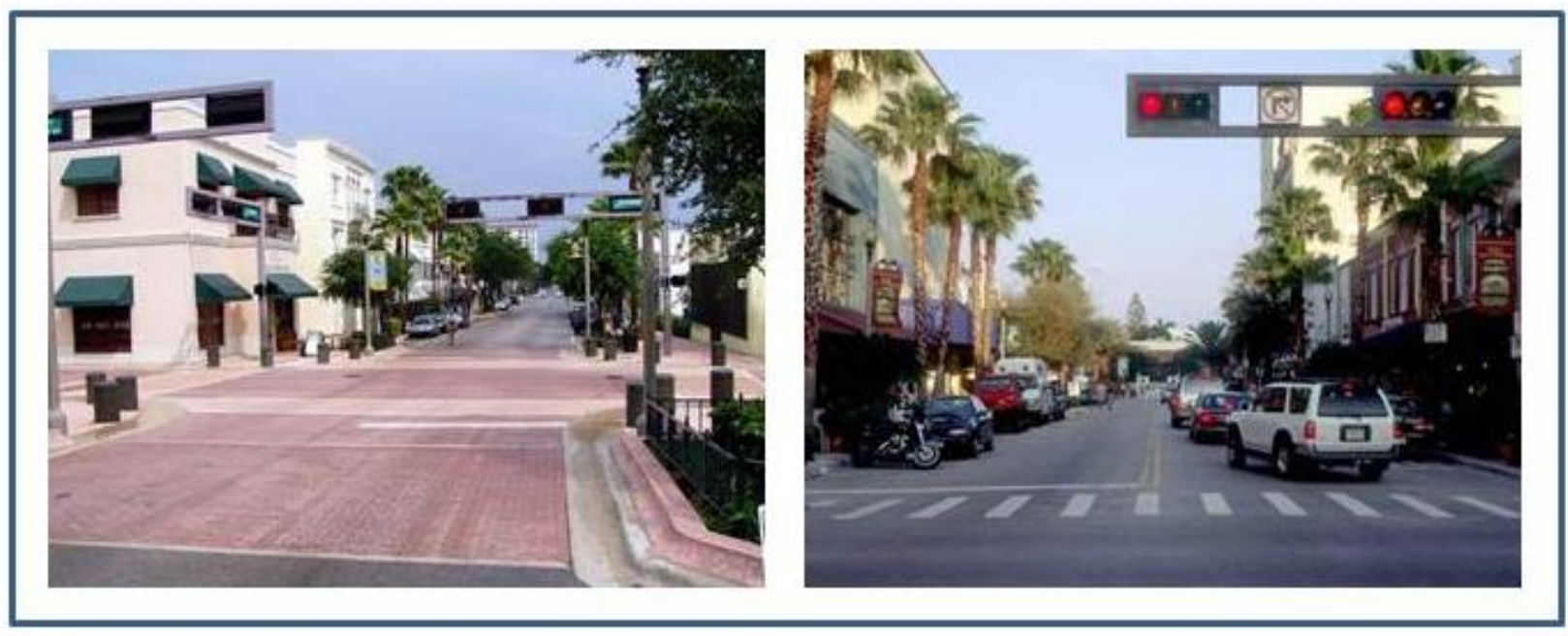

Source: http://contextsensitivesolutions.org/content/case studies/west-palm-beach-florida/\#

Figure 1-14: Complete Streets Elements in West Palm Beach, FL 


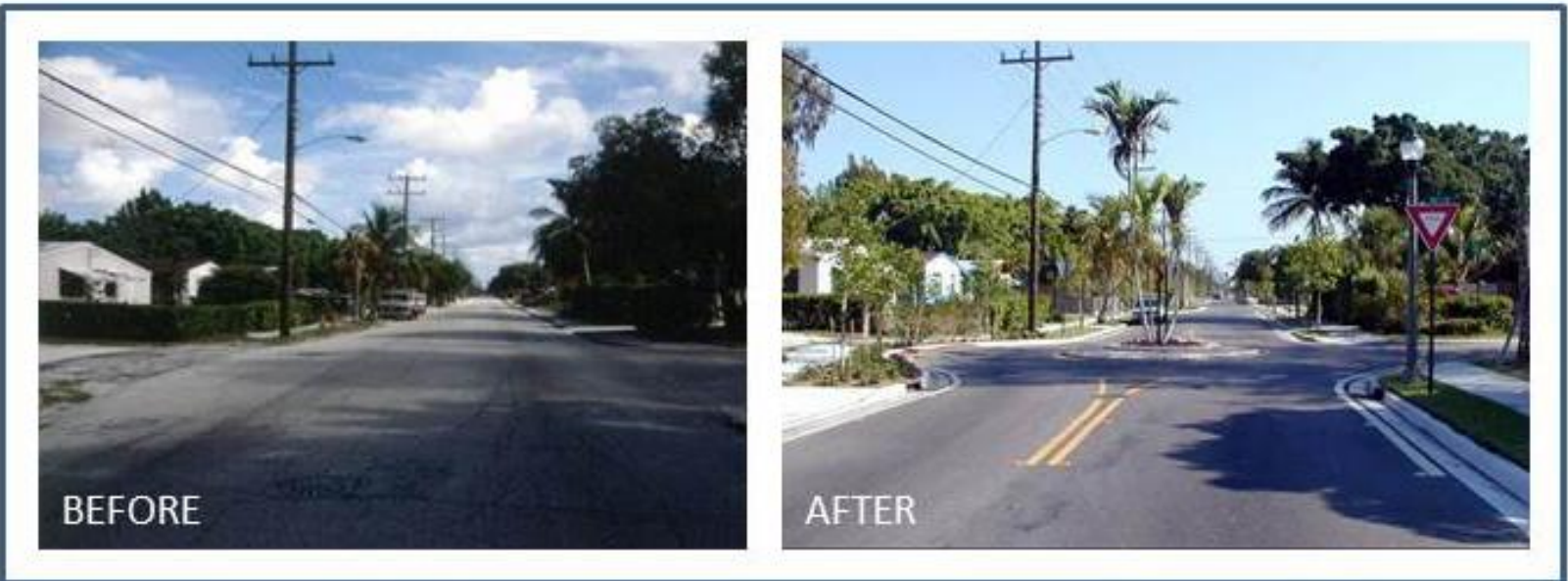

Source: http://contextsensitivesolutions.org/content/case studies/west-palm-beach-florida/\#

Figure 1-15: Before and After Complete Streets, West Palm Beach, FL

\section{Charlotte, North Carolina}

Charlotte was an early adopter of the Complete Streets philosophy, implementing projects starting in 2005 and instituting its Urban Street Design Guidelines (USDG) in 2007. Charlotte's USDG has served as a model for other cities in North Carolina and around the country, earning it the U.S. Environmental Protection Agency's prestigious National Award for Smart Growth Achievement in Policies and Regulations in 2009 [28]. Figure 1-16 displays examples of Complete Streets in Charlotte. 


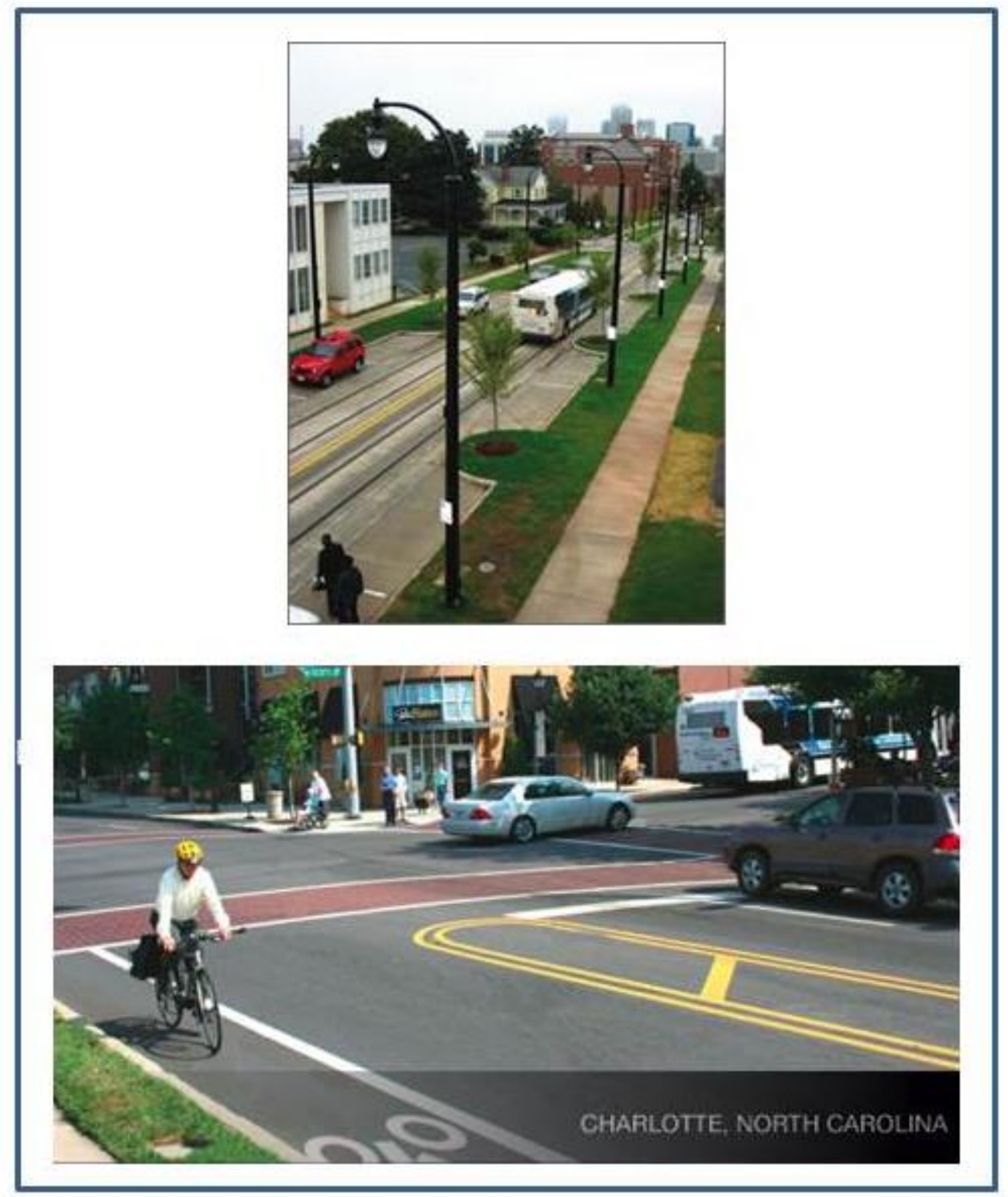

Source: National Complete Streets Coalition

Figure 1-16: Complete Streets in Charlotte, NC

Buffalo, New York

The City of Buffalo, New York, is embracing Complete Streets initiatives, having instituted a Complete Streets ordinance in 2008. There are several projects throughout the city in various stages of development, and the current mayor has committed to installing a minimum of ten miles of bicycle lanes each year (11.3 miles were added in 2013) [29]. 
The Niagara Street Gateway Project is one of the many Complete Streets projects in the city and was featured along with the Niagara Frontier Transportation Authority's (NFTA) Niagara Corridor Project in a presentation at the American Public Transportation Association (APTA) Bus and Paratransit Conference in May 2014. These two particular projects illustrate the need for cooperation and coordination among different entities to ensure successful implementation.

The Niagara Street Gateway Project is essentially a rehabilitation of Niagara Street, which will occur in three phases. The goals of the project are to improve operating conditions and overall safety for vehicles, improve the mobility and overall safety for pedestrians and cyclists, to have pavement in good condition, and to aesthetically enhance the corridor to brand it as the major gateway into the Buffalo central business district (CBD) [29]. See Figure 1-17 on the following page for before and after renderings. Project elements will include the following [29]:

- Pavement widening

- Replacement of street lighting

- Replacement of traffic signals

- Improvements to pedestrian and bicycle facilities

- Landscape features and other amenities

NFTA's Niagara Corridor Project is intended to coordinate with and complement the Niagara Street Gateway Project. The goals of NFTA's project are to create a comprehensive urban transit corridor, improve NFTA bus service, be a model for other corridors, and to redevelop a neighborhood and enhance livability. With the integration of the two projects, the City of Buffalo hopes to reap these benefits [29]:

- Enhanced mobility

- Correlation of transportation investments with employment growth

- Enhanced convenience, safety, and availability of alternative modes

- Reduced energy consumption

- "Seamless interface" among vehicles, pedestrians, and transit

Buffalo City Engineer Peter J. Merlo voiced the city's enthusiasm with the traffic calming elements of the Complete Streets projects, stating, "Everyone's excited about the traffic calming, because that makes it better for pedestrians, and you're not creating gridlock, either" [28]. The project's intent as a gateway to the Buffalo CBD was further expressed by Buffalo Public Works Commissioner Steven Stepniak: "You're just increasing your accessibility to downtown, and that's one of the points of doing all these projects" [30]. 


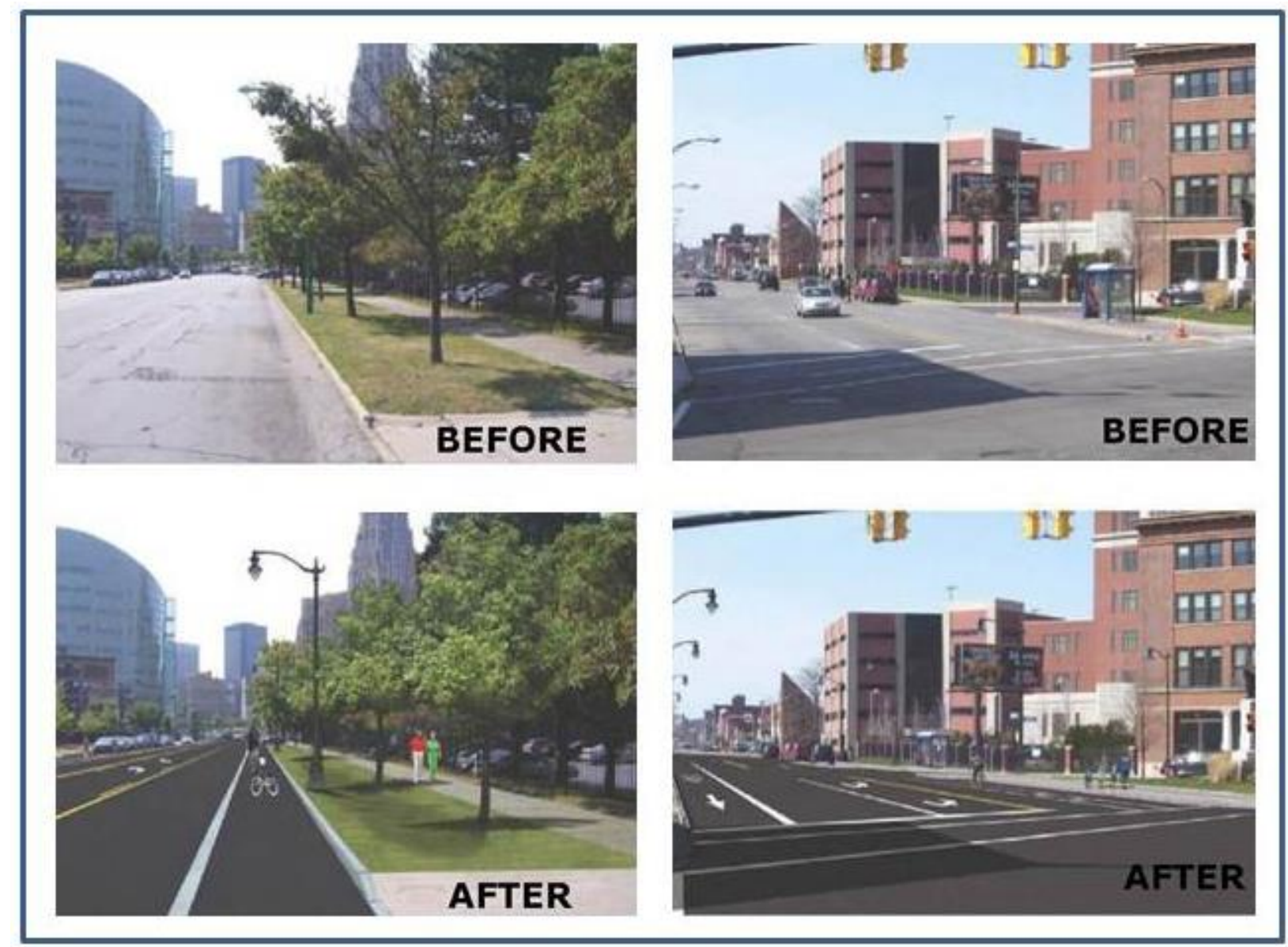

Source: Complete Streets/Complete Trip. Morrell, James K. May 2014. Presentation at 2014 APTA Bus and Paratransit Conference.

Figure 1-17: Renderings of the Niagara Street Gateway Project in Buffalo, NY

\section{Complete Streets Impacts}

A body of research on Complete Streets has emerged and is continuing to grow. Research institutions and universities alike across the nation have begun to take a comprehensive, analytical approach towards deducing Complete Streets' significance. Taking measures towards pedestrian safety when developing road networks is crucial for the progress of multimodal transit. In a study conducted by the University of California, Berkeley, researchers studied pedestrian safety along a California corridor in hopes to construct a comprehensive, quantifiable framework to assess pedestrian well-being, multimodal flexibility and environmental quality. Significant conclusions in the study reveal that installing crosswalks have been positively linked with an increased use by pedestrians and a reduced driver/automobile speed when approaching the enhanced intersection. The study also 
concluded that pedestrian signals with a countdown have been confidently linked with pedestrian obedience with signalization, thus, resulting in safer crossing conduct [31].

There have been many benefits witnessed through the implementation of the pedestrianfriendly Complete Streets policies. Smart Growth America has compiled many findings that reveal the beneficial impacts of Complete Streets implementation. It is found that simple forms of roadway development and refurbishment have the potential to enhance economic activity and increase local business earnings. Such a situation was experienced when a bicycle lane was added along San Francisco's Valencia Street. Nearby businesses saw sales increase as much as 60 percent after lane completion - which local merchants credited to the increased pedestrian and bicycle presence as a result of the bike lane (14). Other beneficial circumstances also arise when bicycle infrastructure is added or redefined throughout certain regions. It is estimated that the State of Colorado accumulates roughly $\$ 1$ billion in benefits from its bicycle industry through manufacturing, retail, and tourism; the City of Portland, Oregon, also receives financial benefits to its economy from its own bike industry, estimated to be $\$ 90$ million [32].

The implementation of various Complete Streets initiatives has been connected with increased participation in physical activities. There is an obvious trend that shows countries with a higher population participation rate in walking, biking, and mass transit have lower obesity rates. One particular study found that recommended activity levels were met by 43 percent of people who had safe (based on Complete Streets principles) places to walk within 10 minutes of their home. In contrast, just 27 percent of individuals without safe places to walk met the recommended levels of activity [33]. Thus, with access to safer streets, there is a greater potential for individuals to develop a healthier, active lifestyle.

Peiravian and Derrible conducted research to quantify vehicle emission impacts of Complete Streets, with mixed results. They found that if a project design allows for less space for vehicles, depending on the characteristics of the corridor, congestion can actually increase along with emissions. Peiravian and Derrible stressed that wide-scale projects would ensure decreased volumes and emissions, and that an emissions analysis should be conducted for any Complete Streets project [34].

As mentioned previously, it has been found that most homebuyers are interested in sidewalks and walkable communities. Walk Score is a company whose mission is to see walkability scores incorporated into the typical listed features of homes for sale or rent. Walk Scores are reported as a number on a scale from 0 to 100, ranging from "car-dependent" to a "walker's paradise." Walk Score has also developed transit and bike scores. The Transit Score ranges from "minimal transit" to a "rider's paradise," and the Bike Score ranges from "somewhat bikeable" to a biker's paradise" [35]. Research has found that homes in areas with high Walk Scores have sold in the range of $\$ 4,000$ to $\$ 34,000$ more than typical homes [36]. A document from the Active Transportation Alliance summarizes other recent research findings [36]: 
- Households that are vehicle-dependent spend 20 percent more income on transportation than households in Complete Streets communities.

- Homes in the Chicago area within one-half mile of a Metra station sell for $\$ 36,000$ more, on average, than homes not within walking distance of a Metra station.

- Washington, D.C. added patterned sidewalks, streamlined public parking, and new traffic signals, which helped one particular business district to attract 44 new businesses and 200 new jobs. Sales, workers, and pedestrians have all significantly increased in the area since the project was completed.

- In Pittsburgh, nearly one third of employers indicated that transportation was the primary barrier to hiring and keeping qualified workers, suggesting that "incomplete" streets are an economic hindrance.

Some of these findings are based on qualitative or anecdotal data. It can be very difficult to separate and identify the specific marginal contributions of Complete Streets elements to these increases in economic activity. It is one of the objectives of this research project to use case studies to further examine changes in economic activity from Complete Streets and nonComplete Streets projects.

\section{Measuring the Performance of Complete Streets}

To evaluate the performance of Complete Streets policies and projects, it is necessary to go beyond the conventional methods that only consider the network efficiency for automobiles. Increasing guidance has been provided by the industry, including the multimodal level of service standards that have been developed by the Transportation Research Board and incorporated into the Highway Capacity Manual [7]. In Pasadena, California, for example, the newer multimodal level of service measures were used in comparison to the existing (and more traditional) measures and it was found that the new measures compared favorably [37].

Communities, however, can select to measure the impacts and/or success of Complete Streets projects in many different ways. Guidance from the National Complete Streets Coalition includes several examples of performance measures, including the list below from New Hope, Minnesota [38]:

- User data (bicycle, pedestrian, transit, and traffic)

- Crash/safety data

- Use of new projects by mode

- Compliments and complaints received

- Linear feet of pedestrian accommodations built

- Number of ADA accommodations built

- Miles of bike lanes or trails built/striped

- Number of transit accessibility accommodations built 
- Number of street trees planted

- Number of exemptions from the policy approved

Other recently published research has focused on how best to evaluate Complete Streets. Sanders, et al. have developed new measures to gauge progress in meeting Complete Streets objectives, with the focus on the safety of pedestrians and cyclists [31]. In addition, Kingsbury, Lowry, and Dixon developed a novel way to measure how "complete" a Complete Streets project is using a four-dimensional approach involving auto users, transit users, pedestrians, and cyclists [39].

The evaluation of the costs and benefits of Complete Streets is another area of ongoing research. Shapard and Cole sought to compare the costs of Complete Streets projects and "incomplete" streets projects, using Charlotte, North Carolina, as a case study (which is a premise related to the objective of this research project). Only slight increases in costs were observed due to the various Complete Streets elements. However, it was also found that those elements comprised a very small percentage of total project costs. The authors concluded that overall market fluctuations in construction costs have a more significant impact on project costs [40].

Litman has provided a comprehensive discussion of Complete Streets impacts, both positive and negative (i.e., benefits and costs). He notes that, as with any project or activity, some people are made better off, and some are made worse off. For example, auto drivers can benefit from some Complete Streets elements, but can also be made worse off. Table 1-1, produced by Litman, provides an excellent summary of Complete Streets benefits and costs, [41]. As can be seen in the table, one particular cost is lower speeds for traffic. The trade-off between many Complete Streets elements and traffic speed can be a major consideration in the implementation of Complete Streets projects [41] [42]. 
Table 1-1: Potential Benefits and Costs of Complete Streets

\begin{tabular}{|c|c|c|c|c|}
\hline & $\begin{array}{l}\text { Improved Transport } \\
\text { Options }\end{array}$ & $\begin{array}{l}\text { Increased Use of } \\
\text { Alternative Modes }\end{array}$ & $\begin{array}{l}\text { Reduced Automobile } \\
\text { Travel }\end{array}$ & $\begin{array}{l}\text { Smart Growth } \\
\text { Development }\end{array}$ \\
\hline $\begin{array}{l}\text { Potential } \\
\text { Benefits }\end{array}$ & $\begin{array}{l}\text { - Improved user } \\
\text { convenience and } \\
\text { comfort } \\
\text { - Improved } \\
\text { accessibility, } \\
\text { particularly for } \\
\text { non-drivers, which } \\
\text { supports equity } \\
\text { objectives } \\
\text { - Option value } \\
\text { - Increased local } \\
\text { property values }\end{array}$ & $\begin{array}{l}\text { - User enjoyment } \\
\text { - Improved public } \\
\text { fitness and health } \\
\text { - Increased } \\
\text { community } \\
\text { cohesion (positive } \\
\text { interactions among } \\
\text { neighbors due to } \\
\text { more walking on } \\
\text { local streets) which } \\
\text { tends to increase } \\
\text { security }\end{array}$ & $\begin{array}{l}\text { - Reduced } \\
\text { congestion } \\
\text { - Road and parking } \\
\text { savings } \\
\text { - Consumer savings } \\
\text { - Reduced traffic } \\
\text { crashes } \\
\text { - Reduced } \\
\text { chauffeuring } \\
\text { burdens } \\
\text { - Energy } \\
\text { conservation } \\
\text { - Reduced air and } \\
\text { noise pollution } \\
\end{array}$ & $\begin{array}{l}\text { - Improved land use } \\
\text { - Trcessibility } \\
\text { - savinsport cost } \\
\text { - Infrastructure } \\
\text { savings } \\
\text { - Open space } \\
\text { preservation } \\
\text { - Improved } \\
\text { aesthetics } \\
\text { - Urban } \\
\text { redevelopment } \\
\text { - Support for local } \\
\text { businesses }\end{array}$ \\
\hline $\begin{array}{l}\text { Potential } \\
\text { Costs }\end{array}$ & $\begin{array}{l}\text { - Planning and } \\
\text { implementation } \\
\text { - Lower traffic } \\
\text { speeds }\end{array}$ & $\begin{array}{l}\text { Additional user } \\
\text { costs (shoes, bikes, } \\
\text { fares, etc.) }\end{array}$ & $\begin{array}{l}\text { - Reduced travel } \\
\text { speeds for mode } \\
\text { shifts } \\
\text { - Reduced parking } \\
\text { convenience }\end{array}$ & $\begin{array}{l}\text { - Increases in some } \\
\text { development costs } \\
\text { - Transition costs }\end{array}$ \\
\hline
\end{tabular}

Source: Litman, Todd, Evaluating Complete Streets, The Value of Designing Roads for Diverse Modes, Users and Activities, Victoria Transport Policy Institute, May 2014, p.10. http://www.vtpi.org/compstr.pdf

Litman also summarizes some accepted measures for quantifying benefits that may be overlooked or seem unquantifiable [41].

This chapter summarized recent literature and background information relevant to Complete Streets. The next chapter provides the methodology used for this project and also some information on potential case study sites. 


\section{CHAPTER 2: METHODOLOGY AND IDENTIFICATION OF CASE STUDY SITES}

This chapter provides a summary of the activities undertaken in Task 2 this project, which involved two parts. First, a methodology was developed for evaluating any economic benefits of Complete Streets projects. Second, potential Complete Streets case study sites/cities were identified.

\section{Evaluating Complete Streets Projects}

As summarized in the first chapter, a body of research on the impacts of Complete Streets is continuing to grow. Initially, much of the research focused primarily on safety concerns for pedestrians and bicyclists. Researchers began documenting how the addition of particular components or amenities such as crosswalks, pedestrian signals, and better sidewalks and bicycle lanes improved safety for pedestrians and bicyclists, and made them more likely to use the facilities. In addition to safety, research was conducted to estimate impacts of Complete Streets elements on the level of physical activity, public health, and air quality [31] [33] [34] [37] [38] [39]. However, others began to envision the possibility of additional benefits, economic in nature. If pedestrians, bicyclists, and transit users felt an increased sense of safety along a corridor, more of them might use the corridor more often and also provide a boost to the surrounding businesses. Perhaps a walkable environment could be an amenity that increases surrounding property values, both commercial and residential. Research emerged showing that Complete Streets projects could positively affect retail sales and that a walkable environment can have many benefits, including increased property values [14] [32] [35] [41].

A recent effort by Smart Growth America used West Des Moines, lowa as a case study for its new methodology for determining net fiscal impacts to the public sector of various development patterns. The goal of the effort was to find a better way to evaluate the fiscal impacts of projects, and to account for the increased cost efficiency related to higher-density development patterns as well as the high opportunity cost of lower-density development patterns. The study found that, by far, the "walkable urban scenario" scored the best, with the highest net fiscal impact (revenues less expenditures) [43]. The walkable scenario was the highest-density scenario and did not include any single-family homes. Interestingly, however, the lower costs estimates of the walkable scenario were partially due to the assumption that multi-family homes attract more households with no children; thus there would be fewer costs to the school district.

Another recent study was completed by the New York City Department of Transportation and evaluated economic benefits of six Complete Streets case studies. Like other recent research efforts, the authors were interested in finding new and better ways to measure the effects of these projects. They noted direct benefits such as improved safety and traffic impacts, as well as indirect benefits including public health, environmental quality, and economic vitality [44]. Regarding economic vitality, the study summarized several potential measures: number of businesses, property values, employment, retail sales, and visitor spending. The authors considered several of these measures, and ultimately selected retail sales tax filings as the 
measure they would use to evaluate the case studies. They studied the corridors before and after the implementation of Complete Streets elements, and also compared the corridors to other similar non-Complete Streets corridors nearby. If suitable control areas were not found, they compared results to the borough as a whole. Retail sales tax filings can be notoriously difficult to acquire, particularly the quarterly data used in this study. The authors worked closely with the New York City Department of Finance to get the required information. After selecting a range of case studies with various characteristics, positive results were found in all cases, albeit with varying magnitudes [44].

In 2014, the Center for Inclusive Design and Environmental Access and GOBike Buffalo developed a document to assist in the evaluation of Complete Streets initiatives and to assist communities in creating an evaluation plan for their individual Complete Streets policies or programs. The work focuses on the following outcomes [45]:

- Bicycle/pedestrian impacts

- Citizen feedback

- Economic impact

- Environmental impact

- Health impact

- Multimodal level of service

- Safety

For the outcome of economic impact listed above, several measures are suggested, including commercial and residential property values, foreclosure data, and retail sales (sales volume or tax receipts).

A year later, Smart Growth America and AARP published a practitioner's guide to evaluating Complete Streets projects. Similar to the work by the Center for Inclusive Design and Environmental Access and GOBike Buffalo, and following on the idea of providing a comprehensive set of outcomes and measures to evaluate Complete Streets projects, this work provided seven performance goals, each with a set of measures that can be used to evaluate how well a project meets a particular goal. The seven goals are listed as [46]:

1. Access

2. Economy

3. Environment

4. Place

5. Safety

6. Equity

7. Public health 
For this research, the goal related to Economy is most relevant. The practitioner's guide provides several metrics and measures for evaluating projects based on this goal [46]:

- Access to opportunities (primarily job accessibility)

- Employment (job creation, local workforce, stability of employment in the area)

- Investments from other sectors (private and foundation/grant/nontransportation investments in surrounding properties)

- Land value (tax yield per acre, value of commercial and residential properties)

- Parking utilization (spaces for cars and bicycles used per day)

- Retail vibrancy (sales volumes at adjacent businesses, customers by mode of travel, number of tourists, surveys, vacancy rates)

All of the information described above and in the first chapter has informed the development of a methodology for this research, discussed in the next section.

\section{Methodology}

At the beginning of this project, a specific methodology had not been identified. Instead, the development of a methodology was embedded within the research as a separate task. The idea of using case studies and control areas, along with a particular set of measures to evaluate the projects was initially proposed, with the understanding that the methodology would be developed and refined based on research into potential case study sites and information gathered from the literature review (summarized in Chapter 1). Since the start of this project, additional research reports have been published which have provided new and valuable information for the conduct of this research.

Specifically, reports by the New York City Department of Transportation and AARP/Smart Growth America have added additional understanding and lessons learned about the evaluation of Complete Streets projects [44] [46]. The former provided insight into the selection of case study sites, while the latter provided a framework for additional measures to consider for the analysis.

For this research, the methodology included the selection of up to five Complete Streets case study sites, both within and outside of Florida. Appropriate control areas (i.e., non-Complete Street sites) were to be selected using input from local planning staff associated with the Complete Streets sites or others with local knowledge. Based on a recent similar study in New York, it is possible that suitable control areas may not be available; in those cases, the results from the Complete Streets projects were compared (proportionately) with similar results from the city and/or county in which the project was located [44]. The proposed case study sites for this project are described in a later section of this chapter.

For the projects within the case study sites, the corridors have been identified and adjacent parcels (commercial and/or residential) are selected for analysis. Some data are also provided 
at the block group level. While the block groups may extend beyond the corridors, they are still the finest level of geography for the analysis of certain socio-economic data that will be helpful to present. Data are collected from before the implementation of the Complete Streets projects, and are then compared to the same information after the project implementation. Two years is typically enough time for any marginal benefits from these projects to be measurable [44].

\section{Quantitative Measures}

Based on the information compiled for this research, a set of measures to estimate economic benefits has been identified. Each type of measurement is described below:

\section{Employment}

For the businesses adjacent to the Complete Streets corridor, employment information can be used to assess economic vitality. The number of jobs can be available directly from the businesses as well as using available Longitudinal Employer-Household Dynamics (LEHD) data, which provides information on the location on jobs as well as wage ranges.

\section{Land Values}

County property appraiser databases are easy to access and provide data on market values, sale prices, and property taxes paid for the current year and also going back several years. For the case study sites selected for this research, the relevant property information was available back to at least 2005. These data could be used on their own and also in addition to other constructed measures such as tax yield per acre, tax receipts as a percentage of project cost, and a ratio of speeds and property values.

\section{Qualitative Measures}

While the focus of this research is on the quantitative measures, the analysis benefits from additional qualitative analysis. This information came from any local reports or articles about the projects, and discussions with individuals representing the local government, local chambers of commerce, and adjacent businesses. Detailed information on sales tax collections or sales volumes was not available for this research; however, some of this information was captured in the qualitative analysis. 


\section{Identification of Case Study Sites}

With Complete Streets policies becoming more and more prevalent across the U.S., communities are now turning to a new way of planning and implementing roadway projects. Complete Streets elements will become ubiquitous as new projects as well as existing projects undergoing rehabilitation are completed. This research examines a variety of Complete Streets projects; two are within Florida and one is outside the state. The case study sites are further described along with the data collected and results of the analysis in Chapter Three.

\section{Gainesville Main Street Corridor}

After two years of construction, the reconfigured Main Street corridor in Gainesville, Florida was complete in 2011. The relevant segment is along Main Street from Depot Avenue north to North $8^{\text {th }}$ Avenue. The corridor contains a mix of land uses including retail, entertainment, restaurant, office, government, and manufacturing. The major reconstruction, considered part of a "road diet," involved going from a four-lane configuration with a center turn lane to a twolane configuration with a center turn lane. Additional elements include reconfigured on-street parking, bicycle lanes, wider sidewalks, bus bays, enhanced lighting, streetscaping, additional mid-block crossing locations, and a roundabout at Depot Avenue [47]. Figure 2-1 shows the corridor before the reconstruction in 2008 and afterward in 2012.

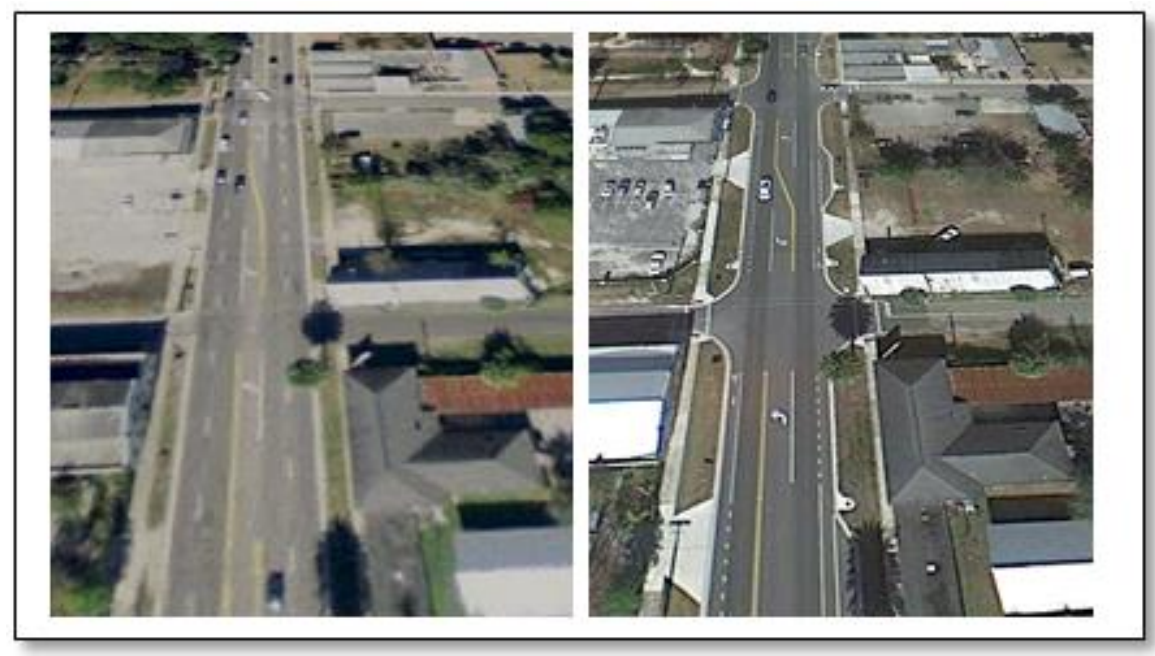

Source: City of Gainesville Public Works Department

Figure 2-1: Gainesville's Main Street Corridor before (2008) and after (2012) 


\section{Fort Myers Beach - Estero Boulevard}

This one-mile segment, from the beginning of North Estero Boulevard at Time Square to Bowditch Park, represents the first of six additional one-mile phases of Complete Streets improvements along the corridor. Planning for the entire project initially began as a way to remedy a major storm water drainage problem. As the roadway was to be completely rehabilitated, it was decided that Complete Streets elements would be included as the other improvements were made [48].

Construction of this first segment began in 2009 and was completed in 2011. Complete Streets elements include five-foot sidewalks on both sides, four-foot bicycle lanes on both sides, bicycle parking, trolley pull-outs, crosswalks, pedestrian signals, wayfinding, and landscaping. Figure 22 shows two photographs of the completed project [49].

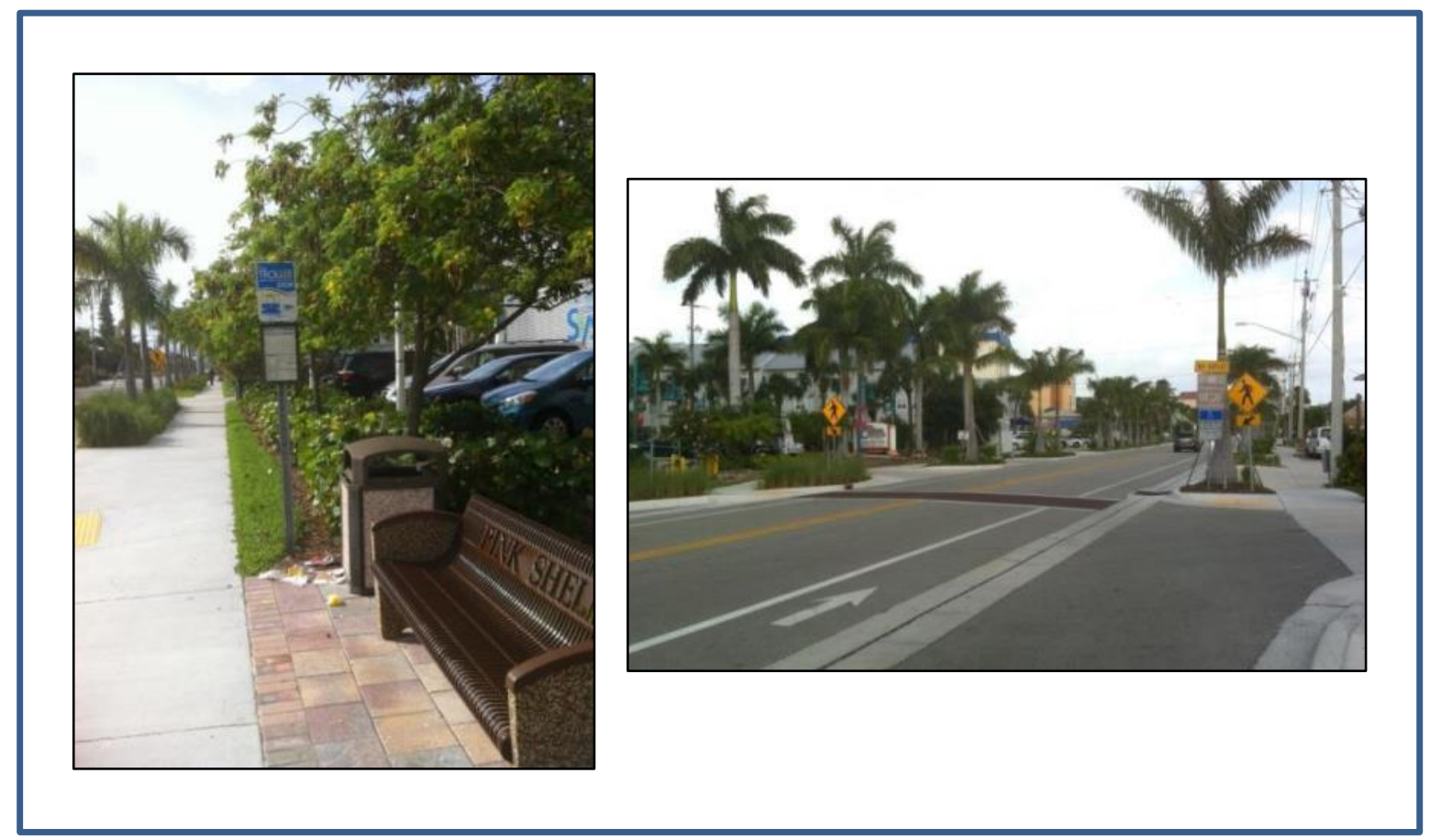

Source: BikeWalkLee

Figure 2-2: Fort Myers Beach Estero Boulevard Project 
For a case study outside of Florida, the Euclid Avenue corridor in Cleveland, Ohio represents an example of a Complete Streets project coupled with a major bus rapid transit (BRT) investment. The Cleveland HealthLine BRT service opened in October 2008 after four years of major reconstruction along seven miles of Euclid Avenue, from Tower City in the central business district east toward University Circle and the Cleveland Clinic medical facility. The project was the result of a decades long planning process to link the two largest regional employment centers. It also achieved the vision of creating a multimodal Complete Streets environment for transit users, bicyclists, pedestrians, and auto users [50].

Elements of the project include: median BRT stations for much of the alignment, four miles of designated bicycle lanes, bicycle racks at BRT stations and the ability to board the transit vehicle with a bike, brick patterned sidewalks and crosswalks, streetscaping, public art, lighting, and concrete bollards that corral pedestrians at signalized intersections thus discouraging jaywalking [50]. It should be noted that the analysis of this case study site will only include a portion of the seven-mile BRT corridor. Figure 2-3 below provides photos of this project.

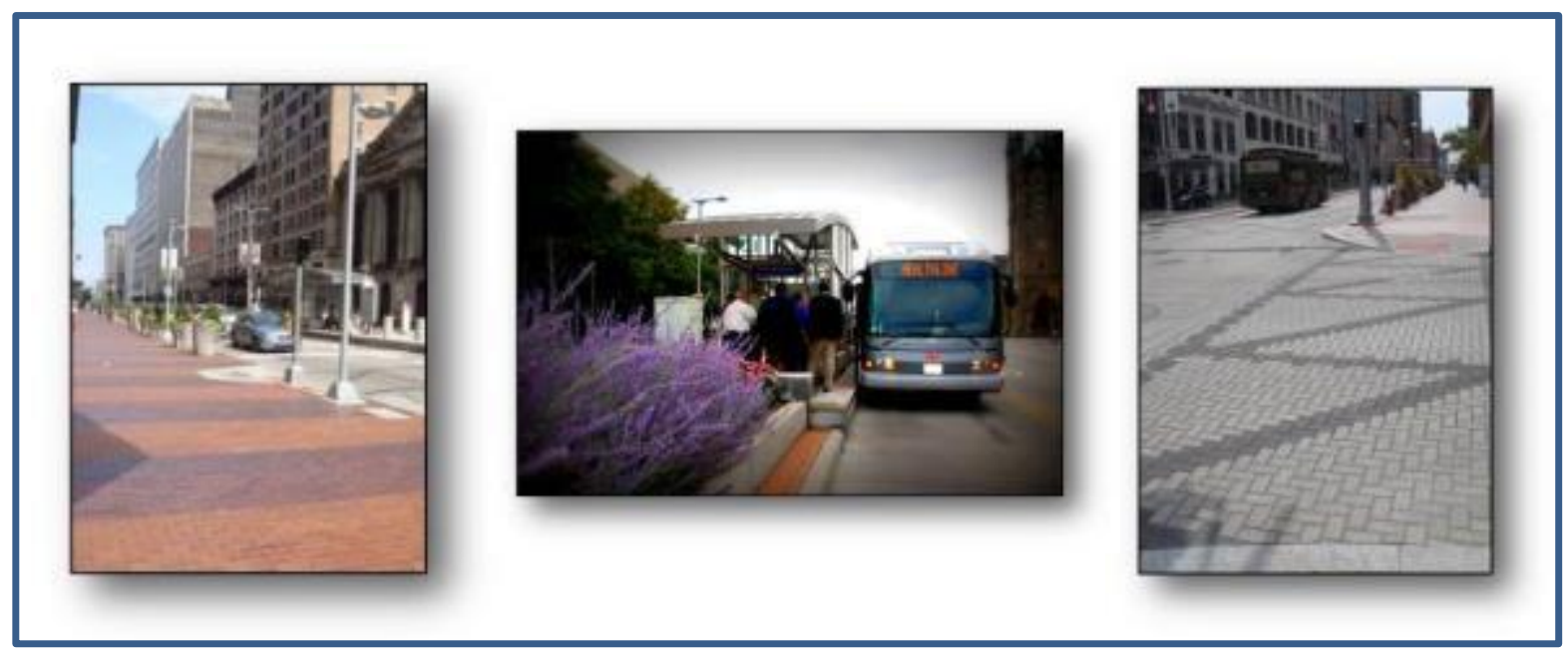

Photos by Victoria Perk

Figure 2-3: Cleveland Euclid Corridor 


\section{Cape Canaveral - Ridgewood Avenue}

In 2012, the Ridgewood Avenue Complete Streets project was finished in Cape Canaveral, in Brevard County, Florida. The project encompassed a 1.3-mile segment of the roadway, including a large residential area. Elements of the project included an eight-foot-wide bicycle/pedestrian path on the west side of the road, a new five-foot-wide sidewalk on the east side, crosswalks with pattern-stamped pavement, landscaping, solar-powered lighting, and additional stop signs to further slow vehicles on the 25-miles-per-hour road. In addition, the roadway itself was reduced to 22 feet from a width of 30 feet.

Residents of the area were initially concerned about the disruption from the construction of the project. However, today, they are very happy with the improvements and are more likely to walk and bicycle in the area, and feel much safer doing so [51].

\section{North Carolina - West Jefferson Streetscape Project}

An additional potential case study outside Florida is in a smaller town: West Jefferson, North Carolina. For many years, the town had been in decline. High auto speeds through the central business district made walking and other activity in the area not only undesirable but dangerous. A routine resurfacing project was converted into a Complete Streets project that added several pedestrian-friendly and traffic calming elements, ultimately transforming the corridor by 2012. To slow traffic, two intersections were modified to remove signals and revert to stop-control. Pedestrian improvements included paved crosswalks with curb extensions that not only shorten crossing distance but also provide a place for gathering, specialized lighting, and street furniture [52]. Figure 3-10 shows a photo of several of the Complete Streets elements of this project including crosswalks, street furniture, and specialized lighting.

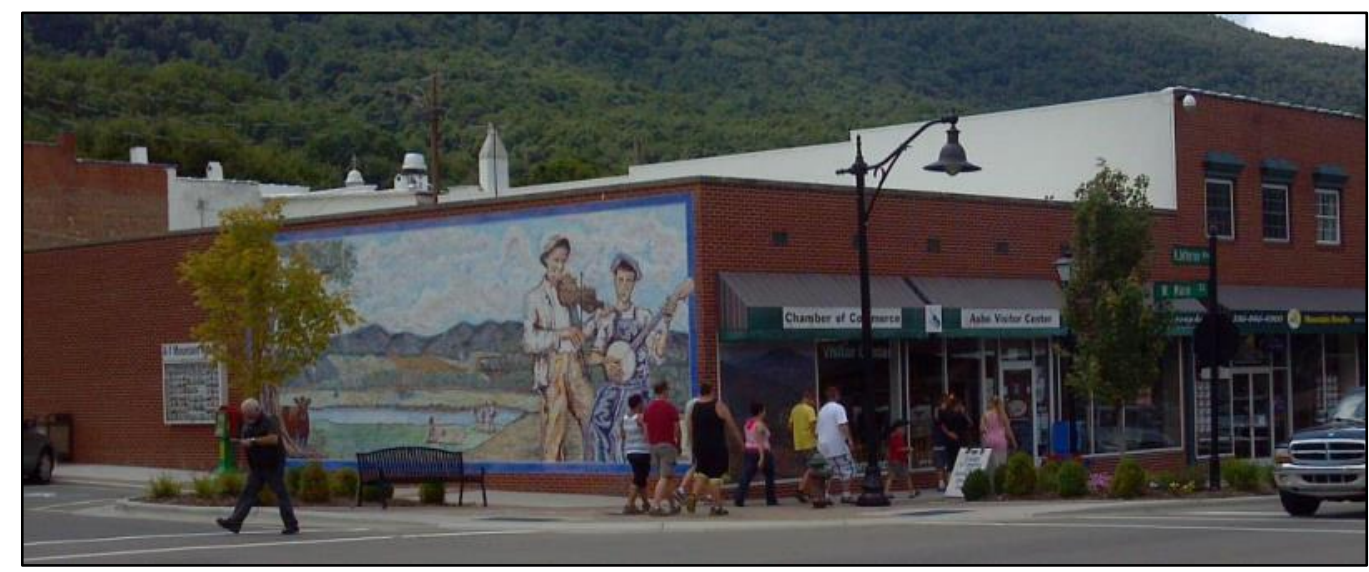

Photo by Dean Ledbetter

Figure 2-4: West Jefferson, North Carolina - Streetscape Project 
This chapter has outlined the methodology for assessing economic impacts of Complete Streets projects for this work. In addition, five potential case studies were briefly described. The next chapter, Chapter 3, provides additional information on the case studies, data collected and analyzed, and the results. A conclusion is also provided in Chapter 3. 


\section{CHAPTER 3: CASE STUDY PROJECTS AND RESULTS}

This chapter provides a summary of the activities undertaken in Task 3 this project, which involved the analysis of the selected case study sites and projects for this research. Data were collected and evaluated for three case study sites, two within the state of Florida, and one outside of Florida. The two sites in Florida are the Gainesville Main Street Corridor and the Estero Boulevard project in Fort Myers Beach, Florida. The out-of-state example is the Euclid Avenue Corridor in Cleveland, Ohio. Two additional case study sites were considered for this research, but not all data were available to complete the analysis; however, this chapter contains descriptions of those sites and projects.

\section{Case Study Projects}

The case studies selected for this research include:

- Gainesville, Florida - Main Street Corridor

- Fort Myers Beach, Florida - Estero Boulevard

- Cleveland, Ohio - Euclid Avenue Corridor

- Cape Canaveral, Florida - Ridgewood Avenue

- West Jefferson, North Carolina - West Jefferson Streetscape Project

Each is discussed in greater detail on the following pages. 


\section{Gainesville Main Street Corridor}

The major reconstruction of a portion of the Main Street corridor in Gainesville, Florida began in 2009 and was completed in 2011. Reconstruction and the implementation of Complete Streets elements occurred along the segment from North $8^{\text {th }}$ Avenue south to Depot Avenue. The corridor is shown below in Figure 3-1. The corridor contains quite a mix of land uses including retail, entertainment, restaurant, office, government, and manufacturing. Including the parcels on the east and west side of the segment, the area totals 60.1 acres. This project was considered part of a "road diet," and transformed a four-lane configuration with a center turn lane to a two-lane configuration with a center turn lane [47]. Figure 3-2 on the following page shows the corridor before the reconstruction in 2008 and afterward in 2012.

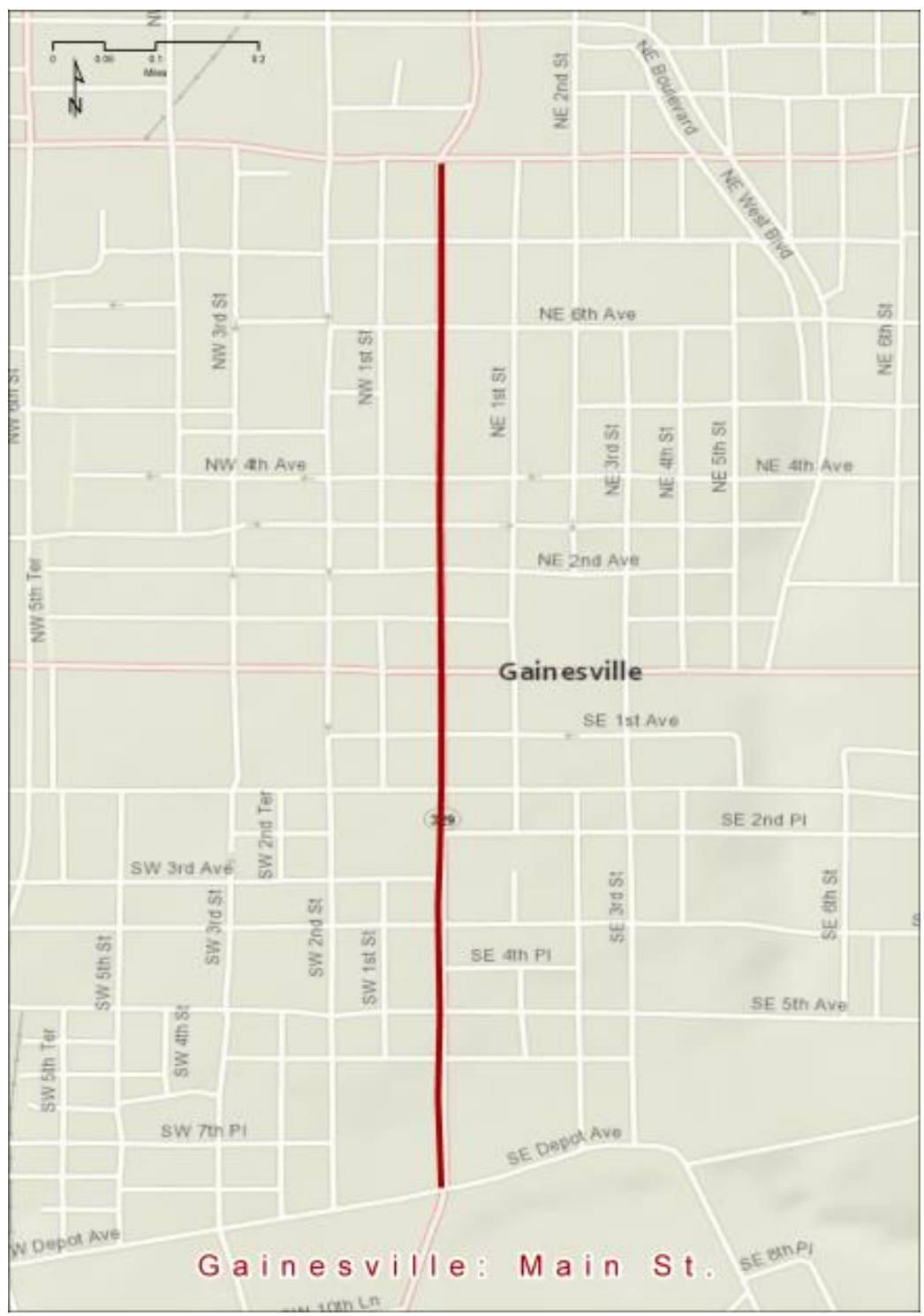

Figure 3-1: Gainesville's Main Street Corridor - North $8^{\text {th }}$ Avenue to Depot Avenue 


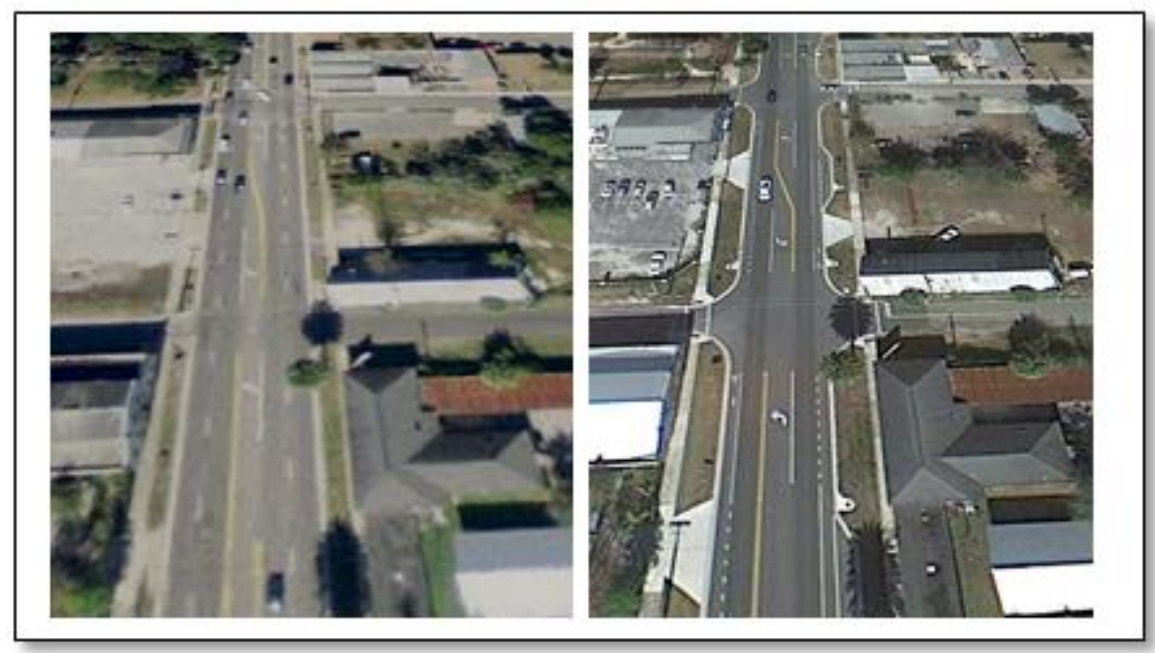

Source: City of Gainesville Public Works Department

Figure 3-2: Gainesville's Main Street Corridor before (2008) and after (2012)

Complete Streets elements added as part of the project include [47]:

- Reconfigured on-street parking

- Modified signal timing

- Removal of some traffic signals

- Bicycle lanes

- Wider sidewalks with bulb-outs at intersections

- Bus bays

- Enhanced lighting

- Streetscaping

- Additional mid-block crossing locations

- Roundabout at Depot Avenue, the southern end of the segment.

Additional photos of the completed project are shown in Figure 3-3 on the following page. In the photos, elements such as the parking configuration, bicycle lanes, streetscaping, sidewalk bulbs, and bus bays are visible. Gainesville Regional Transit System currently operates three bus routes along this segment of Main Street (Routes 6, 15, and 27). 


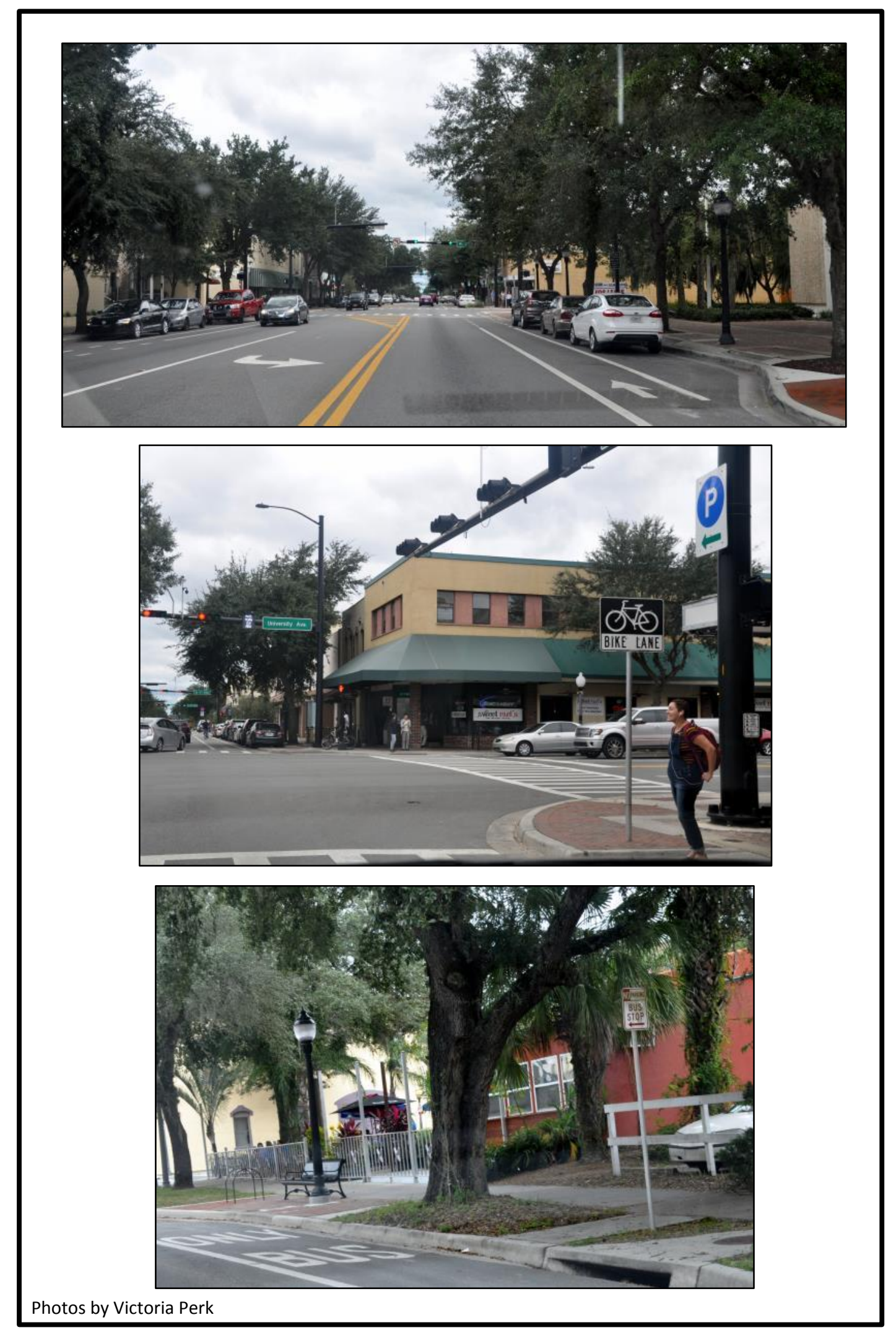

Figure 3-3: Gainesville's Main Street Corridor - 2015 
The City of Gainesville Public Works Department analyzed some data on the segment and found that, after the improvements were made, traffic volumes were found to have decreased 21 percent. However, they noted that traffic volumes and daily vehicle miles traveled (VMT) had decreased slightly (approximately four percent) countywide during the same time period. In addition, travel speeds declined approximately two miles per hour, resulting in a 29 second increase in average travel time along the entire segment. During peak periods, the increase is approximately 105 seconds. Further, bicycle and pedestrian volumes have increased since the improvements, and there has been a remarkable decline in the number of crashes. There were 59 accidents during the period of January 2008 to June 2009, but only 18 accidents during the period from January 2012 to June 2013 [47].

In addition, several properties have made improvements since the project began construction. In 2010, there were 18 permits issues for remodels, and there was also a large increase in annual rate of permits secured for new businesses [47].

Additional data were collected for this case study, including the market values of properties adjacent to the corridor along the relevant segment along with the amount of property taxes paid (from the Alachua County Property Appraiser). Also, Longitudinal Employer-Household Data (LEHD) were collected along the segment for the years 2008 and 2013, representing one year before construction began and two years after the project was completed.

First, Table 3-1 presents the information on the market values of the adjacent properties and the property taxes collected from those properties. The years of data that were available for this analysis were 2006 (before construction) and 2014 (three years after construction). These years represent a wide enough time period that, by 2014, the real estate markets were starting to show recovery after the severe 2007-2009 recession. The values shown in Table 3-1 are presented in constant 2014 dollars. To adjust the values, the Consumer Price Index (CPI) values for the southern United States for the years 2006 and 2014 were collected from the Bureau of Labor Statistics and applied to the 2006 dollar values.

Table 3-1: Changes in Market Values of Parcels and Property Taxes Paid Gainesville Main Street

\begin{tabular}{|l|c|c|c|}
\hline & $\begin{array}{c}2006 \\
\mathbf{( 2 0 1 4} \$ \mathbf{)}\end{array}$ & $\mathbf{2 0 1 4}$ & Percent Change \\
\hline Market Value of Parcels & $\$ 52,466,710$ & $\$ 55,463,600$ & $6 \%$ \\
\hline $\begin{array}{l}\text { Property Taxes Paid by } \\
\text { Parcel Owners }\end{array}$ & $\$ 583,650$ & $\$ 624,579$ & $7 \%$ \\
\hline
\end{tabular}

Source: Alachua County Property Appraiser and Bureau of Labor Statistics for inflation adjustment. 
From Table 3-1, it can been seen that the market value of the parcels adjacent to the reconstructed segment of Main Street increased seven percent from 2006 to 2014, when accounting for inflation (the unadjusted increase is 24 percent). While it is difficult to compare this information to the overall commercial property market in Gainesville during this time, it is clear that the property values in this area are performing quite well, especially considering that much of the area, as well as the entire state of Florida, has just begun to see evidence of recovery from the recent severe recession. Also in Table 3-1, it is shown that property tax collections, in constant 2014 dollars, have increased similarly during this time, at a rate of approximately six percent (the unadjusted figure is nearly 27 percent).

A second measure of the economic activity along the Main Street corridor is the number of jobs within the blocks adjacent to the segment. This information is presented in Table 3-2, on the following page. The table contains LEHD data for the specific blocks along the segment, as well as for the City of Gainesville as a whole for comparison, for the years 2008 to 2013 (representing the years that these data were collected for this case study).

Table 3-2: Changes in Number of Jobs - Gainesville Main Street and City of Gainesville

\begin{tabular}{|l|c|c|c|}
\hline & 2008 & 2013 & Percent Change \\
\hline $\begin{array}{l}\text { Total Jobs Adjacent to } \\
\text { Main Street Corridor }\end{array}$ & 1,587 & 1,924 & $21 \%$ \\
\hline $\begin{array}{l}\text { Total Jobs City of } \\
\text { Gainesville }\end{array}$ & 60,051 & 70,081 & $17 \%$ \\
\hline
\end{tabular}

Source: LEHD, 2008 and 2013.

As shown in Table 3-2 above, the number of jobs has been increasing in the Gainesville area, showing some recovery from the recession (jobs in the city as a whole have actually declined from the levels in 2003). While the total number of jobs in the City of Gainesville grew by 17 percent between 2008 and 2013, the total number of jobs along the Main Street Corridor grew at a faster rate of 21 percent during this time.

While an exact causal relationship cannot be determined, it does appear that the significant improvements made along this corridor have resulted in increased economic activity in the immediate area. Site visits in April 2015 and September 2015 made by project staff revealed a healthy mix of activities along the corridor, with relatively slow traffic speeds and an abundance of pedestrian activity.

There was some concern about the slower traffic speeds along the segment, but the cost of the slower speeds (an average increase of 29 seconds to travel the segment, with a peak period increase of only 105 seconds) seems to be outweighed by the improvements in safety mentioned previously as well as the increased pedestrian, bicycling, and economic activity. 
The Town of Fort Myers Beach has long been plagued with major storm water drainage issues that led to flooding during heavy rains. Beginning in 1999, planning commenced for complete water and gas replacement and improvements to the drainage systems [48]. The case study project included herein represents the North End of Estero Boulevard, one of six one-mile segments slated for complete reconstruction. This segment begins at Bowditch Point Park and continues south for one mile along Estero Boulevard to Time Square at Old San Carlos Boulevard, as shown in Figure 3-4 below.

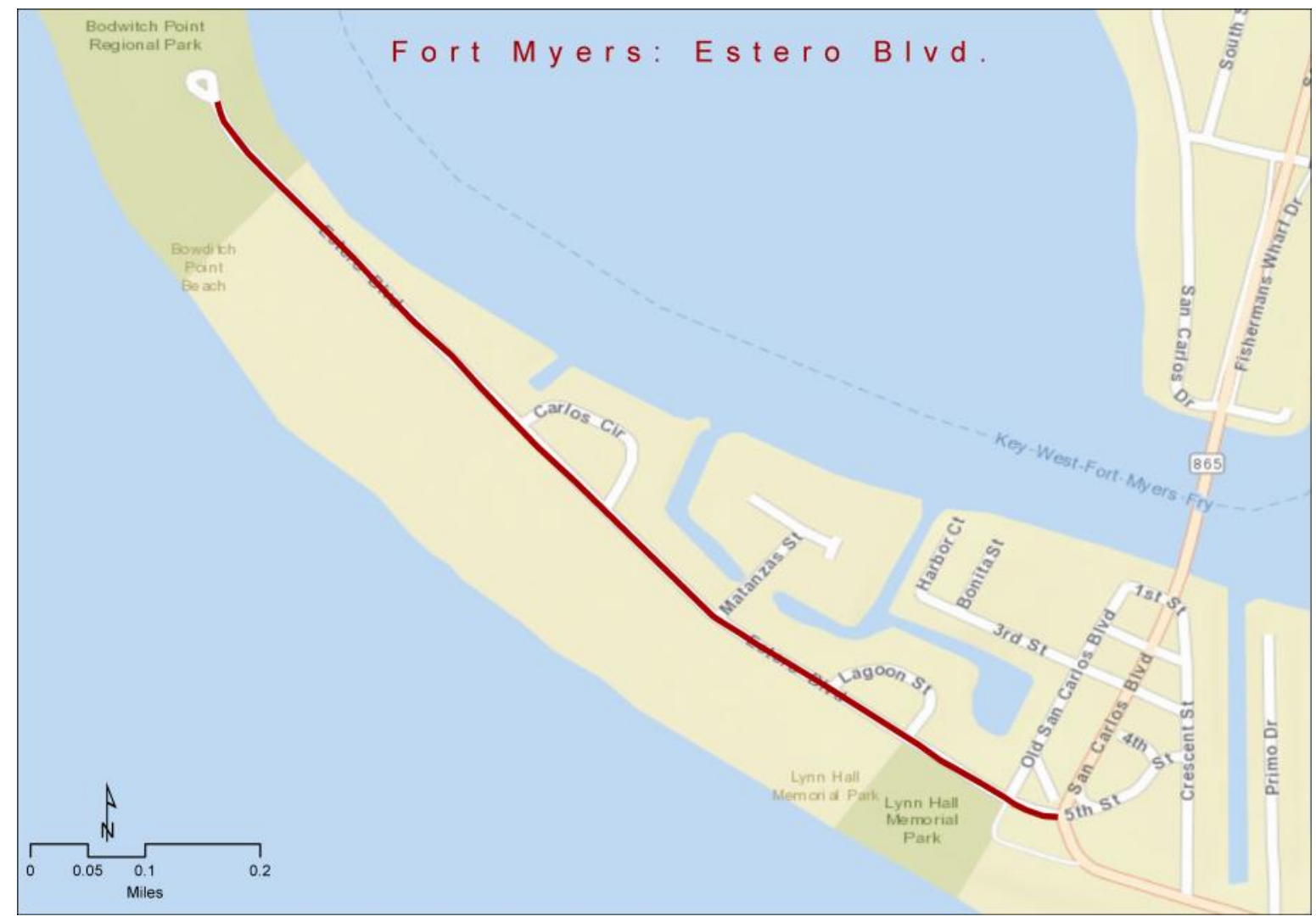

Figure 3-4: Fort Myers Beach - Estero Boulevard Project, North End

This one-mile segment represents the first of six one-mile phases of reconstruction along the corridor. As the roadway is being totally reconstructed, it was determined that Complete Streets elements would be included as the other improvements were made [48]. Figure 3-5 shows Google Street View images of a section of the corridor in 2007, before construction, and in 2015 , four years after construction of this segment was completed. 


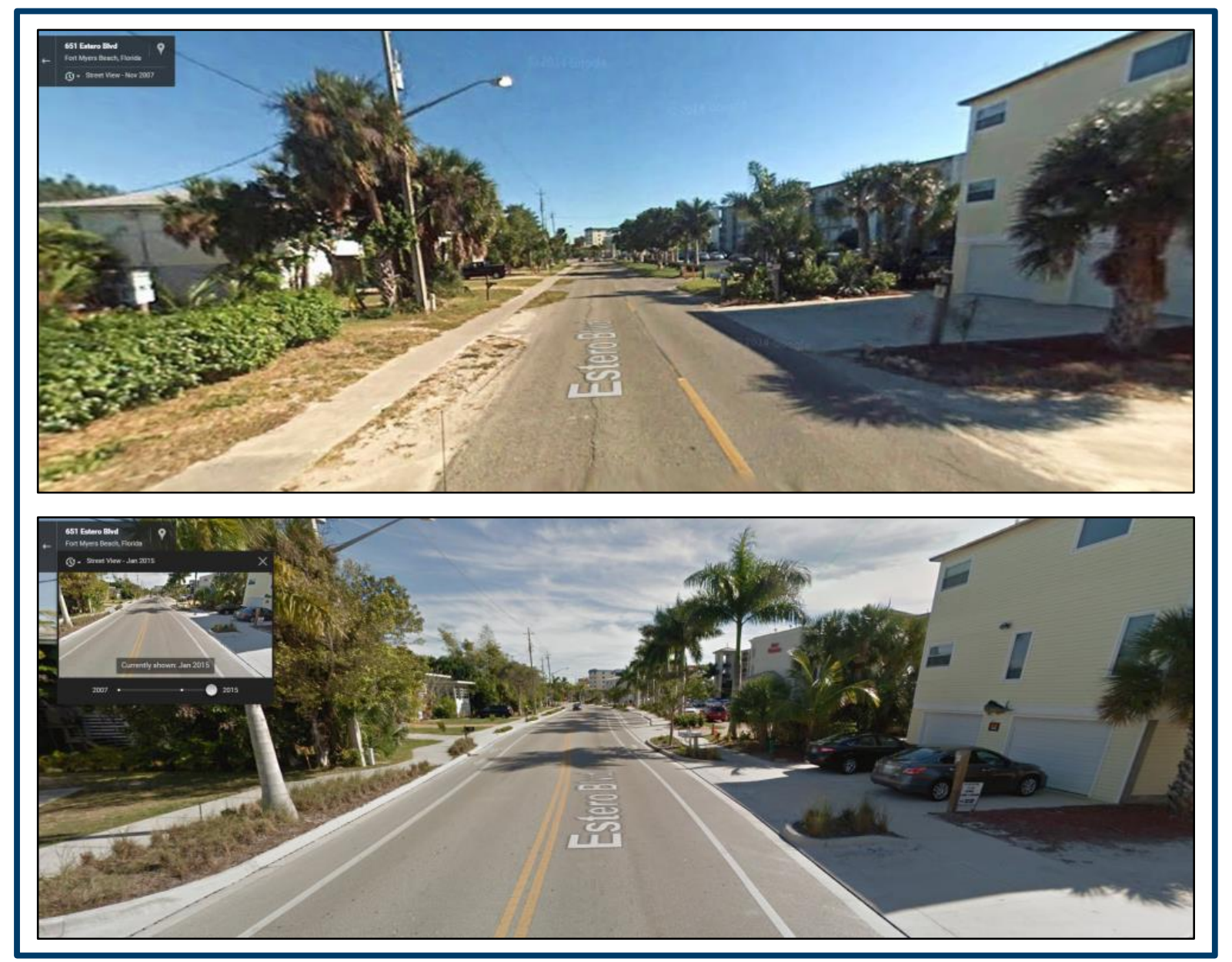

Source: Google Street View

Figure 3-5: Fort Myers Beach - Estero Boulevard Project, North End before (2007) and after (2015)

Similar to the Gainesville case study, construction of this first segment began in 2009 and was completed in 2011. Before construction, discontinuous sidewalks and the total absence of bicycle lanes characterized this corridor. After the construction, Complete Streets elements include:

- $\quad$ Five-foot sidewalks on both sides, set back from the road behind a vegetation strip

- Four-foot signed and marked bicycle lanes on both sides

- Bicycle parking and rental

- Trolley pull-outs (LeeTran serves 73 bus stops along the entire six-mile corridor)

- Crosswalks with pavers and yellow warning lights for motorists

- Pedestrian signals

- Wayfinding

- Landscaping. 
Figures 3-6 and 3-7 show photographs of the completed project and its various elements, including trolley stops and pull-outs, crosswalks, bicycle lanes, and pedestrian signals [49].

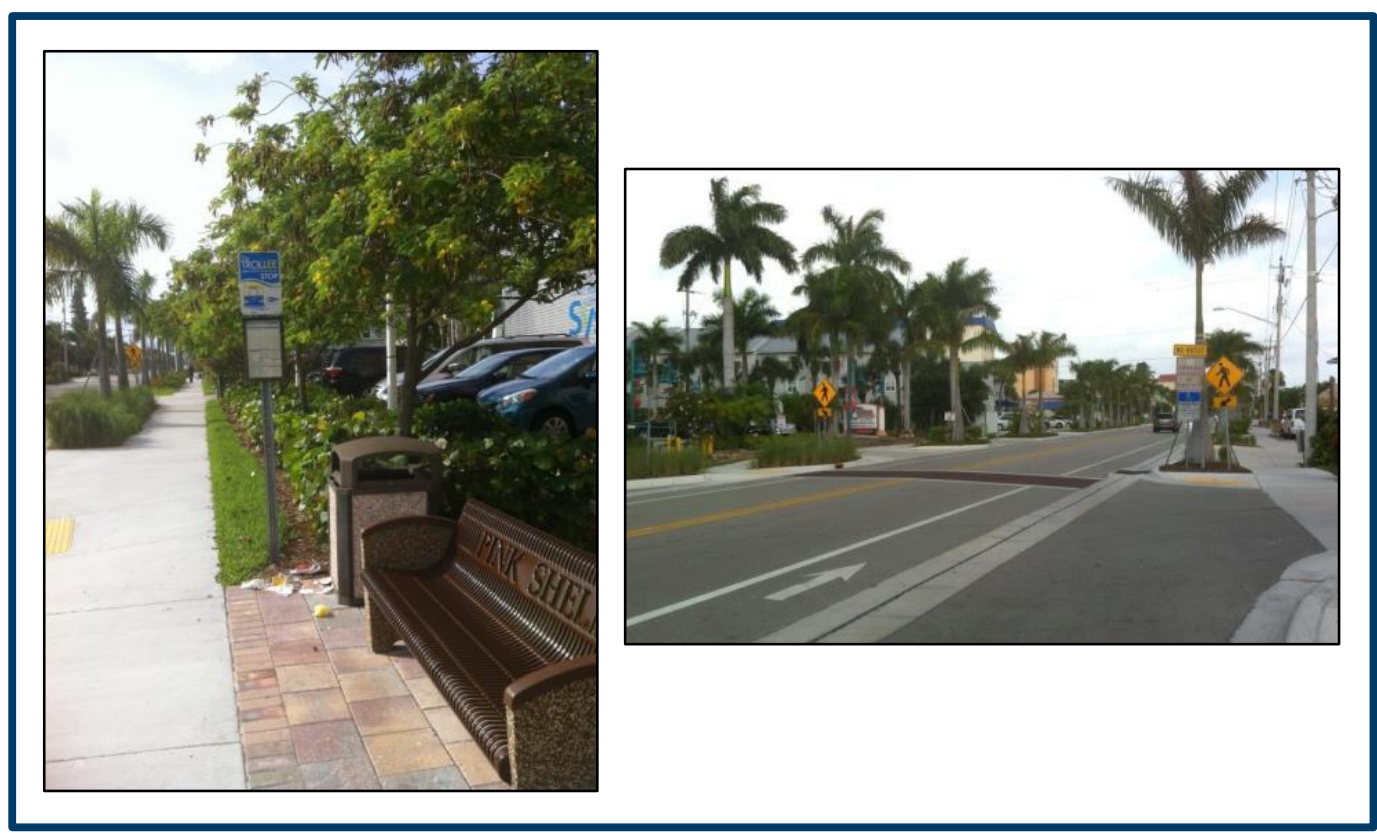

Source: BikeWalkLee

Figure 3-6: Fort Myers Beach Estero Boulevard Project, Completed North End

This section of Fort Myers Beach includes a mix of retail, restaurants, offices, government, and residential (both single-family and multi-family). Clearly, the area also attracts tourists from around the country and around the world. The area is known for its beaches, and there are 35 beach access points along the entire corridor. Traffic volumes tend to be quite high, and they are not projected to grow much over the next several years [48]. It is planned that LeeTran's trolley will take additional vehicles off the road in the future as it expands and builds a parking facility off the island [53]. With parking and easy access to the trolley before crossing to Fort Myers Beach, it is anticipated that transit will carry more trips along the corridor in the future.

Data collected for this case study site include market values and property taxes for the commercial and residential parcels along this completed one-mile segment of Estero Boulevard. In addition, LEHD data were collected to record the number of jobs adjacent to the corridor both before and after the completed construction of this segment. 


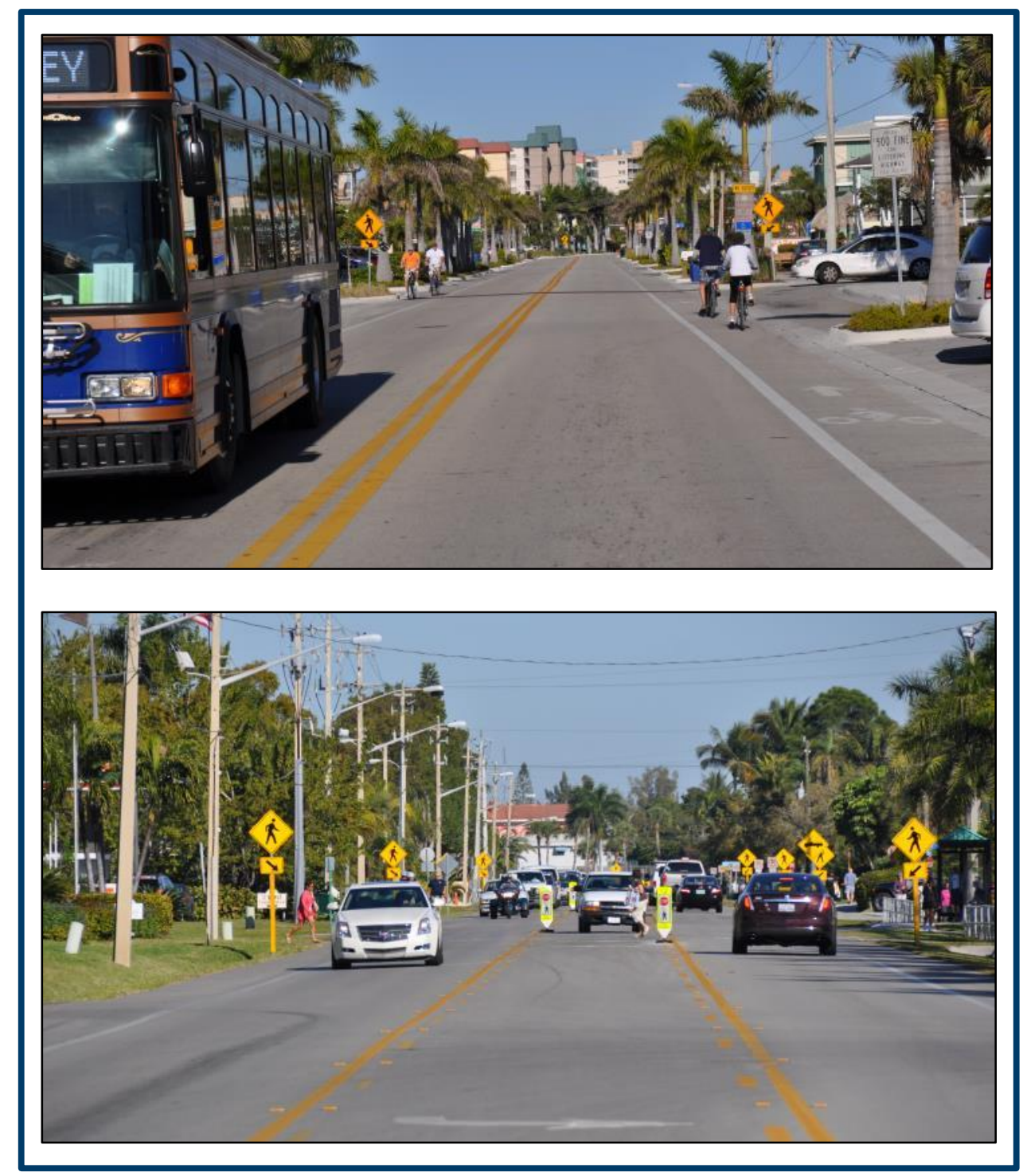

Photos by Lee County Department of Transportation

Figure 3-7: Fort Myers Beach Estero Boulevard Project, Completed North End

First, Table 3-3 shows property value (market value) information for both commercial and residential parcels adjacent to the corridor for the years 2007 (representing the period prior to construction) and the year 2014 (representing three years after the completion of this first onemile segment). Clearly, property values have not fully recovered from the 2007-2009 recession and housing crisis. And, Fort Myers was affected very significantly by the housing crisis, known nationwide as one of the top cities most adversely affected by the economic downturn [54] [55].

For purposes of this project, it is instructive to compare the decline in market values with the decline elsewhere in the Town of Fort Myers Beach. According to housing indexes compiled by 
Zillow, from 2007 to 2014, overall market values fell 34 percent. Single-family home values fell 26 percent, while condominium values declined 36 percent [56]. Based on these data, it seems that properties at the north end of Estero Boulevard declined by approximately the same percentage as properties elsewhere in Fort Myers Beach.

Table 3-3: Changes in Market Values of Parcels and Property Taxes Paid Fort Myers Beach, Estero Boulevard, North End

\begin{tabular}{|l|c|c|c|}
\hline & $\begin{array}{c}\mathbf{2 0 0 7} \\
\mathbf{( 2 0 1 4} \$ \mathbf{)}\end{array}$ & $\mathbf{2 0 1 4}$ & Percent Change \\
\hline Market Value of Parcels & $\$ 296,379,456$ & $\$ 193,769,178$ & $-35 \%$ \\
\hline $\begin{array}{l}\text { Property Taxes Paid by } \\
\text { Parcel Owners }\end{array}$ & $\$ 4,173,225$ & $\$ 3,010,841$ & $-28 \%$ \\
\hline
\end{tabular}

Source: Lee County Property Appraiser and Bureau of Labor Statistics for inflation adjustment.

Table 3-4 shows how the number of jobs has changed, both along the completed one mile segment of Estero Boulevard and also in the City of Fort Myers as a whole. While the total number of jobs along the segment is relatively small, there has been a 21 percent increase in the number of jobs between 2008 and 2013. Overall, job growth in the City of Fort Myers as a whole was only five percent during this same time frame, based on LEHD data.

Table 3-4: Changes in Number of Jobs - Fort Myers Beach, Estero Boulevard, North End and City of Fort Myers

\begin{tabular}{|l|c|c|c|}
\hline & 2008 & 2013 & Percent Change \\
\hline $\begin{array}{l}\text { Total Jobs Adjacent to } \\
\text { Estero Boulevard } \\
\text { Corridor, North End }\end{array}$ & 469 & 566 & $21 \%$ \\
\hline $\begin{array}{l}\text { Total Jobs City of Fort } \\
\text { Myers }\end{array}$ & 300,564 & 315,214 & $5 \%$ \\
\hline
\end{tabular}

Source: LEHD, 2008 and 2013.

Although the property value information continues to be plagued by the significant irregularities in the area real estate market, job growth in the segment has been strong, indicating continued and increasing economic activity after the Complete Streets implementation. Again, a direct causal link cannot be made between the implementation of 
the project and the growth in jobs, for example. However, this is another case study where there is an association between the project and increased economic activity.

As of this writing, construction has been continuing on the next one-mile segment of the project. Unfortunately, the construction has been causing heavy traffic and delays for vehicle travelers wishing to enter or exit the area. Locals seem to be avoiding the area and businesses are experiencing lost sales [57]. Each segment is planned to take 18 months to complete, but Lee County is asking FDOT for an additional \$15 million (total cost for the six miles is estimated at $\$ 70$ million) to speed up construction (the North End segment cost an estimated \$4 million) [57]. 


\section{Cleveland, Ohio - Euclid Avenue Corridor}

For a case study outside of Florida, the Euclid Avenue corridor in Cleveland, Ohio represents an example of a Complete Streets project coupled with a major bus rapid transit (BRT) investment. The Cleveland HealthLine BRT service opened in October 2008 after four years of major reconstruction along seven miles of Euclid Avenue, from Tower City in the central business district east toward University Circle and the Cleveland Clinic medical facility. The project was the result of a decades long planning process to link the two largest regional employment centers. It also achieved the vision of creating a multimodal Complete Streets environment for transit users, bicyclists, pedestrians, and auto users [50]. Figure 3-8 shows the four-mile portion of the corridor that is used as a case study in this research.

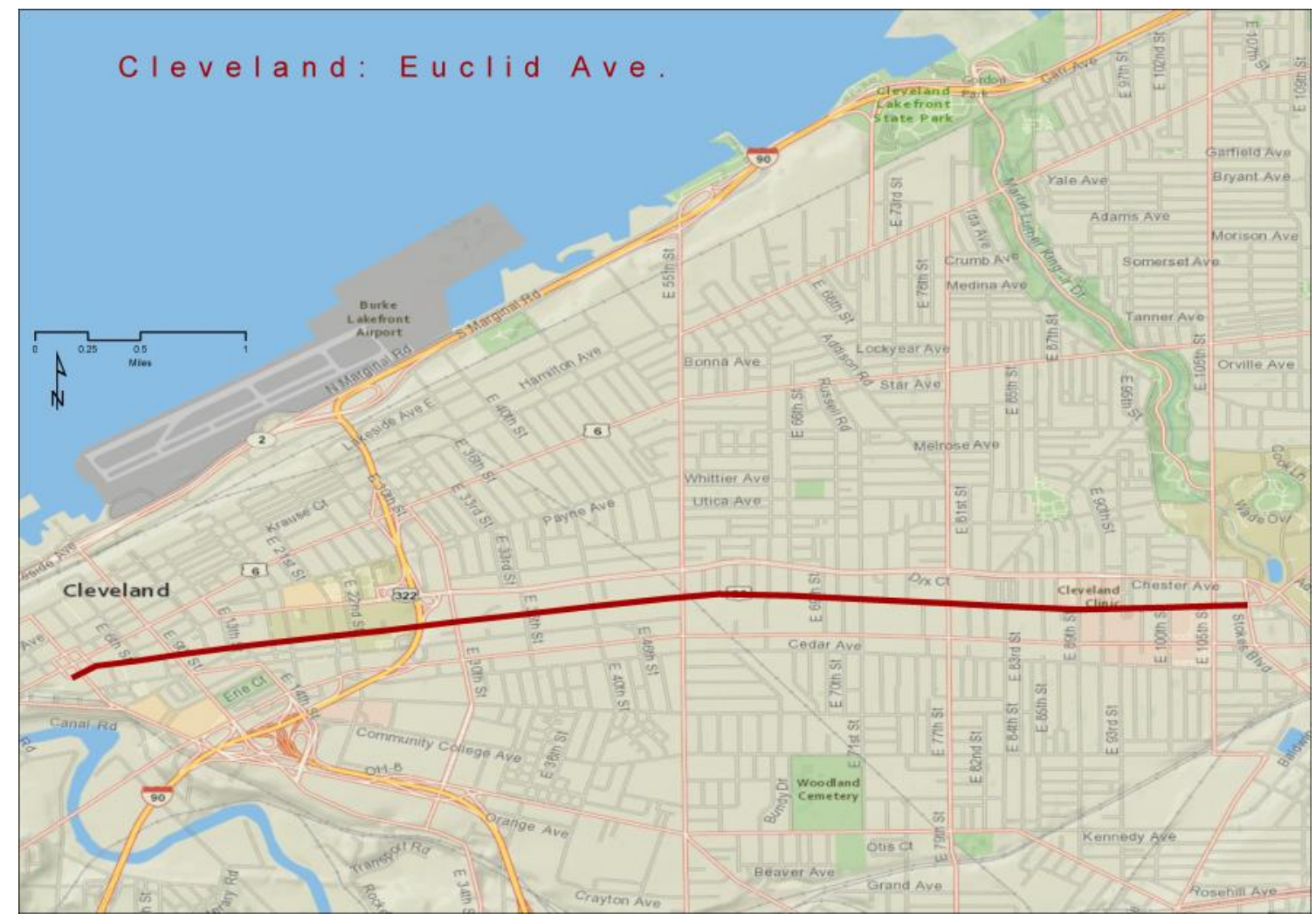

Figure 3-8: Cleveland, Ohio - Euclid Avenue Corridor

The full project cost $\$ 168.4$ million, and construction took approximately four years, from 2004 through 2008. In total, over nine miles of Euclid Avenue were reconstructed and/or rehabilitated. The resulting HealthLine BRT line is a little more than seven miles in length. However, many Complete Streets elements were included in the project, including the city's first dedicated bicycle lanes. There are four miles of signed and marked bicycle lanes along the 
corridor, from East $22^{\text {nd }}$ Street to Adelbert Road near University Circle [58]. It is this four-mile segment that is used as a case study for this research.

As described above, the BRT line is a definite focal point of the corridor; there are many other elements of the project that make it truly a Complete Street. Elements of the completed project include [50]:

- Median BRT stations along much of the alignment

- Four miles of designated bicycle lanes

- Bicycle racks at BRT stations and the ability to board the transit vehicle with a bike

- Brick patterned sidewalks and crosswalks

- Pedestrian signals

- Streetscaping

- Public art (even the trash cans can be considered public art)

- Specialized lighting

- Concrete bollards to corral pedestrians at signalized intersections to promote safety and discourage jaywalking

Figure 3-9 on the following page provides photos of this project. In the photos, various elements of Complete Streets are seen, such as the brick pavers in the sidewalks and crosswalks, the BRT alignment, streetscaping and public art, and the bicycle lanes. 


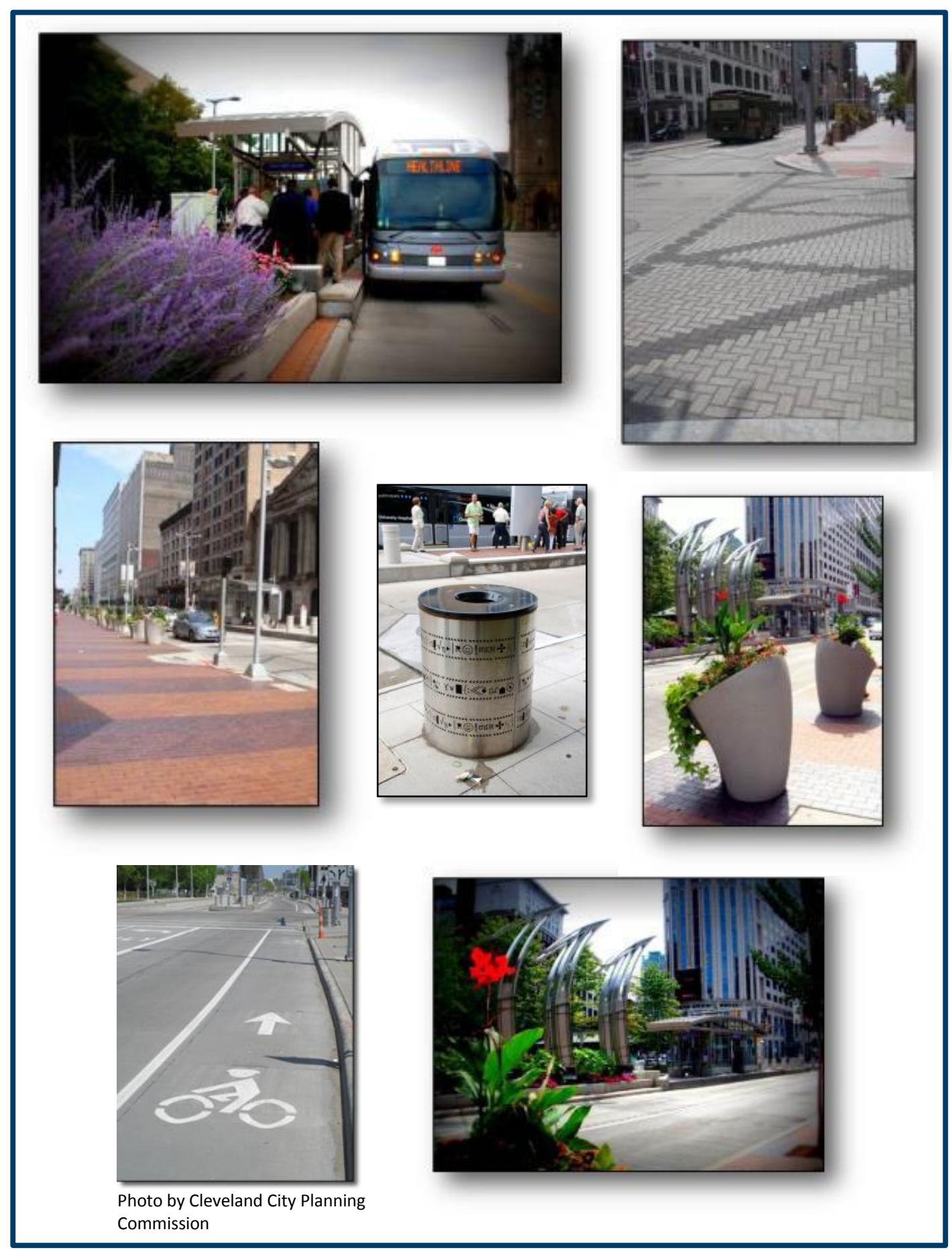

Photos by Victoria Perk, unless otherwise noted

Figure 3-9: Cleveland, Ohio - Euclid Avenue Corridor Completed Project 
Some other recent research has compiled data on property values along the Euclid Corridor. Some key findings include that industrial property values increased by 20 percent from 2006 to 2009 in the eastern edge of the corridor (Cleveland Clinic area), which was a significantly higher rate than all other areas within and outside of this corridor. Property values for offices increased by 11 percent between 2006 and 2009 in the Midtown area, near the center of the segment included in this research. Other areas of the city only saw these values increase approximately seven percent during this time [59].

Forthcoming research from the Center for Urban Transportation Research will show that, by 2009, sale prices of single-family homes located close to the Euclid corridor were approximately 30 percent higher than homes farther away. This occurred despite falling sale prices for singlefamily homes throughout the city. As sale prices continued to fall until 2012, the 30 percent premium declined, as well. However, began to rise again in 2013. Between 2005 and 2009, the median sale price of a single-family home in the City of Cleveland fell from $\$ 91,200$ to $\$ 73,400$, a decline of 20 percent. Median sale prices fell another 23 percent over the next two years to a low of $\$ 56,500$ in 2011 . However, prices are recovering, and the median sale price of a singlefamily home in Cleveland had grown to $\$ 76,000$ as of August 2015 and is forecast to continue growing [60].

Table 3-5, on the next page, shows how the number of jobs has changed, both along the fourmile segment of Euclid Avenue and also in the City of Cleveland as a whole. Reflecting the overall economic conditions in the City of Cleveland, the data in Table 3-5 show that, overall, the city lost approximately four percent of its total jobs between 2003 and 2013. However, the level of job growth and activity along the relevant four-mile segment of Euclid Avenue significantly outperforms that of the city as whole. Between 2003 and 2013, the total number of jobs adjacent to the corridor increased 29 percent. This increase is representative of the large investments that have taken place along the corridor both during construction and after the project was completed. In particular, large employers such as Cleveland State University and the Cleveland Clinic Foundation (medical complex) expanded during this time. In addition, more than 5,000 jobs were created near the University Circle area during this time period [59]. While certainly business decisions such as location and expansion consider many outside factors, it is very likely that the conditions and improvements along the corridor played some role in these changes. Even during a significant economic downturn, during which the entire northeast Ohio area was strongly affected, investments continued in this area, outpacing activities outside the corridor [59]. 
Table 3-5: Changes in Number of Jobs - Cleveland Euclid Corridor and City of Cleveland

\begin{tabular}{|l|c|c|c|}
\hline & 2003 & 2013 & Percent Change \\
\hline $\begin{array}{l}\text { Total Jobs Adjacent to } \\
\text { Euclid Corridor, 4-mile } \\
\text { segment }\end{array}$ & 44,632 & 57,426 & $+29 \%$ \\
\hline $\begin{array}{l}\text { Total Jobs City of } \\
\text { Cleveland }\end{array}$ & 273,412 & 262,744 & $-4 \%$ \\
\hline
\end{tabular}

Source: LEHD, 2003 and 2013.

This research contains just a brief description of two other potential case studies for additional research. The scope of services for this project included a minimum of three case studies, which are included herein. However, up to five case studies might have been completed. Information on the additional two locations, for which data could not be obtained in a timely manner, are presented below.

\section{Cape Canaveral - Ridgewood Avenue}

In 2012, the Ridgewood Avenue Complete Streets project was finished in Cape Canaveral, in Brevard County, Florida. The project encompassed a 1.3-mile segment of the roadway, including a large residential area. Elements of the project included an eight-foot-wide bicycle/pedestrian path on the west side of the road, a new five-foot-wide sidewalk on the east side, crosswalks with pattern-stamped pavement, landscaping, solar-powered lighting, and additional stop signs to further slow vehicles on the 25 -miles-per-hour road. In addition, the roadway itself was reduced to 22 feet from a width of 30 feet.

Residents of the area were initially concerned about the disruption from the construction of the project. However, today, they are very happy with the improvements and are more likely to walk and bicycle in the area, and feel much safer doing so [51].

\section{North Carolina - West Jefferson Streetscape Project}

An additional case study outside Florida is in a smaller town: West Jefferson, North Carolina. For many years, the town had been in decline. High auto speeds through the central business district made walking and other activity in the area not only undesirable but dangerous. A routine resurfacing project was converted into a Complete Streets project that added several pedestrian-friendly and traffic calming elements, ultimately transforming the corridor by 2012. To slow traffic, two intersections were modified to remove signals and revert to stop-control. Pedestrian improvements included paved crosswalks with curb extensions that not only shorten crossing distance but also provide a place for gathering, specialized lighting, and street furniture 
[52]. Figure 3-10 shows a photo of several of the Complete Streets elements of this project including crosswalks, street furniture, and specialized lighting.

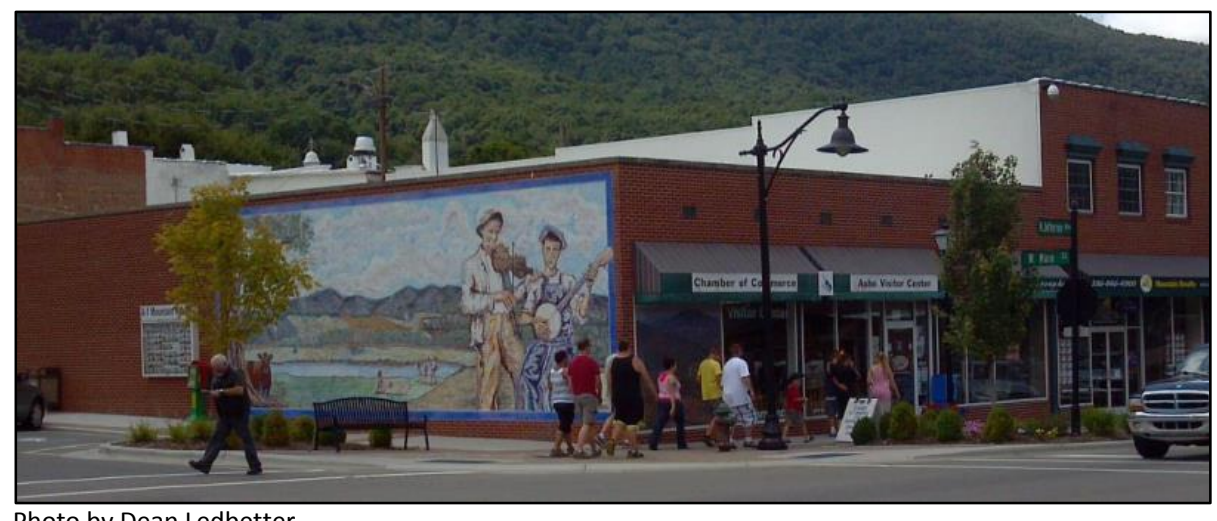

Photo by Dean Ledbetter

Figure 3-10: West Jefferson, North Carolina - Streetscape Project

\section{Conclusion}

This project has attempted to go beyond the clear safety benefits of Complete Streets projects to show that such projects also make economic sense. Research was outlined in this report that demonstrated that Complete Streets projects, in many cases, are showing economic benefits. In most cases, a direct causal link cannot be established; however, there is a strong association between such projects and increased economic activity that often outpaces other areas in the city and the city itself. The benefits are further enhanced because the cost of many of the Complete Streets elements themselves tend to represent relatively small portions of overall project costs, as shown in an earlier chapter of this research.

The case studies presented in this research represent a wide variety of Complete Streets applications: from a business district in Gainesville, Florida, to a beach community in Fort Myers Beach, Florida, to a larger urban city up north (Cleveland, Ohio) with a major transit investment. Additional case studies suggested but not completed include a residential area in Florida (Cape Canaveral) and a smaller town in North Carolina. There is a plethora of new Complete Streets projects in the planning and construction phases in Florida and around the country. Clearly, communities across the nation have realized that Complete Streets projects represent better transportation planning.

It is recommended that this research be continued to advance the knowledge and understanding of the economic impacts of these projects. Further research can strengthen the anecdotal and causal linkages between such projects and increased economic activity through the acquisition and use of more comprehensive data. To ensure that comparable data are available for any new potential case study sites in various time periods, it may be necessary to 
purchase large data sets that contain detailed data on business activity. The use of such data sets allows for a larger number of uniform measures on individual business activity that can be applied to any number of case study sites or projects selected for future research.

Beyond the three case study sites that were fully analyzed in this report, there are several other sites and projects that were described in this report that could be considered as case studies in a future research project. The residential Complete Streets project in Cape Canaveral, Florida and the small-town project in West Jefferson, North Carolina, are two such examples. The Buffalo-Niagara project (New York) is another potential case study. Other sites for future study in Florida might include additional segments of the project on Estero Boulevard in Fort Myers Beach (as they are completed), projects in Tampa, and projects in southeast Florida including Fort Lauderdale. Another potential case study in Florida for future research that was not mentioned earlier in this report is the City of Delray Beach. After a period of decline, the city worked to transform a stretch of Atlantic Avenue into a pedestrian-friendly corridor with revitalized businesses by calming traffic and also restoring old and abandoned buildings [61].

Currently, there are 50 Complete Streets policies in place in Florida cities and counties, including the Florida Department of Transportation [20]. In the near future, it is clear that there will be many additional projects, particularly in Florida, that can be studied for their effects. As such, there will be additional research opportunities to showcase the wide-ranging benefits, including economic benefits, of Complete Streets. 


\section{REFERENCES}

[1] Smart Growth America. 2015. Introduction to Complete Streets (PowerPoint presentation). Washington, D.C., Smart Growth America. Available: http://www.smartgrowthamerica.org/complete-streets/complete-streetsfundamentals\#presentation. [Accessed 20 October 2015].

[2] Institute of Transportation Engineers, Designing Walkable Urban Thoroughfares: A Context-Sensitive Approach, An ITE Recommended Practice, ITE, Washington, D.C., 2009.

[3] H.R. 2468: Safe Streets Act of 2013, Washington, D.C.: U.S. Congress, 2013.

[4] S. 2004: Safe Streets Act of 2014, Washington, D.C.: U.S. Senate, 2014.

[5] National Complete Streets Coalition, "Benefits of Complete Streets," [Online]. Available: http://www.smartgrowthamerica.org/complete-streets/complete-streetsfundamentals/benefits-of-complete-streets/. [Accessed 15 May 2014].

[6] J. N. LaPlante and B. McCann, "Complete Streets in the United States," in 2011 TRB Annual Meeting, Compendium of Papers, Transportation Research Board, Washington, D.C., 2011, pp. 4-5, 9-10.

[7] D. Burden and T. Litman, "America Needs Complete Streets," ITE Journal, April 2011, pp. 36-41.

[8] R. L. Sanders, A. Griffin, K. E. MacLeod and J. F. Cooper, "Drivers, Pedestrians, and Cyclists in California Want Complete Streets: A Comparison of Results from Roadway Design Surveys of Pedestrians, Drivers, Bicyclists, and Transit Users in Northern and Southern California," in 2014 TRB Annual Meeting, Compendium of Papers, Transportation Research Board, Washington, D.C., 2014, pp. 3-4, 14-15.

[9] B. Davis, T. Dutzik, and P. Baxandall, Transportation and the New Generation: Why Young People Are Driving Less and What it Means for Transportation Policy, U.S. PIRG Education Fund, Boston, 2012.

[10] J. Lynott, J. Haase, K. Nelson, A. Taylor, H. Twaddell, J. Ulmer, B. McCann and E. R. Stollof, Planning Complete Streets for an Aging America, AARP Public Policy Institute, Washington, D.C., 2009.

[11] J. Lynott, How the Travel Patterns of Older Adults Are Changing: Highlights from the 2009 National Household Travel Study, AARP Public Policy Institute, Washington, D.C., 2011.

[12] K. Clifton, S. Bronstein and S. Morrissey, "The Adoption of Complete Streets Policies in Transportation Disadvantaged Communities: Lessons from U.S. Case Studies," in 2013 TRB Annual Meeting, Compendium of Papers, Transportation Research Board, Washington, D.C., 2013, pp. 3-5, 15-17.

[13] D. Smith, "Complete Streets Meet Accessible Pathways!" (presentation). 2014 APTA Bus and Paratransit Conference, Kansas City, MO, May 4-7, 2014.

[14] S. Guzman, "Planning Complete Streets for an Aging America" (presentation). 2014 APTA Bus and Paratransit Conference, Kansas City, MO, May 4-7, 2014. 
[15] Local Government Commission Center for Livable Communities, The Economic Benefits of Walkable Communities, [Online]. Available:

http://www.lgc.org/wordpress/docs/freepub/community_design/focus/walk_to_money. pdf.

[16] S. Ibendahl, "Are Complete Streets an Economic Advantage for Communities? The Answer is Yes," Common Cents, November 2012.

[17] National Complete Streets Coalition. Complete Streets: Policy Basics. National Complete Streets Coalition, Washington, D.C. Available:

http://www.smartgrowthamerica.org/documents/cs/cs-brochure-policy.pdf. [Accessed 15 May 2014].

[18] S. Seskin and B. McCann, Complete Streets Policy Analysis of 2011, Smart Growth America, Washington, D.C., 2012.

[19] S. Seskin and C. Murphy, The Best Complete Street Policies of 2013, Smart Growth America, Washington, D.C., 2014.

[20] National Complete Streets Coalition, Policy Atlas, 2014. [Online]. Available: http://www.smartgrowthamerica.org/complete-streets/changing-policy/completestreets-atlas. [Accessed 20 June 2014].

[21] J. O'Neill, "Improvements in East Tampa Symbolize Progress," Tampa Tribune. 13 September 2013. [Online]. [Accessed 21 April 2014].

[22] R. Danielson, "Millions in 22nd Street Improvements Give East Tampa 'A New Front Door'," 4 September 2013. [Online]. Available:

http://www.tampabay.com/news/localgovernment/millions-in-22nd-streetimprovements-gives-east-tampa-a-new-front-door/2140009. [Accessed 5 June 2014].

[23] National Cooperative Highway Research Program (NCHRP) Report 672, Roundabouts: An Information Guide, Second Edition. Transportation Research Board, U.S. Department of Transportation, Federal Highway Administration, Washington, D.C., 2010.

[24] B. Wallman, "Broward Road Laws Rewritten for Walkers, Bike Riders," Sun Sentinel. 23 February 2014. [Online]. [Accessed 23 April 2014].

[25] City of Fort Lauderdale, "Building Community Today," Available: http://www.fortlauderdale.gov/departments/transportation-andmobility/transportation-division/building-community-today [Accessed 21 December 2015].

[26] City of Fort Lauderdale, "Sustainable Transportation and Mobility," Available: http://www.fortlauderdale.gov/departments/transportation-andmobility/transportation-division/sustainable-transportation-and-mobility [Accessed 21 December 2015].

[27] A. Streeter, "South Florida Communities Aiming to Create 'Complete Streets'," Sun Sentinel. 24 August 2012. [Online]. [Accessed 23 April 2014].

[28] S. Seskin, "Charlotte's Complete Streets Policy Wins National Award," 2 December 2009. [Online]. Available: http://www.smartgrowthamerica.org/2009/12/02/charlottescomplete-streets-policy-wins-national-award/. 
[29] J. K. Morrell, "Complete Streets/Complete Trip," (presentation). 2014 APTA Bus and Paratransit Conference, Kansas City, MO, May 4-7, 2014.

[30] J. D. Epstein, "'Complete Streets' Initiative Aims to Rejuvenate City Roadways," The Buffalo News. 30 April 2014. [Online]. Available: http://www.buffalonews.com/cityregion/buffalo/complete-streets-initiative-aims-to-rejuvenate-city-roadways-20140430.

[31] R. L. Sanders, E. Macdonald, A. Anderson, D. R. Ragland and J. F. Cooper, "Performance Measures for Complete, Green Streets: Initial Findings for Pedestrian Safety along a California Corridor," in 2011 TRB Annual Meeting, Compendium of Papers, Transportation Research Board, Washington, D.C., 2011. pp. 4-7, 17-18.

[32] Smart Growth America. Complete Streets Stimulate the Economy, Washington, D.C., 2012.

[33] K. Carr, "Regional Livability Planning and Complete Streets," (presentation) 2011 TRB Annual Meeting Online Compendium, Transportation Research Board, Washington, D.C., 2011.

[34] F. Peiravian and S. Derrible, "Complete Streets Designs: A Comparative Emission Impact Analysis," in 2014 TRB Annual Meeting Compendium of Papers, Transportation Research Board, Washington, D.C. , 2014, pp. 2-6, 10-11.

[35] Redfin Walk Score. [Online]. Available: http://www.walkscore.com/live-more/. [Accessed 10 July 2014].

[36] Active Transportation Alliance, Complete Streets Make Economic Sense, [Online]. Available:

http://www.atpolicy.org/sites/default/files/CompleteStreetsMakeEconomicSense.pdf. [Accessed 10 July 2014].

[37] F. C. Dock, E. Greenberg and M. Yamarone, "Multimodal and Complete Streets Performance Measures in Pasadena, California," ITE Journal, January 2012, pp. 33-37.

[38] National Complete Streets Coalition, Complete Streets Policy Analysis 2011, August 2012. [Online]. Available: http://www.smartgrowthamerica.org/documents/cs/resources/cspolicyanalysis.pdf.

[39] K. T. Kingsbury, M. B. Lowry and M. P. Dixon, "What Makes a "Complete Street" Complete? A Robust Definition Based on Context and Public Input," in 2011 TRB Annual Meeting Compendium of Papers, Transportation Research Board, Washington, D.C. , 2011, pp. 3-6, 10-14.

[40] J. Shapard and M. Cole, "Do Complete Streets Cost More than Incomplete Streets?," in 2013 TRB Annual Meeting, Compendium of Papers, Transportation Research Board, Washington, D.C. , 2013. pp. 2-7.

[41] T. Litman, Evaluating Complete Streets, The Value of Designing Roads for Diverse Modes, Users and Activities, May 2014. [Online]. Available: http://www.vtpi.org/compstr.pdf.

[42] Z. Bent, The State of Complete Streets: Lessons on Implementing State Complete Street Policies (presentation). 2014 APTA Bus and Paratransit Conference, Kansas City, MO, May 4-7, 2014.

[43] Smart Growth America, The Fiscal Implications of Development Patterns: West Des Moines, IA, 2015. 
[44] New York City Department of Transportation, The Economic Benefits of Sustainable Streets, New York, 2015.

[45] Center for Inclusive Design and Environmental Access and GOBike Buffalo, Evaluating the Impact of Complete Streets Initiatives, 2014.

[46] AARP and Smart Growth America, "Evaluating Complete Streets Projects: A Guide for Practitioners," 2015. [Online]. Available:

www.smartgrowthamerica.org/documents/evaluating-complete-streets-projects.pdf. [Accessed 14 July 2015].

[47] City of Gainesville Public Works Department, Main Street Corridor: Evaluation of Effects of Roadway Modifications, 2013.

[48] Lee County, "Estero Boulevard Project," [Online]. Available: http://www.leegov.com/dot/engineeringservices/projectsplans/esteroblvdproject. [Accessed 16 July 2015].

[49] BikeWalkLee, "Fort Myers Beach's North Estero Blvd. is a Model Complete Streets Project," [Online]. Available: http://bikewalklee.blogspot.com/2012/06/fort-myersbeachs-north-estero-blvd-is.html. [Accessed 16 July 2015].

[50] National Bus Rapid Transit Institute, "Community-Oriented BRT: Urban Design, Amenities, and Placemaking," Federal Transit Administration, November 2012. [Online]. Available: http://www.fta.dot.gov/documents/FTA_Report_No._0034.pdf. [Accessed 7 July 2015].

[51] R. N. Moody, "'Complete Streets' Improve Brevard Roads for All Users," Florida Today. 28 March 2015. [Online]. Available: http://www.floridatoday.com/story/news/local/2015/03/27/street-projects-aimimprove-roads-users/70537784/. [Accessed 21 July 2015].

[52] J. Penn, "West Jefferson Streetscape Project," [Online]. Available: http://completestreetsnc.org/project-examples/ex-westjefferson/. [Accessed 15 July 2015].

[53] R. Phelan, Interviewee, Engineer, Lee County Department of Transportation. [Interview]. 14 July 2015.

[54] B. Briody, "Nine Worst Recession Ghost Towns in America," The Fiscal Times, 3 August 2011.

[55] D. Cave, "In Florida, Despair and Foreclosures," The New York Times, 7 February 2009.

[56] Zillow, "Fort Myers Beach Home Prices and Values," 22 September 2015. [Online]. Available: http://www.zillow.com/fort-myers-beach-fl/home-values/.

[57] C. Dulaney, "Fort Myers Beach Traffic Not Going Anywhere," News Press, 6 November 2015.

[58] "Bikeway Master Plan," [Online]. Available: http://planning.city.cleveland.oh.us/bike/euclid.html. [Accessed 22 September 2015].

[59] B. A. Mikelbank, Greater Cleveland Regional Transit Authority Euclid Corridor Transportation Project BRT Before and After Study, Cleveland State University, Cleveland, $\mathrm{OH}, 2012$. 
[60] "Cleveland, Ohio Home Prices and Values," [Online]. Available:

http://www.zillow.com/cleveland-oh/home-values/. [Accessed 22 September 2015].

[61] Federal Highway Administration, Office of Planning, Domestic Scan Tour II Report, Integration of Land Use and Transportation Planning: Lessons Learned from the Second Domestic Scan Tour, [Online]. Available:

https://www.planning.dot.gov/documents/domesticscan/domscan2.htm. U.S.

Department of Transportation, Washington, D.C. [Accessed 21 December 2015]. 